\title{
Effects of Novel Feed Ingredients and Additives on Feed Quality and Broiler Performance
}

\author{
Ashley Marie Evans
}

Follow this and additional works at: https://researchrepository.wvu.edu/etd

\section{Recommended Citation}

Evans, Ashley Marie, "Effects of Novel Feed Ingredients and Additives on Feed Quality and Broiler Performance" (2014). Graduate Theses, Dissertations, and Problem Reports. 5558.

https://researchrepository.wvu.edu/etd/5558

This Dissertation is protected by copyright and/or related rights. It has been brought to you by the The Research Repository @ WVU with permission from the rights-holder(s). You are free to use this Dissertation in any way that is permitted by the copyright and related rights legislation that applies to your use. For other uses you must obtain permission from the rights-holder(s) directly, unless additional rights are indicated by a Creative Commons license in the record and/ or on the work itself. This Dissertation has been accepted for inclusion in WVU Graduate Theses, Dissertations, and Problem Reports collection by an authorized administrator of The Research Repository @ WVU.

For more information, please contact researchrepository@mail.wvu.edu. 
Effects of Novel Feed Ingredients and Additives on Feed Quality and Broiler Performance

Ashley Marie Evans

Dissertation submitted to the Davis College of Agriculture, Natural Resources, and Design at West Virginia University in partial fulfillment of the requirements for the degree of

Doctor of Philosophy
in

Nutrition and Food Science

Joseph S. Moritz, Ph.D., Chair

Robert L. Taylor Jr., Ph.D.

K. Marie Krause, Ph.D. Deborah A. Boone, Ph.D. Stacy A. Gartin, Ph.D.

Division of Animal and Nutritional Sciences Morgantown, West Virginia 2014

Keywords: broiler, rooster, enzymes, algae, poultry litter biochar 


\section{ABSTRACT \\ Effects of Novel Feed Ingredients and Additives on Feed Quality and Broiler Performance Ashley M. Evans}

In the poultry industry, feed and feed manufacture account for 60 to $70 \%$ of production costs. Because of this, integrators are continually seeking ways to decrease costs while maintaining pellet quality and bird performance. The research presented in this dissertation offer several novel feed ingredients that have the potential to replace costly feed ingredients, increase pellet quality, improve bird growth and performance, and improve nutrient digestibility. In Chapter 2, four experimental phytase enzymes (A - D) were examined for thermostability during pelleting, as well as efficacy in vivo. Phytase activity post-pelleting demonstrated high variability between phytases, ranging from 120 to $1,300 \mathrm{FTU} / \mathrm{kg}$. Bird performance revealed the most consistency with enzymes A and $\mathrm{D}$, with enzyme A resulting in the highest phosphorus sparing. The take home message in Chapter 2 is that high efficacy in vitro may not translate to high efficacy in vivo, and both experiments must be completed prior to phytase commercialization. In Chapter 3 , the efficacy of two enzyme cocktails (Allzyme SSF and VegPro) was assessed in diets containing meat and bone meal. Birds were fed diets containing SSF and VegPro separately or in combination; the enzymes, both separately or in combination, demonstrated improvement over the negative control for ending bird weight, live weight gain, and feed conversion ratio. The combination of enzymes demonstrated improved ileal amino acid digestibility compared to the negative control, while the enzymes separately demonstrated improved true amino acid digestibility for several amino acids. The digestibility of meat and bone meal did not improve with enzyme supplementation, likely due to the enzyme's target substrate being vegetable in origin. In Chapter 4, the effects of algae biomass were examined. The nutrient digestibility of algae was determined and these data were used to formulate a practical broiler starter diet containing $21 \%$ algae, and the effects of diets containing incrementally increasing levels of algae on performance and amino acid digestibility were assessed. Algae biomass energy and digestible amino acid content was determined to be most similar to soybean meal and was used as a replacement for this ingredient in diet formulation. The $21 \%$ algae diet increased pellet durability, suggesting algae as a pellet binder. Diets containing up to $16 \%$ algae resulted in similar performance and amino acid digestibility as the $0 \%$ algae diet. The two appendices represent research conducted to assess poultry litter biochar as a replacement for rock phosphates. In Appendix A, biochar was found to improve pelleting characteristics. Performance benefits were not observed, potentially due to arsenic contamination. However, some bone mineralization was observed. The biochar used in Appendix B was found to contain a lower level of arsenic. Pellet durability was again increased with dietary biochar inclusion and performance was improved. Performance was most improved with dietary inclusions of both biochar and phytase. No differences were observed for digesta viscosity. Amino acid digestibility and bone mineralization are currently being examined for this experiment. 


\section{DEDICATION}

I dedicate this dissertation to my maternal grandmother, Mernie Shultz. She is a woman of great strength and someone I strive to be like every day. She has survived the Great Depression, countless wars, and me as a child. She may have many miles on her tires, but she is still young at heart and nothing (not even illness) can slow her down. My grandmother taught me how to cook, bake, sew, and strive to be the greatest version of myself. She taught me that nothing comes easy, hard work always trumps idleness, and to share kind words with others. I will always carry the lessons and words of wisdom she has instilled in me. Without her influence in my life, I would not be where I am today. 


\begin{abstract}
AKNOWLEDGEMENTS
I would first like to thank my advisor and mentor, Dr. Joseph Moritz for his guidance and support throughout my collegiate career. I am deeply honored he has allowed me the opportunity to work within his lab for the past six years. The people and connections I have made will take my career to heights I never imagined, and for that I am eternally grateful. Next, I would like to thank my committee members, Drs. Janet Tou, Marie Krause, Deborah Boone, and Stacy Gartin for their constant support throughout my research. I would also like to thank all WVU staff and faculty for all the help they have provided me. Research is a labor intensive job; therefore, I would like to extend my sincerest gratitude towards my fellow lab mates for all of their support and hard work throughout this journey: John Boney, Brian Glover, Kolby Foltz, Mark Lemons. Without their help, none of this would be possible. Lastly, I would like to thank my family: my parents Robbie and Sue, my grandmothers Mernie and Nina, my uncles Charles and Chester, and my boyfriend Willy. Without their support, patience, and constant motivation, I would have never made it to this precipice in my life.
\end{abstract}




\section{Table of Contents}

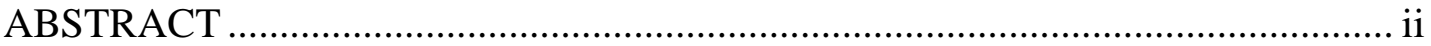

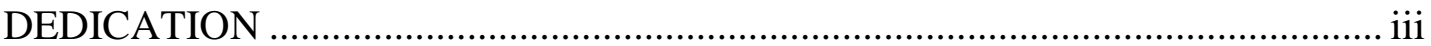

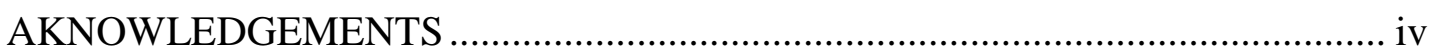

LIST OF TABLES ..................................................................................... viii

LIST OF SYMBOLS/NOMENCLATURE .......................................................... xi

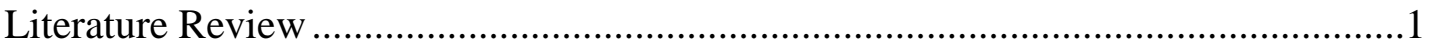

I.United States Poultry Production .................................................................

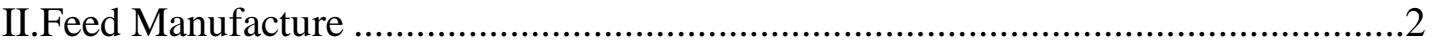

III.Phosphorus.............................................................................................

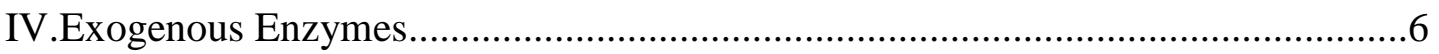

Thermostability of Exogenous Enzymes................................................................... 7

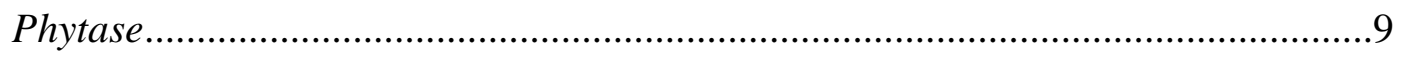

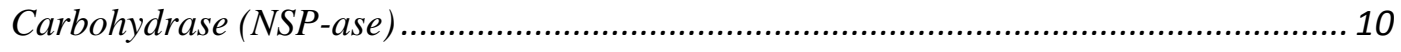

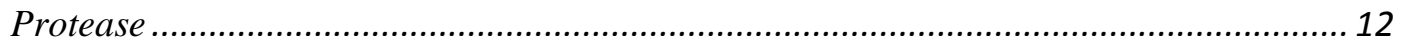

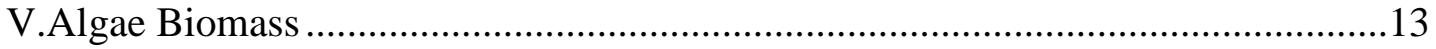

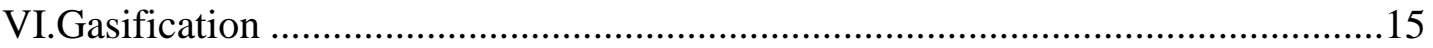

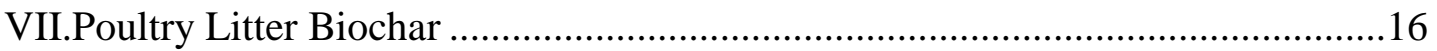

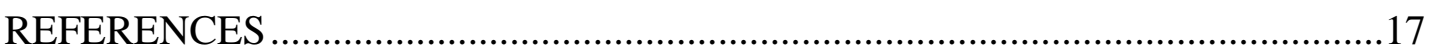

Manuscript submitted to Journal of Applied Poultry Research: Effects of Novel Phytase Enzymes on Activity Post-Pelleting, 3-21D Broiler Performance, and Bone

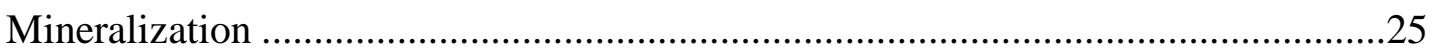

SUMMARY ...........................................................26

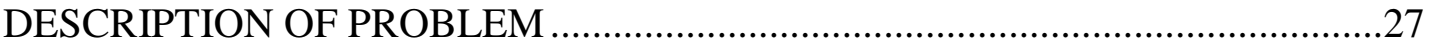

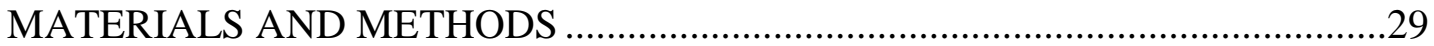




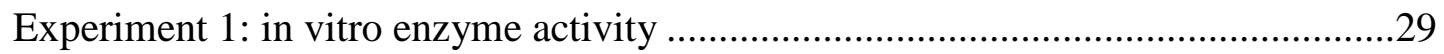

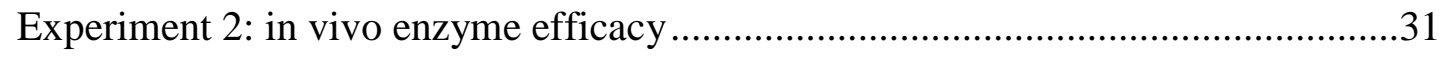

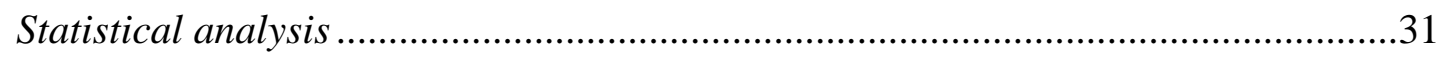

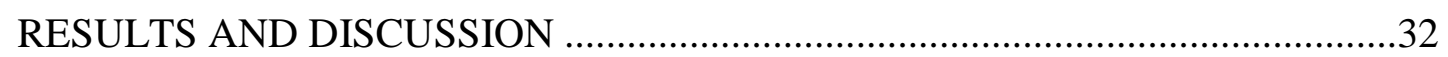

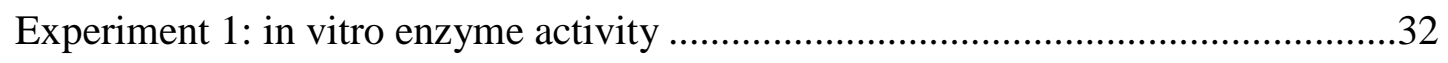

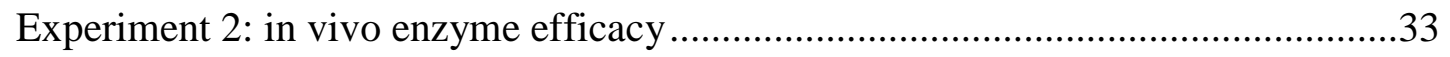

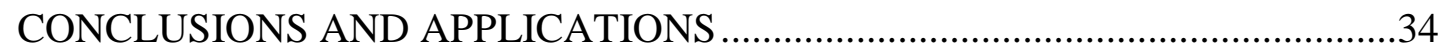

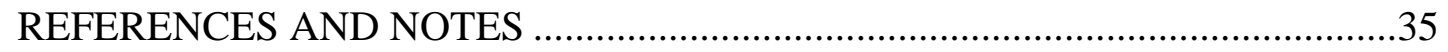

Manuscript submitted to Journal of Applied Poultry Research: Effects of Enzyme Supplementation on Nutrient Digestibility and Growth Performance of Chicks Fed Diets Containing Meat and Bone Meal ...............................................................44

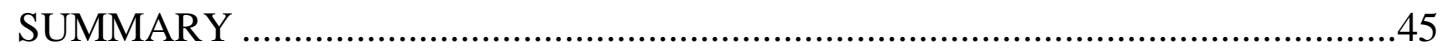

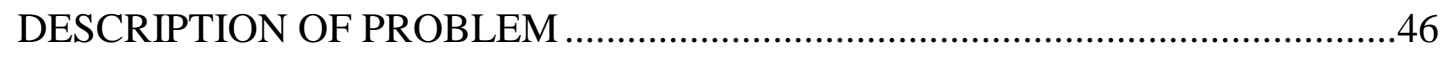

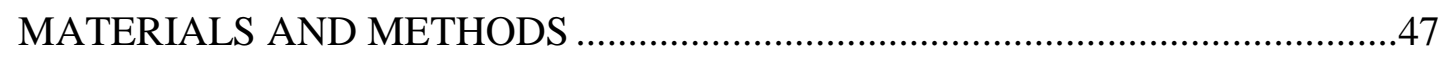

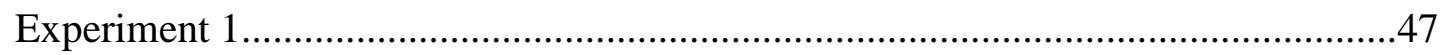

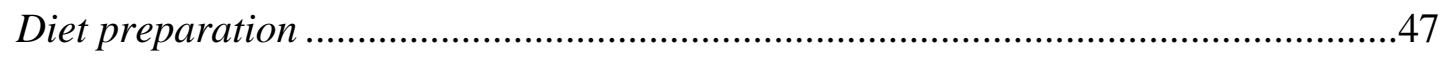

Live Bird Performance ................................................................................48

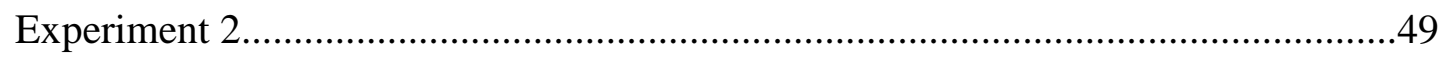

Part 1: TAAD of complete diets.......................................................................49

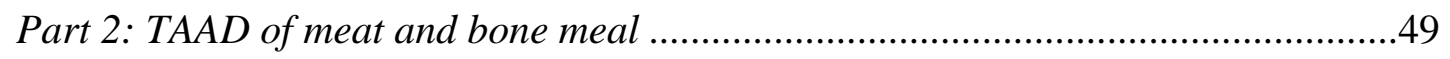

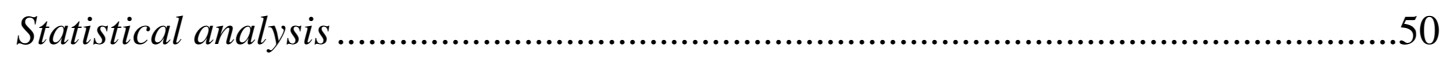

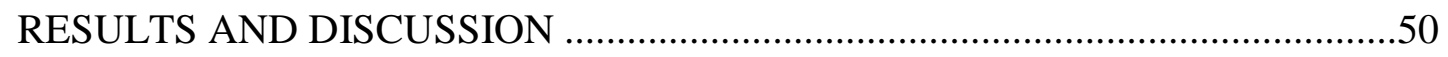

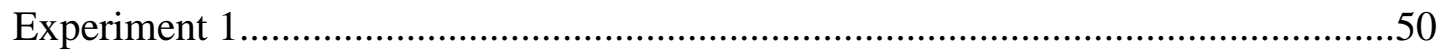

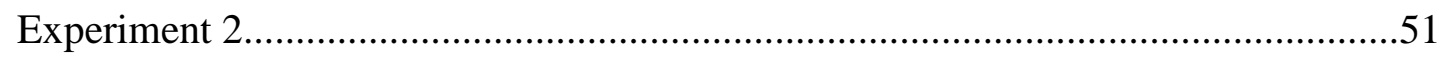

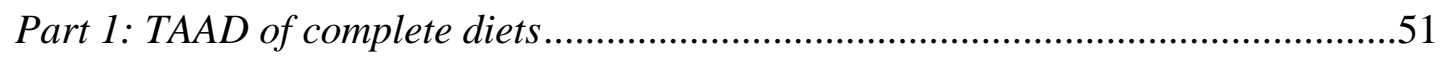




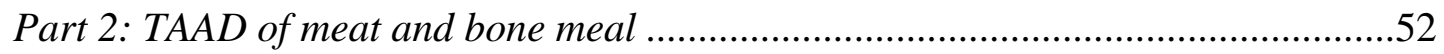

CONCLUSIONS AND APPLICATIONS ........................................................53

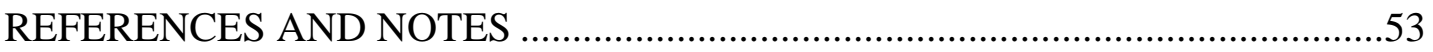

Manuscript submitted to Journal of Applied Poultry Research: Effects of Algae

Incorporation into Broiler Starter Diet Formulations on Nutrient Digestibility and 3-

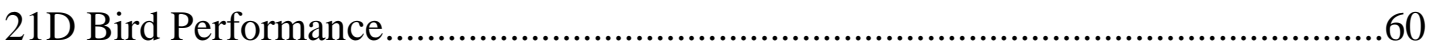

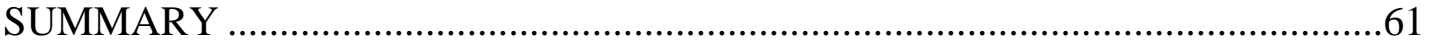

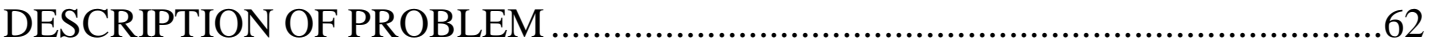

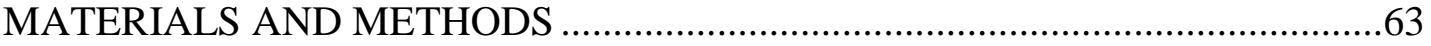

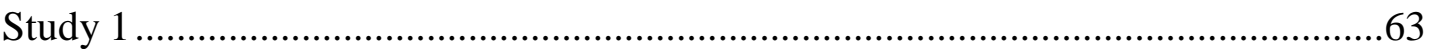

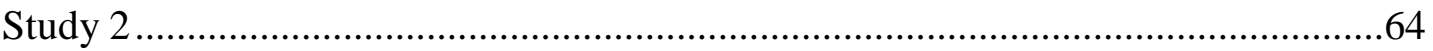

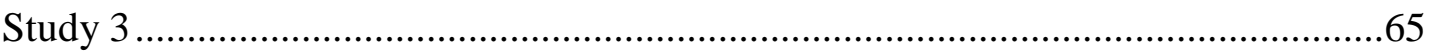

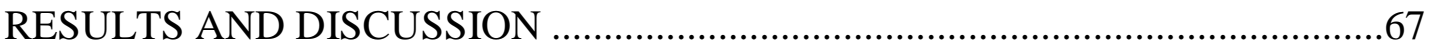

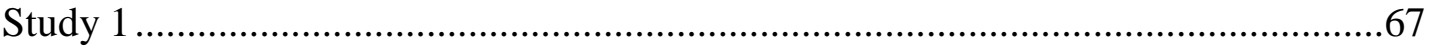

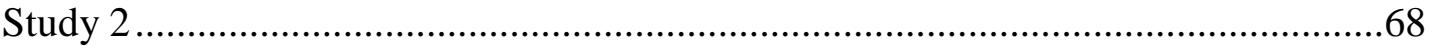

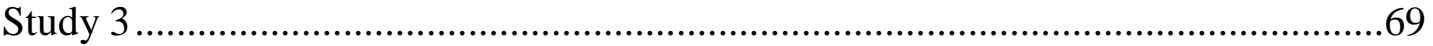

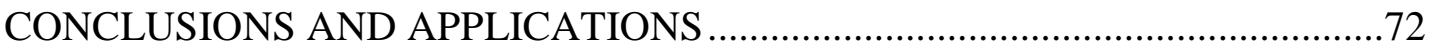

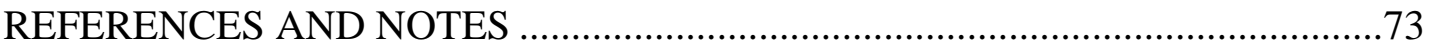

Manuscript submitted to Journal of Applied Poultry Research : The Effect of Poultry Litter Biochar Diet Inclusion on Feed Manufacture and Performance Variables in 4-

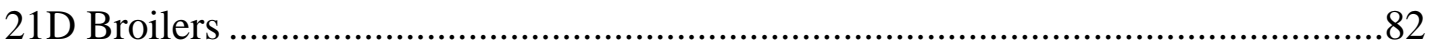

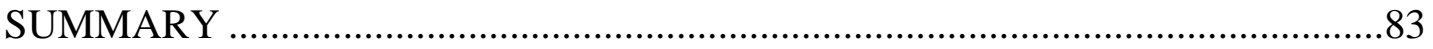

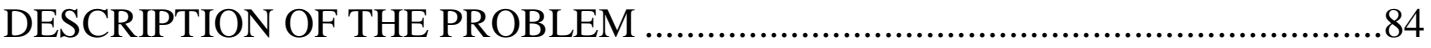

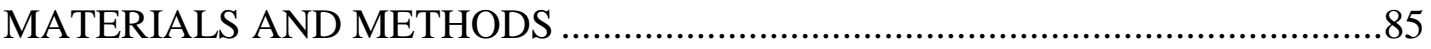

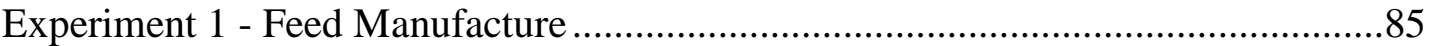


Experiment 2 - Live Bird Performance

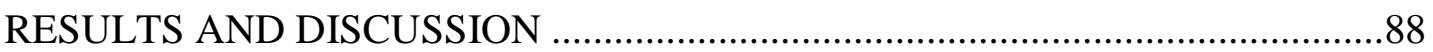

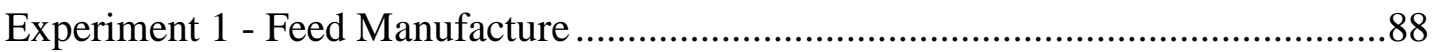

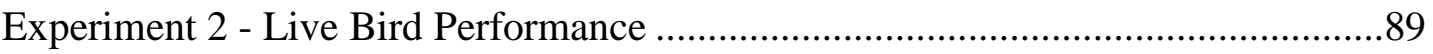

CONCLUSIONS AND APPLICATIONS .............................................................90

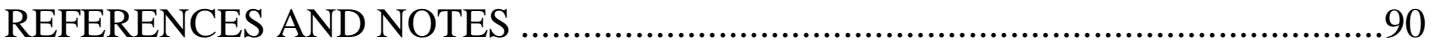

Manuscript prepared for Journal of Applied Poultry Research: The Effect of Poultry

Litter Biochar on Pellet Quality, 1-21D Broiler Performance, and Digesta

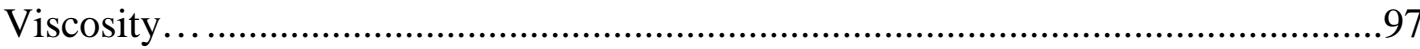

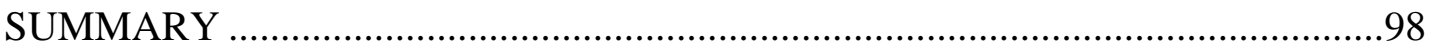

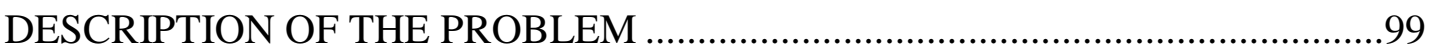

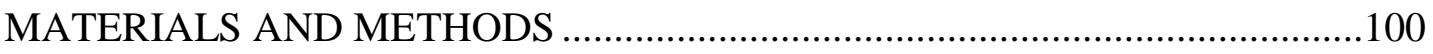

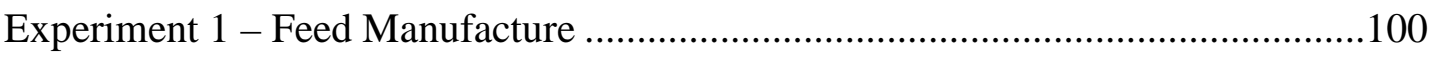

Experiment 2 - Live Bird Performance...............................................................102

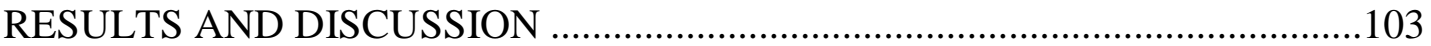

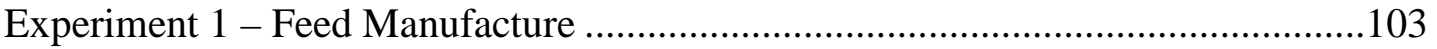

Experiment 2 - Live Bird Performance....................................................................104

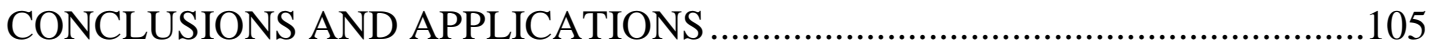

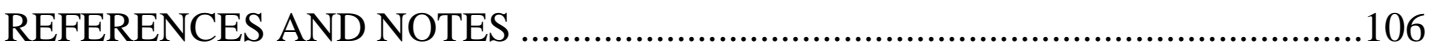

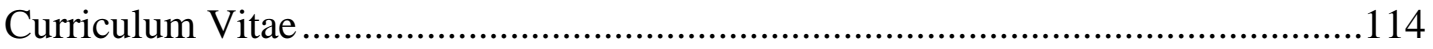

\section{LIST OF TABLES}

Manuscript submitted to Journal of Applied Poultry Research: Effects of Novel Phytase Enzymes on Activity Post-Pelleting, 3-21D Broiler Performance, and Bone Mineralization: 
Table 1. Diet formulations for positive and negative control diets differing in available phosphorus

Table 2. Descriptive feed manufacture data for standard diets containing increasing levels of phosphorus and four phytase variants (Experiment 1)

Table 3. Analyzed phytase activity of four phytase variants in mash and pelleted feed (Experiment 1)

Table 4. The effect of four phytase variants utilized in $90^{\circ} \mathrm{C}$ conditioned pelleted feed on live bird performance (Experiment 2)

Table 5. Sparing effects for enzyme variants A - D calculated from standard curve linear regression using tricalcium phosphorus (Experiment 2)

Table 6. Sparing effects for enzyme variants A - D calculated from standard curve quadratic regression using tricalcium phosphorus (Experiment 2)

Manuscript submitted to Journal of Applied Poultry Research: Effects of Enzyme Supplementation on Nutrient Digestibility and Growth Performance of Chicks Fed Diets Containing Meat and Bone Meal:

Table 1. Diet composition for the negative and positive control diets

Table 2. The effects of Alltech SSF and VegPro on live bird performance of Hubbard x Cobb 500 broiler chickens (Experiment 1).

Table 3. Percent Digestible Amino Acid ${ }^{1}$ for Positive and Negative Control Diets and Diets Containing SSF, VegPro, or SSF + VegPro using Hubbard x Cobb 500 Straight-Run Broiler Apparent Ileal Digestibility (Experiment 1).

Table 4. Percent Digestible Amino Acid ${ }^{1}$ for Positive and Negative Control Diets and Diets Containing SSF, VegPro, or SSF + VegPro using cecectomized Single Comb White Leghorn Roosters (Experiment 2, Part 1)

Table 5. Percent Digestible Amino Acid ${ }^{1}$ for Meat and Bone Meal (MBM), MBM + SSF, MBM + VegPro, or MBM + SSF + VegPro using cecectomized Single Comb White Leghorn Roosters (Experiment 2, Part 2). 
Manuscript submitted to Journal of Applied Poultry Research: Effects of Algae Incorporation into Broiler Starter Diet Formulations on Nutrient Digestibility and 321D Bird Performance:

Table 1. Algae ${ }^{1}$ nutrient composition used for diet formulation .............................76

Table 2. Diet composition for the 0 and $21 \%$ algae diets.....................................77

Table 3. True metabolizable energy (TMEn) and true amino acid digestibility (TAAD) value for treatments $100 \%$ corn, $100 \%$ algae, $100 \%$ soybean meal and 50:50 corn: algae (Study 1)

Table 4. Descriptive feed manufacture data for diets containing 0 and $21 \%$ algae and $0 \%$ algae with a green food coloring addition (Study 2) ......................................79

Table 5. Effects on performance variables for 3-21 day Hubbard X Cobb 500 broilers when fed diets containing $0,6,11,16,21 \%$ algae and a diet containing $0 \%$ algae and a green food coloring (Study 3 ).

Table 6. Percent digestible amino acid $^{1}$ for diets containing $0,6,11,16,21 \%$ algae, and a diet containing $0 \%$ algae with a green food coloring addition using Hubbard $\mathrm{X}$ Cobb 500 straight-run broiler ileal digestibility (Study 3)

Manuscript submitted to Journal of Applied Poultry Research : The Effect of Poultry Litter Biochar Diet Inclusion on Feed Manufacture and Performance Variables in 421D Broilers:

Table 1. Proximate analysis values, mineral content, and heavy metal composition of PLB derived from built-up broiler litter.

Table 2. Ingredient and calculated nutrient composition of diets provided to Cobb $\mathrm{x}$ Cobb 500 broilers from 4-21 d of age.

Table 3. Effects on feed manufacture variables when PC (Diet 4), PC with PLB (Diet 5), COM (Diet 6), and COM with PLB (Diet 7) were pelleted........................95

Table 4. Effects on performance variables for 4-21 day broilers when fed NC (Diet 1), Diet 2, Diet 3, PC (Diet 4), PC with PLB (Diet 5), COM (Diet 6), or COM with PLB (Diet 7). 
Manuscript prepared for Journal of Applied Poultry Research: The Effect of Poultry Litter Biochar on Pellet Quality, 1-21D Broiler Performance, and Digesta Viscosity:

Table 1. Proximate analysis values, mineral content, and heavy metal composition of PLB derived from built-up broiler litter.

Table 2. Ingredient and calculated nutrient composition of diets provided to Cobb $\mathrm{x}$ Cobb 500 broilers from 1-21 d of age. .110

Table 3. Descriptive feed manufacture data for diets PC, NC, 2 and 4\% PLB .111

Table 4. Effects on performance variables for 1-21 day broilers when fed PC, NC, 2 and $4 \%$ PLB

Table 5. Effects on digesta viscosity for 1-21 day broilers when fed PC, NC, 2 and 4\% PLB (with or without phytase).

\section{LIST OF SYMBOLS/NOMENCLATURE}

\section{CHAPTER 1}

1. Phosphorus $-\mathrm{P}$

2. Adenosine triphosphate - ATP

3. Deoxyribonucleic acid - DNA

4. Ribonucleic acid - RNA

5. Available phosphorus $-\mathrm{aP}$

6. Inositol hexakisphosphate - IP6

7. Non-phytate phosphorus - nPP

8. United States Environmental Protection Agency - USEPA

9. Total maximum daily load - TMDL

10. Concentrated animal feeding operation - CAFO

11. Best management practice - BMP

12. Non-starch polysaccharide - NSP

13. Poultry litter biochar - PLB

\section{CHAPTER 2}

1. Positive control - PC

2. Negative control - NC

3. Non-phytate phosphorus - nPP

4. Ending birds weight - EBW

5. Feed intake - FI

6. Live weight gain - LWG

7. Feed conversion ratio - FCR 
8. Tibia ash - TA

9. Association of official agricultural chemists - AOAC

10. Pellet durability index - PDI

11. Modified pellet durability index - MPDI

12. Analysis of variance - ANOVA

\section{CHAPTER 3}

1. Meat and bone meal - MBM

2. Positive control - PC

3. Negative control - NC

4. Ending bird weight - EBW

5. Feed conversion ratio - FCR

6. Live weight gain - LWG

7. Apparent amino acid digestibility - AIAAD

8. Non-starch polysaccharide - NSP

9. Inductively coupled plama mass spectrometry - ICP

10. Single comb white leghorn - SCWL

\section{CHAPTER 4}

1. Apparent ileal amino acid digestibility - AIAAD

2. True metabolizable energy - TMEn

3. True amino acid digestibility - TAAD

4. Single comb white leghorn - SCWL

5. Pellet durability index - PDI

6. Modified pellet durability index- MPDI

7. Ending bird weight - EBW

8. Feed intake - FI

9. Live weight gain - LWG

10. Feed conversion ratio - FCR

11. Inductively coupled plasma mass spectrometry - ICP

12. Analysis of variance - ANOVA

\section{APPENDIX A}

1. Poultry litter biochar - PLB

2. Live weight gain $-\mathrm{LWG}$

3. Feed conversion ratio - FCR

4. Negative control - NC

5. Positive control - PC

6. Positive control with poultry litter biochar (Diet 5) - PC with PLB

7. Commercial diet (Diet 6) - COM

8. Commercial diet with poultry litter biochar (Diet 7) - COM with PLB

9. Pellet durability index - PDI

10. Modified pellet durability index - MPDI 
11. Non-phytate phosphorus - nPP

12. Feed intake - FI

\section{APPENDIX B}

1. Poultry litter biochar - PLB

2. Positive control - PC

3. Non-phytate phosphorus - nPP

4. Negative control - NC

5. Feed intake - FI

6. Ending bird weight - EBW

7. Live weight gain - LWG

8. Feed conversion ratio - FCR

9. Association of official agricultural chemists - AOAC

10. Pellet durability index - PDI

11. Modified pellet durability index - MPDI 


\section{Literature Review}

\section{United States Poultry Production}

The United States is the largest producer of poultry in the world and the second largest egg producer. In 2013, the production value of all poultry products (broilers, eggs, turkeys, chickens) was \$44.1 billion, up 15 percent from \$38.2 billion in 2012. From this, \$30.7 billion was specifically broiler production. These values are 24 percent higher compared to 2012, with 8.52 billion broilers produced comprising 50.6 billion pounds of live weight [1].

The United States commercial poultry industry is vertically integrated which allows for product quality control throughout an entire grow-out and processing period. The integrator will own all aspects of production including: the feed mill, hatchery, breeder flock, and processing plant(s) in a particular area. They are responsible for supplying the grower with the chicks, feed, supervision, the transportation of both the chicks and feed, and processing of the final product. The grower will be under a contract with the integrator and will be responsible for daily labor (management, etc.), facilities (house, etc.), and any energy costs (electric, gas). At the end of a grow-out, typically 38 to 42 days, the birds are caught and loaded onto trucks, hauled to a processing plant and weighed. The grower is paid by pound of live weight (approximately \$0.05/lb.) and due to the short grow-out period (approximately 6 weeks), can have up to seven flocks of birds per year. 


\section{West Virginia Poultry Production}

Poultry is West Virginia's number one agricultural commodity and ranks $19^{\text {th }}$ in the country for broiler production. From December 1, 2011 to November 30, 2012, 94 million broilers were produced in West Virginia. This resulted in 376 million pounds of chicken, valued at $\$ 188$ million [1]. The majority of this poultry is raised in five counties located in the Potomac Highlands Region: Hardy, Grant, Hampshire, Mineral, and Pendleton. The majority of this product is processed in Moorefield, WV, where 2 million birds are processed each week. Pilgrim's Pride, located in Moorefield, WV, is the main integrator in West Virginia and is the second largest producer in the country.

\section{Feed Manufacture}

Feed and feed manufacture comprise approximately $70-75 \%$ of total production cost. Diet formulation is one of the most important factors affecting this cost, which has a direct influence on pellet formation, quality, and subsequently bird performance. Many nutritionists formulate diets at minimal costs while still fulfilling the animal's nutritional requirements. Because of this, a wide variety of feedstuffs may be used to meet nutritional requirements. Pellet quality may vary significantly depending on the ingredients utilized. Pellet quality is defined as the ability of a feed pellet to maintain its structural integrity from the feed mill to the feed pan [2]. Ingredient selection should be determined with respect to price, bioavailability, and the effect on both physical and nutritional pellet quality. Feed ingredients are comprised of primary components including: starch, protein, sugars, non-starch polysaccharides, lipids, inorganic matter and water [3]. Corn is the major ingredient in broiler diets in the United States and starch 
gelatinization is often afforded primary importance. However, protein has been shown to significantly affect pellet quality and should be considered in diet formulation $[4,5,6]$. Briggs and cohorts increased crude protein from 16.3 to $21 \%$ and subsequently increased pellet durability from 75.8 to $88.8 \%$, respectively [6]. Similarly, Winowiski reported increased pellet durability when crude protein was increased by using wheat [4].

Current industry practice is to reduce the amount of added fat in broiler diets to reduce diet cost and improve pellet quality [7]. However, research has shown that low mixer-added fat can be harmful to heat sensitive nutrients and mixer-added exogenous enzymes $[8,9,10]$. High mixer-added fat inclusion has shown to improve enzyme efficacy by coating the feed particles [11] and providing lubrication within the die to decrease frictional heat [12].

\section{Steam Conditioning}

Steam conditioning is a major part of the pelleting process. Moisture and temperature of a mash feed are increased by steam injection into the conditioner barrel, prior to extrusion through the pellet die. The addition of moist heat is essential for formation of a durable pellet [13]. Other benefits, such as improved throughput [14] and die lubrication $[14,15]$, result in reduced electrical energy usage. Steam conditioning at $70^{\circ} \mathrm{C}$ improved broiler performance compared to mash as reported by Belay and others [16]. Nutrient availability and broiler performance may be compromised above a certain temperature, despite apparent benefits of steam conditioning [17]. The upper threshold for steam conditioning temperature appears to be approximately $80-95^{\circ} \mathrm{C}$, as specified in several studies $[16,18,19,20]$. While care should always be taken to ensure nutrient 
retention, it is particularly important during winter months when more steam is required to reach the desired conditioning temperature [21].

\section{Phosphorus}

Phosphorus (P) is a mineral required by all life forms. It plays a critical role in cellular metabolism, part of the energy currency of cells, cellular regulatory mechanisms, and in bone mineralization [22]. P is a component of adenosine triphosphate (ATP), deoxyribonucleic acid (DNA), ribonucleic acid (RNA), and phospholipids found in cell membranes. Bone is the largest storage form of $\mathrm{P}$, accounting for $85 \%$ of the body's total P [22]. It is especially important to broiler chicks that grow from 50 grams to approximately $2.5 \mathrm{~kg}$ in only 38 to 42 days. Therefore, it is vital that broilers have strong skeletal systems to support their large body mass and meat accretion.

Phosphorus can be obtained from several sources in a diet. Some ingredients (i.e. corn and soybean) contain minute amounts of $\mathrm{P}$ and approximately $2 / 3$ of this $\mathrm{P}$ is in the phytate form, making it unavailable for non-ruminants [23]. The largest quantity of available phosphorus (aP) is obtained from inorganic feed phosphates, derived from rock phosphates. While these sources supply the animal with aP, they are expensive and nonrenewable [24]. There are various names for both phytate and non-phytate phosphorus which depend on what form the molecule is found in. Phytic acid or inositol hexakisphosphate (IP6) is a phosphorylated cyclic sugar alcohol. In salt or anion form, it is referred to as phytate. In mature seeds, phytate is present as a complex salt of calcium, magnesium, and potassium, and can sometimes also be bound to proteins and starches. 
This chelated molecule is known as phytin and is commonly referred to as non-phytate phosphorus (nPP) [25].

\section{Environmental Implications of Phosphorus}

Another reason the poultry industry has embraced phytase enzymes is due to environmental regulations. One such local example is the Chesapeake Bay Watershed, consisting of 64,000 square miles in parts of six different states: New York, Pennsylvania, Virginia, Maryland, West Virginia, and Delaware [26]. Over the past several years, nutrients such as nitrogen and phosphorus have accumulated in the Chesapeake Bay; these nutrients come from many sources, however, agricultural practices have been pinpointed as the main cause of pollution, specifically poultry. Overenrichment of a body of water caused by these nutrients can lead to eutrophication which is defined as the accumulation of organic matter [27]. Eutrophication can lead to algal blooms and the depletion of available oxygen levels in the water. This process results in an unbalanced system resulting in the death of many organisms, including fish and plant life. Eutrophication has been identified as the main problem of surface waters [28]. The increase in both the concentration of poultry production and operation size in many regions of the United States has led to an increase in manure application to the land. This application of manure has resulted in more $\mathrm{P}$ being added than crops require; resulting in an accumulation of $\mathrm{P}$ and an increased potential in $\mathrm{P}$ surface runoff [29]. The $\mathrm{P}$ inputs in a body of water can increase the potential for eutrophication [30, 31]. 
To combat the over-enrichment of the Chesapeake Bay, the United States Environmental Protection Agency (USEPA) has established Total Maximum Daily Load (TMDL) for waterways, setting maximum limits of nitrogen and phosphorus that the body of water can receive. For the Chesapeake Bay to meet the requirements set in the Clean Water Act, the TMDL limits the amount of P influx to 12.5 million lbs per year. This would eventually result in a $24 \%$ reduction of $\mathrm{P}$ in the bay, thus decreasing eutrophication [32].

Due to agriculture operations being pinpointed as the main pollution source, the USEPA has also defined a concentrated animal feeding operation (CAFO). The definition of a CAFO is any feeding operation that confines a set number of animals for 45 days or more in a 12 month period. A poultry facility is considered a CAFO if it confines 30,000 or more broiler or at least 55,000 turkeys [33] and many producers exceed this number. If a facility is determined to be a CAFO, a voluntary or incentivebased best management practice (BMP) may be implemented. These BMPs consist of three parts: 1) soil information for a particular area is collected; 2) the crop potential and amount of nutrients required to reach that potential is determined; 3) manure application rate is recommended for the area or field [34]. BMPs are devised to help reduce eutrophication in the Chesapeake Bay.

\section{Exogenous Enzymes}

It is common practice in broiler diets to supplement with exogenous enzymes in order to increase nutrient digestibility, decrease digesta viscosity, decrease diet cost and decrease nutrient excretion [35, 36]. Although the benefits of exogenous enzyme 
addition are numerous and well-established, enzymes may be denatured during the pelleting process. Broiler diets are typically formulated below intended nutrient values because it is assumed that exogenous enzymes will improve nutrient utilization preventing decreased production [36]. Therefore, if the majority of the added enzyme is denatured during pelleting, the diet will be nutrient deficient and may lead to decreased broiler performance. Thermostability of exogenous enzymes will be discussed in the following section.

\section{Thermostability of Exogenous Enzymes}

Some research has focused on exogenous enzyme retention after pelleting [20, 37, 38, 39, 40], although the applicability of the data is questionable. Enzyme stability is determined by several factors including: amino acid sequence, three-dimensional structure and the sum of many non-covalent interactions (hydrogen bonds, Van der Waals forces, hydrophobic interactions, and ion-pair networks) (Yip et al., 1995; Daniel et al., 1996). Thermostable enzymes may be recovered from naturally-occurring thermophiles, or may be achieved through enzyme coating [21]. There are many different commercial enzyme preparations that differ greatly in origin, production, and stability; however, it is not likely that retention data from one study can be applied to other enzymes. Care should be taken by feed mill managers to maintain pelleting temperatures below the published denaturation temperature for a particular enzyme. Additionally, lubrication of the pellet die by addition of fat in the mixer may improve enzyme retention and efficacy [7]. 
Many studies have been conducted to determine the thermostability of various exogenous enzymes and conflicted data exists. Eeckhout and coauthors concluded that most enzyme denaturation from processing occurs during steam conditioning instead of during extrusion through the pellet die [41]. For example, a typical conditioning temperature for poultry feeds is $85^{\circ} \mathrm{C}$, however the optimal temperature for many Bacillus spp. proteases is approximately $55^{\circ} \mathrm{C}$ [42]. In contrast, some studies conclude that enzyme deactivation is due to frictional heat and pressure associated with extrusion through a pellet die [7, 43]. A study conducted by Kirkpinar and others demonstrated denaturation of phytase preparations after steam conditioning at $60^{\circ} \mathrm{C}$ [44], while Hughes reported decreased phytase activity at $75^{\circ} \mathrm{C}$ [45]. Other research demonstrated that steam conditioning feed at temperatures of $78-81^{\circ} \mathrm{C}$ did not lower enzyme activity, but enzyme activity decreased at $84-87^{\circ} \mathrm{C}$ [46]. Gibson showed that two of three phytase preparations suffered inactivation after being exposed to temperatures of $65-95^{\circ} \mathrm{C}$; however, only one commercially available enzyme retained the majority of its activity when pelleted at $85^{\circ} \mathrm{C}$ and above [47]. Pasamontes and coauthors reported a heat-stable phytase able to withstand pelleting temperatures up to $100^{\circ} \mathrm{C}$ over a period of 20 minutes, with a loss of only $10 \%$ of the initial enzyme activity [48]. As with other exogenous enzymes, carbohydrases differ in terms of thermostability. Inborr and Bedford tested carbohydrase activity in feed and found that conditioning the feed at $85^{\circ} \mathrm{C}$ did not reduce enzyme activity compared to $75^{\circ} \mathrm{C}$; however, $95^{\circ} \mathrm{C}$ conditioning caused significant inactivation [37]. Esteve-Garcia and others tested the effects of pelleting diets supplemented with carbohydrase at temperatures around $80^{\circ} \mathrm{C}$ and found that the 
enzymes maintained over $80 \%$ of their activity [49]. Conversely, Almirall and others incubated carbohydrase in solution at $70^{\circ} \mathrm{C}, 80^{\circ} \mathrm{C}$, and $100^{\circ} \mathrm{C}$ and found that activity was reduced to 65,20 , and $0 \%$ respectively [50]. Viveros and others autoclaved carbohydrases at 50,70 , and $90^{\circ} \mathrm{C}$ and due to the increase of growth in the birds fed diets containing enzyme, no inactivation took place [51].

\section{Phytase}

Phytases are phosphatase enzymes able to catalyze the hydrolysis of phosphate ester bonds. Phytases are most commonly found in plants and can be produced by various bacteria, including micro flora found in the GI tract [52]. However, poultry and other monogastrics produce minimal endogenous phytase [53]. Therefore, incorporating exogenous phytase to poultry feed has been common practice since the 1990's in order to significantly increase phosphorus availability and utilization [54, 55], as well as decrease environmental impact [56]. Phytase enzymes can be expressed from different types of organisms and the host organism can dramatically affect how the enzyme performs in vivo. The first commercially available phytase, developed in the 1990's, was derived from Aspergillus niger. Currently, phytase products include those expressed from a variety of fungal, bacterial, yeast, and plant sources [57]. Cultures of Escherichia coli are often used to produce phytase because it can produce the enzyme quickly and in high volume compared to other sources [58].

Two classes of phytase enzymes exist: 1) a 3-phytase; and 2) a 6-phytase which cause dephosphorylation of the IP6 molecule at either the 3 or 6 position on the inositol ring, respectively. Generally, plants produce 6-phytase and microorganisms produce 3- 
phytase [59, 60]; however, researchers have reported 6-phytase activity in Escherichia coli [61] and 3-phytase activity in soybeans [62]. In vitro and in vivo studies have demonstrated differences in biochemical properties and efficacy between phytase sources $[63,64]$. This may be related to their optimum $\mathrm{pH}$ and stereospecificity of phytate hydrolysis (3- or 6-phytase). The $\mathrm{pH}$ optimum for phytase activity for A. niger is bimodal (pH 2.5 and 5.5), whereas it occurs at $\mathrm{pH} 4.0$ to 4.5 for Peniophora lycii and $\mathrm{pH}$ 2.5 to 3.5 for E. coli derived phytase [65]. A. niger phytase is a 3-phytase, whereas $P$. lycii and E. coli-derived phytases are 6-phytases [66, 67].

The host organism also affects phytase activity. It is likely that phytate hydrolysis takes place in the fore-stomach of poultry i.e. crop, proventriculus, and gizzard. The crop is most likely the primary site of phytate degradation by exogenous phytase [68, 69, 70]. However, there is evidence to suggest that $E$. coli-derived phytases are more active in the small intestine than phytases derived from $P$. lycii [71]. This may be attributed to the greater resistance of $E$. coli-derived phytases to endogenous, proteolytic enzymes [72].

\section{Carbohydrase (NSP-ase)}

In recent years, many nutritionists have a renewed interest in feeding non-starch polysaccharide (NSP) enzymes due to the potential cost savings they offer. The most popular nsp-ases or carbohydrases are xylanase, glucanase, and mannasase. These enzymes were developed due to their ability to target several substrate components within plant material including: fiber, starch, and some plant proteins. These enzymes have been demonstrated to be most effective in diets based on barley and wheat [73]. Without enzyme supplementation, diets containing high inclusions of wheat and barley have been 
associated with wet litter, which can lead to decreased performance, a lower foot pad score, and foot pad and breast blisters [74].

Carbohydrases have two main functions; cell wall destruction and bacterial population stimulation. The cell wall material in the starchy endosperm of corn and sorghum is constructed mainly of small amounts of cellulose encrusted with hemicelluloses [75]. Since poultry do not possess the necessary enzymatic capacity to degrade plant cell walls, a majority of the content within this material can either bypass digestion or not be absorbed until it reaches the lower gut by bacteria. This factor of encapsulation is based on the fact that some endosperm cells in corn and other ingredients manage to avoid physical breakdown during the activities of grinding and pelleting in feed manufacturing, and gizzard activity. Effective degradation of this material requires the addition of sufficient amounts of the appropriate NSP enzyme activity which created holes in the cell wall [73]. This allows water hydration and large enough amounts of pancreatic proteases and amylases to enter the cell wall and enable digestion of the starch and protein more rapidly. Xylanases, and to a lesser extent cellulases have proven most effective in the breakdown of corn cell wall material [76, 77]. Mannanases and pectinases have shown to target the soy more so than the corn fraction of the diet [78].

The second function of carbohydrases is bacterial population stimulation. Exogenous carbohydrases have proven to breakdown plant cell wall carbohydrates and reduce chain length producing smaller polymers and oligomers [79]. At some point the fragments become small and numerous enough to act as a substrate for bacterial fermentation. These short chain oligosaccharides travel to the lower gut and become 
substrates for bacterial fermentation in the ileum and cecum [79]. This is beneficial in altering bacterial populations and altering volatile fatty acid production. Medium to long chain oligomers have shown to increase fermentation in the jejunum and ileum region. However, feeding a xylanase significantly decreases fermentation and shifts it to the cecum. If the diet is well digested in the upper part of the digestive tract by using carbohydrases, smaller amounts of starch are present in the ileum and more cell wall oligomers are present in the cecum [80].

\section{Protease}

Typical poultry diets are comprised of corn and soybean meal. These two ingredients, particularly soybean meal, contribute to the majority of the protein fraction in a diet [81, 82]. While the protein associated with soybean meal is relatively high in terms of digestibility, exogenous proteases can be incorporated in diets to further increase protein digestibility. If adding exogenous protease allows for greater protein digestion, the overall protein content of the feed can be lowered, which results in lower cost of production and potential nitrogen that can be excreted [83]. Lower manure nitrogen content can reduce the amount of environmental pollution and potential eutrophication of waterways. Furthermore, greater protein digestion by protease supplementation can improve broiler performance and carcass yields $[84,85,86]$. The exogenous proteases incorporated into poultry feeds work by hydrolyzing proteins; bacterial derived proteases from Bacillus spp. seems to possess the highest presence of activity [42]. Proteases have a broad range of activities including degradation of insoluble keratin [87, 88, 89], soybean meal, and casein [88, 89, 90, 91]. 
Previous studies on the effects of protease have shown various results. Stark and coauthors have shown that protease supplementation improved LWG and FCR in lowprotein diets as compared to diets with adequate protein, despite decreased protease activity in the feed. However, feed intake was not affected by the protease [40]. In a study conducted by Odetallah and coauthors, protease supplementation improved FCR and LWG in adequate and low-protein diets [92]. Angel and coauthors concluded that protease supplementation improved protein digestibility and consequently improved broiler performance [93]. Freitas and coauthors demonstrated that protease supplementation caused a slight improvement in FCR however did not improve LWG [94]. Another study showed the effects of different proteases; one protease did not improve performance whereas another protease did improve performance [95]. This makes it essential for producers to fully test proteases to determine amounts of protein that can be removed from the diet without sacrificing nutrient availability and bird performance.

\section{Algae Biomass}

Algae represent a very large and diverse group of eukaryotic organisms, ranging from the unicellular Chlorella spp. to multicellular forms such as the giant kelp that can grow to 50 meters in length [96]. Crude oil prices have influenced the development of next generation alternative fuel sources. Algae is a leading candidate as an alternative fuel due to its short growing cycle, lack of requirement for arable land or potable water, and photosynthetic efficiency. The extraction of oil from algae generates a co-product, that when dried, has potential as a feed ingredient. Algae has the potential to be used in 
various animal feeds including: poultry, swine, and cattle; however, several variables are associated with production, thus necessitating research that compares method of production and feeding value. Variables for consideration include the extraction, drying, and storage of the co-product. The growth and harvest of algae consists of several stages. The algae may be grown in outdoor ponds, collected and passed through a series of cleaning screens, and spray dried to remove the moisture, resulting in a dry algae product [97]. Algae can be further processed to remove the oil for biofuel production and the resulting by-product may be used in animal feeds and human nutrition. Algae, regardless of oil-extraction, is high in several nutrients including: crude protein, beta carotene, gamma linolenic acid, vitamin $\mathrm{B}_{12}$, and iron [98, 99].

As a human supplement, the effects of algae has been well documented. Several studies have shown that algae supports the immune function in humans [100, 101, 102, 103]. Algae was found to decrease inflammation and contain antioxidant agents in several studies [100, 103]. Little research exists testing algae's effects in animal production. Ross and Dominy reported no detrimental effects by feeding broiler chickens up to $12 \%$ Spirulina algae [104]. Drewery and cohorts reported no significant differences in forage intake, digestion, or nitrogen balance with steers fed algae [105]. Becker named algae as a novel source of protein. Becker compared algae's amino acid profile to egg and soybean and it demonstrated similarities with an egg profile. The author also cited poultry as the target domestic animal due to poultry diets offering the most promising prospect for commercial algae use [106]. 


\section{Gasification}

Gasification is defined as the thermo-chemical conversion of a solid or liquid carbonbased material into a combustible gaseous product by the supply of a gasification agent [107]. The idea of gasification to produce an energy source has been around for years but interest in the process has recently risen due to the realization of problems facing global energy use. Gasifiers can be classified into two types; fixed-bed and fluid-bed. Of these two categories fixed-bed gasifiers can be classified further into updraft, Imbert downdraft, throat less downdraft, cross draft and two stage gasifiers. Each of these gasification systems are specific for the type of material being processed, moisture content of the material, as well as temperature range. The fixed bed gasifier has a bed of solid fuel particles through which the gasifying media and gas move either up or down. It is the simplest type of gasifier usually consisting of a cylindrical space for fuel and gasifying media with a fuel feeding unit, an ash removal unit, and a gas exit. In the fixed bed gasifier, the fuel bed moves slowly down the reactor as the gasification occurs. The fixed bed gasifiers are of simple construction and generally operate with high carbon conversion, long solid residence time, low gas velocity, and low ash carry over [108, 109]. Fixed bed gasifiers can be classified by which way the gasifying agent enters the system i.e. updraft, downdraft, cross draft, two stage. The gasifying media can be air, oxygen, steam, or a mixture of gasses. The result of gasification is heat, gas (syngas), tar, and char or ash. After purification, the syngas can be used as a fuel source. Two stage gasifiers separate the pyrolysis zone (first stage) from the reduction zone (second stage). The gasifier has two levels of air intakes, primary air supply at the top section and secondary air at the middle section of the gasifier. The high temperature achieved in the 
second stage due to the addition of a secondary air helps in reducing the tar level to a considerably lower value [110].

\section{Poultry Litter Biochar}

Poultry litter biochar (PLB) is produced by the gasification process of poultry litter. This process is beneficial to both the producer and the environment. Poultry litter stored in CAFOs or spread on fields poses the potential risk of runoff and subsequent eutrophication of waterways. The gasification of this poultry litter substantially reduces the volume of waste and may be more easily transported and stored. PLB is high in phosphorus and potassium, making it a viable source of fertilizer for crops [111]. The high amount of phosphorus also could prove PLB to be useful in poultry nutrition as a replacement for rock phosphorus. In 2008, suppliers of feed phosphates announced to their customers that supply of phosphates would not be enough to meet orders from the animal feed industry due to exceptionally high demand for phosphorus containing fertilizers (feed phosphates and fertilizers are both produced from a common raw material). These global shortages result from a combination of increased global demand, poor harvests, and the emergence of the bio-fuels industries which divert cereals and oil from plant protein sources into bio-ethanol and bio-diesel production [112]. Although it would seem that PLB would be a logical replacement of rock phosphorus, only three published study exists. The results of these studies found PLB to be a potential phosphorus source in broiler diets [113, 114, 115]. 
Feed ingredients and additives discussed here (exogenous enzymes, algae biomass, and poultry litter biochar) demonstrate several alternatives to traditional, expensive ingredients. Their efficacy in poultry diets can be debated, necessitating more research.

\section{REFERENCES}

1) USDA. Poultry Production and Value. http://usda.mannlib.cornell.edu/usda/current/PoulProdVa/PoulProdVa-04-29-2014.pdf. Accessed August 26, 2014.

2) Cramer, K. R., K. J. Wilson, J. S. Moritz, and R. S. Beyer. 2003. Effect of sorghum-based diets subjected to various manufacturing procedures on broiler performance. J. Appl. Poult. Res. 12:404-410.

3) Thomas, M., T. van Vliet, and A.F.B. Van der Poel. 1998. Physical quality of pelleted animal feed. 1. Contribution of feedstuff components. Anim. Feed Sci. Tech. 70: 59-78.

4) Winowiski, T. 1988. Wheat and pellet quality. Feed Manage. 39(9): 58-64.

5) Thomas, M., D.J. van Zuilichem, and A.F.B. Van der Poel. 1997. Physical quality of pelleted animal feed. 2. Contribution of processes and its conditions. Anim. Feed Sci. Tech. 64: 173-192.

6) Briggs, J.L., D.E. Maier, B.A. Watkins, and K.C. Behnke. 1999. Effect of ingredients and processing parameters on pellet quality. Poult. SCi. 78: 14641471.

7) Gehring, C. K., K. G. S. Lilly, L. K. Shires, K. R. Beaman, S. A. Loop, and J. S. Moritz. 2011. Increasing mixer-added fat reduces the electrical energy required for pelleting and improves exogenous enzyme efficacy for broilers. J. Appl. Poult. Res. 20:75-89.

8) Gehring, C.K. 2009. Improvement of the physical and nutritional quality of pelleted feed. M.S. Thesis. West Virginia University, Morgantown.

9) N.P. Buchanan, K.G.S. Lilly, C.K. Gehring, and J.S. Moritz. The effects of altering diet formulation and manufacturing technique on pellet quality. J. Appl. Poult. Res. 2010 19:112-120.

10) Lilly, K. G. S., C. K. Gehring, K. R. Beaman, P. J. Turk, M. Sperow, and J. S. Moritz. 2011. Examining the relationships between pellet quality, broiler performance, and bird sex. J. Appl. Poult. Res. 20: 231 - 239.

11) Zimonja, O., A. Stevnebø, and B. Svihus. 2007. Nutritional value of diets for broiler chickens as affected by fat source, amylose level and diet processing. Can. J. Anim. Sci. 87:553-562.

12) Cutlip, S.E., J.M. Hott, N.P. Buchanan, A.L. Rack, J.D. Latshaw and J.S. Moritz. 2008. The effect of steam conditioning practices on pellet quality and growing broiler nutritional value. J. Appl. Poult. Res. 17:241-269.

13) Froetschner, J.R. 2005. Current issues in feed manufacturing. DSM. 
14) Skoch, E.R., K.C. Behnke, C.W. Deyoe, and S.F. Binder. 1981. The effect of steam-conditioning rate on the pelleting process. Anim. Feed Sci. Tech. 6:83.

15) Skoch, E. R., S. F. Binder, C. W. Deyoe, G. L. Allee, and K. C. Behnke. 1983. Effects of steam pelleting conditions on performance of pigs fed a corn-soybean meal diet. J. Anim. Sci. 57:922-928.

16) Bayley, H.S., J.D. Summers, and S.J. Slinger. 1968. The effect of steam pelleting feed ingredients on chick performance: effect on phosphorous availability, metabolizable energy value and carcass composition. Poult. Sci. 47:1140-1148.

17) Cutlip, S. E., J. M. Hott, N. P. Buchanan, A. L. Rack, J. D. Latshaw and J. S. Moritz.2008.The effect of steam conditioning practices on pellet quality and growing broiler nutritional value. J. App. Poult. Res.17: 249-261.

18) Nissinen, V. 1994. The effects and interactions of enzymes and hydrothermal pretreatments and their contribution to feeding value. Inter. Mill. Flour Feed.May: $21-22$.

19) Nir. I., R. Hillel, I. Ptichi, and G. Shefet. 1995. Effect of particle size on performance. Grinding pelleting interactions. Poult Sci. 74: 771-783.

20) Silversides, F. G., and M. R. Bedford. 1999. Effect of pelleting temperature on the recovery and efficacy of a xylanase enzyme in wheat-based diets. Poult. Sci. 78:1184-1190.

21) Wyatt, C. L. 2009. Technical tools for supporting next generation thermo-tolerant enzymes in poultry diets. Multi-State Poultry Feeding and Nutrition Conference. May 19-21, Indianapolis, IN.

22) Applegate, T. J., and R. Angel. 2008. Animal sciences: phosphorus requirements for poultry. Purdue University Cooperative Extension Service, West Lafayette, IN.

23) Angel, R. 2011. Calcium and Phosphorus Requirements in Broilers and Laying Hens. Australian Poultry Science Symposium, Sydney, New South Wales. Poultry Research Foundation, University of Sydney and World’s Poultry Science Association, Australia.

24) Grimbergen, A. H. m., J. P. Cornelissen, and H. P. Stappers. 1985. The relative availability of phosphorus in inorganic feed phosphates for young turkeys and pigs. Anim. Feed Sci. and Technol. 13: 117 - 130.

25) Graf, E. 1986. Chemistry and applications of phytic acid: anoverview. Phytic Acid: Chemistry and Applications, E. Graf, ed. Pilatus Press, Minneapolis, MN. 173-194.

26) Chesapeake Bay Watershed. http://chesapeakebay.net/. Accessed February 29, 2012.

27) Rabalias, N.N., Turner, R.E., Diaz, R. J., and Justic, D. Global change and Eutrophication of coastal water. Ices Journal of Marine Science. 66: 1528-1537.

28) United States Environmental Protection Agency. 1996. Environmental indicators of water quality in the United States. EPA 841-R-96-002. USEPA, Office of Water, U.S. Government Printing Office, Washington, DC.

29) Sharpley, A. 1999. Agricultural phosphorus, water quality, and poultry production: Are they compatible?. Poult. Sci. 78:660-673. 
30) Schindler, D. W., 1977. Evolution of phosphorus limitation in lakes. Science 195: $260-262$.

31) Carpenter, S. R., N. F. Caraco, D. L. Correll, R. W. Howarth, A. N. Sharpley, and V. H. Smith. 1998. Nonpoint Pollution of surface waters with phosphorus and nitrogen. Ecol. Appl. 8:559-568.

32) United States Environmental Protection Agency. 2011. Chesapeake Bay TMDL. http://www.epa.gov/reg3wapd/tmdl/ChesapeakeBay/index.html. asp Accessed January 10, 2012.

33) United States Environmental Protection Agency. Federal Register. http://www.epa.gov/npdes/regulations/cafo_final_rule_preamble2008.pdf. Accessed_March 6, 2012.

34) United States Environmental Protection Agency. Best Management Practices. http://www.epa.gov/agriculture/anafobmp.html. Accessed March 6, 2012.

35) Bedford, M. R. 2000. Exogenous enzymes in monogastric nutrition-their current value and future benefits. Anim. Feed Sci. Tech. 86:1-13.

36) Bedford, M. R. 2002. The role of carbohydrases in feedstuff digestion. Pages 319-336 in Poultry Feedstuffs-Supply, Composition and Nutritive Value. J. M. McNab and K. N. Boorman, ed. CABI Publ., England.

37) Inborr, J., and M.R. Bedford. 1994. Stability of feed enzymes to steam pelleting during feed processing. Anim. Feed Sci. Tech. 46: 176-196.

38) Spring, P., K.E. Newman, C. Wenk, R. Messikommer, and M. Vukić Vranjkeš. 1994. Influence of pelleting temperature on the activity of different enzymes. Poult. Sci. 75: 357-361.

39) Cowieson, A.J., M. Hruby, and M. Faurschou Isaksen. 2005. The effect of conditioning termpeature and exogenous xylanase addition on the viscosity of wheat-based diets and the performance of broiler chickens. Br. Poult. Sci. 46: 717-724.

40) Stark, C.R., B.E. Spencer, J.C.H Shih, C.G. Chewning, and J.J. Wang. 2009. Evaluation of keratinase stability in pelleted broiler diets. J. Appl. Poult. Res. 18: 30-33.

41) Eeckhout, M., M. DeSchrijver, and E. Vanderbeke. 1995. The influence of process parameters on the stability of feed enzymes during steam pelleting. Pages 163-179 in: Proceedings of the $2^{\text {nd }}$ European Symposium on Feed Enzymes. Noordwijkerhout, The Netherlands.

42) Brandelli, A., D.J. Daroit, and A. Riffel. 2009. Biochemical features of microbial keratinases and their production and applications.

43) Spring, P. K. E. Newman, C. Wenk, R. Messikommer, and M. Vukic Vranjes. 1996. Effect of pelleting temperature on the activity of different enzymes. Poult. Sci. 75:357-361.

44) Kirkpinar, F., H. Basmacioglu. 2006. Effects of pelleting temperature of phytase supplemented broiler feed on tibia mineralization, calcium, and phosphorus content of serum and performance. Czech Journal of Animal Science. 51: 78-84. 
45) Hughes, A., 1993. Importance of phytates and cereal phytases in the feeding of pigs. Enzymes in Animal Nutrition. C Wenk, ed. ETH-Zurich, Zurich. pp. 192 198.

46) Pandey, A., G. Szakacs, C. R. Soccol, J. A. Rodriguez-Leon, and V. T. Soccol. 2001. Production, purification, and properties of microbial phytases. Biores. Technol. 77: 203-214.

47) Gibson, K. (1995) The pelleting stability of animal feed enzymes. In: van Hartingsveldt, W., Hessing, M., van der Lugt,J.T. and Somers.W.A.C. (eds) Proceedings of the $2^{\text {nd }}$ Annual Symposium on enzymes in animal nutrition.Noordwijkerhout, The Netherlands, pp 157-162.

48) Pasamontes, L., M. Haiker, M. Wyss, M. Tessier, and A. P. G. M. vanLoon. 1997. Gene cloning, purification, and characterization of a heat-stable phytase from the fungus Aspergillus fumigatus. Appl. Enivon. Microbio. 63: 1696 - 1700.

49) Esteve-Garcia, E., J. Brufau, A. Pérez-Vendrell, A. Miquel, and K. Duven. 1997. Bioefficacy of enzyme preparations containing $\beta$-glucanase and xylanase activities in broiler diets based on barley or wheat, in combination with flavomycin. Poult. Sci. 76:1728-1737.

50) Almirall, M., M. Francesch, A. M. Pérez-Vendrell, J. Brufau, and E. EsteveGarcia. 1995. The differences in intestinal viscosity produced by barley and $\beta$ glucanase alter digesta enzyme activities and ileal nutrient digestibilities more in broiler chicks than in cocks. J. Nutr. 125:947-955.

51) Viveros, A., A. Brenes, M. Pizzarro, M. Castaño. 1994. Effect of enzyme supplementation of a diet based on barley, and autoclave treatment, on apparent digestibility, growth performance and gut morphology of broilers. Anim. Feed Sci. and Tech. 48: 237-251.

52) Angel, R., N. M. Tamim, T. J. Applegate, A. S. Dhandu, and L. E. Ellestad. 2002. Phytic acid chemistry: influence on phytin-phosphorus availability and phytase efficacy. J. Appl. Poult. Res. 11:471-480.

53) Nelson, T. S. 1976. The hydrolysis of phytin phosphorus by chicks and laying hens. Poult. Sci. 55:2262-2264.

54) Ravindran, V., W. L. Bryden, and E. T. Kornegay. 1995. Phytin: Occurrence, bioavailability and implications in poultry nutrition. Poult. Avian Biol. Rev. 6:125-143.

55) Shaw, A.L., Blake, J.P., and Gordan, J.W. 2010. Evaluation of commercial phytase enzymes on performance and tibia-breaking strength of male broiler chicks. J. Appl. Poult. Res. 19:415-421.

56) Mullaney, E. J., C. B. Daly, and A. H. J. Ullah. Advances in Phytase Research. Adv. Appl. Microbio. 47: 157 - 199.

57) Wodzinski, R. J., and A. H. J. Ullah. 1996. Phytase. Adv . Appl. Microbiol. 42: $263-302$.

58) Viveros, A., C. Centeno, A. Brenes, R. Canales, and A. Lozano. 2000. Phytase and acid phosphatase activities in plant feedstuffs. J. Agric. Food Chem. 48:40094013. 
59) Reddy, N. R., S. K. Sathe, and D. K. Saunkhe. 1982. Phytates in legumes and cereals. Adv. Food Res. 28:1-92.

60) Nayini, N. R., and P. Markakis. 1986. Phytases. Phytic Acid: Chemistry and Applications. E. Graf, ed. Pilatus Press, Minneapolis, MN. 101-118.

61) Greiner, R., U. Konietzny, and K. D. Jany 1993. Purification and characterization of two phytases from Escherichia coli. Arch. Biochem. Biophys. 303:107-113.

62) Phillippy, B. Q., M. R. Johnston, S. H. Tao, and M. R. S. Fox. 1988. Inositol phosphates in processed foods. J. Food Sci. 53:496-499.

63) Rodriguez, E., Y. M. Han, and X. G. Lei. 1999. Cloning, sequencing, and expresson of an Escherichia cloi acid phosphatase/phytase gene (appA2) isolated from pig colon. Biochem. Biophys. Res. Comm. 257: 117 - 123.

64) Yin, Q. Q., Q. H. Zheng, and X. T. Kang. 2007. Biochemical characteristics of phytases from fungi and the transformed microorganism. Anim, Feed Sci. Technol. 132: 341 - 350.

65) Adeola, O., J. S. Sands, P. H. Simmins, and H. Schulze. 2004. The efficacy of an Escherichia coli-derived phytase preparation. J. Anim. Sci. 82: 2657 - 2666.

66) Kornegay, E. T. 2001. Digestion of phosphorus and oter nutrients: The role of phytases and factors influencing their activity. Pages 237 - 272 in Enzymes in Farm Animal Nutrition. M. R. Bedford and G. G. Partridge, eds. CAB International, Wallingford, UK.

67) Augspurger, N. R., D. M. Webel, X. G. Lei, and D. H. Baker. 2003. Efficacy of and E. coli phytase expressed in yeast for releasing phytate-bound phosphorus in young chicks and pigs. J. Anim. Sci. 81: $474-483$.

68) Leibert, F., C. Wecke, and F. J. Schoner. 1993. Phytase activities in different gut contents of chickens as dependent on level of phosphorus and phytase supplementations. Int Proceedings of $1^{\text {st }}$ European Symposium Enzymes in Animal Nutrition, pp. $202-205$.

69) Takemasa, M., H. Murakami, and M. Yamazaki. 1996. Reduction of phosphorus excretion of chicks by addition of yeast phytase. Jpn. Poult. Sci. 33: $104-111$.

70) Kerr, M. J., H. L. Classen, and R. W. Newkirk. 2000. The effects of gastrointestinal traft micro-flora and dietary phytase on inositol hexaphosphate hydrolysis in the chicken. Poult. Sci. 79 (suppl. 1), 11 (abstract).

71) Onyango, E. M., M. R. Bedford, and O. Adeola. 2005. Phytase activity along the digestive tract of the broiler chick: a comparative study of an Escherichia coliderived and Peniophora lycii phytase. Can. J. Anim. Sci. 85: 61 - 68.

72) Igbasan, F. A., O. Simon, G. Milksch, and K. Manner. 2000. Comparative studies of the in vitro properties of phytases from various microbial origins. Ach. Anim. Nutr. 53: 353 - 373.

73) Wyatt, C.L., T. Parr, and M. Bedford. 2008. Mechanisms of action for supplemental NSP and phytase enzymes in poultry diets. Proceedings from $35^{\text {th }}$ Poultry Nutrition Conference. North Carolina. pp 12-22.

74) Martland, M.F. 1985. Ulcerative dermatitis in broiler chickens: the effect of wet litter. Avian Pathology. 14: 353-364.

75) Stone, B.A. 2004. Cell walls of cereal grains. pp. 1-9. Minneapolis: AACC. 
76) Leslie MA, ET, Jr., Moran, and M.R. Bedford. 2007. The effect of phytase and glucanase on the ileal digestible energy of corn and soybean meal fed to broilers. Poult. Sci. 86: 2350-2357.

77) Zanella I., N.K. Sakomura, A.P. Rosa, A.N. Figueiredo, and L. Magon. 2004. Enzyme supplementation on digestibility of corn-soybean diets for broiler chicks. Ars. Veterinaria. 20: 144-150.

78) Jackson M.E., K. Geronian, A. Knox, J. Mcnab, and E. McCartney. 2004. A dose-response study with the feed enzyme beta-mannanase in broilers provided with corn-soybean meal based diets in the absence of antibiotic growth promoters. Poult. Sci. 83: 1992-1996.

79) Apajalahti, J., and M.R. Bedford. 1999. Improve bird performance by feeding its microflora. World Poultry, 15: 20.

80) Engberg, R.M., M.S. Hedemann, S. Steenfeldt, and B.B. Jensen. 2004. Influence of whole wheat and xylanase on broiler performance and microbial composition and activity in the digestive tract. Poult. Sci. 83: 925.

81) Van Kempen, T. A. T. G., I. B. Kim, A. J. M. Jansman, M. W. A. Verstegen, J. D. Hancock, D.J. Lee, D. M. Albin, G. C. Fahey, Jr. C. M. Grieshop, and D. Mahan. 2002. Regional and processor variation in the ileal digestible amino acid content of soybean meals measured in growing swine. J. Anim. Sci. 80:429-439.

82) Huang, K., X. Li, V. Ravindran, L.I. Hew, and W. L. Bryden. 2003. Influence of age on ileal lysine digestibility of feedstuffs in broiler chickens. Page 70 in Proceedings of the $15^{\text {th }}$ Annual Australian Poultry Science Symposium, Sydney, NSW, Australia. University of Sydney, Sydney, Australia.

83) Oxenboll, K.M., K. Pontoppidan, and F. Fru-Nji. 2011. Use of a Protease in Poultry Feed Offers Promising Environmental Benefits. International Journal of Poultry Science, 10:842-848.

84) Wang, H.Y. Guo, J.C.H. Shih. 2008. Effects of dietary supplementation of keratinase on growth performance, nitrogen retention and intestinal morphology of broiler chicken fed diets with soybean and cotton seed meals. Anim. Feed Sci. Tech. 140:376-384.

85) Odetallah, N.G., J.J.Wang, J.D. Garlich, and J.C.H. Shih. 2003. Keratinase in starter diets improves growth of broiler chicks. Poult. Sci. 82:664-670.

86) Wang, J.J., J.D. Garlich, and J.C.K. Shih. 2006. Beneficial effects of Versazyme, a keratinase feed additive, on body weight, feed conversion, and breast yield of broiler chickens. J Appl Poult Res 15:544-550.

87) Gradisar, H.,S. Kern, and J. Friedrich.2000.Keratinase of Doratomyces microspores. Appl Microbiol Biotechnol 53:196-200.

88) Gradisar, H.,J. Friedrich, I. Krizaj, and R. Jerala. 2005. Similiarities and specificities of fungal keratinolytic proteases: comparison of keratinases of Paecilomyces marquandii and Doratomyces microspousto some known proteases. Appl Environ Microbiol 71:3420-3426.

89) Brandelli, A. 2005. Hydrolysis of native proteins by a keratinolytic strain of Chryseobacterium sp. Ann Microbiol 55:47-50. 
90) Vignardet, C., Y.C. Guillaume, L. Michel, J. Friedrich, and J. Millet. 2001. Comparison of two hard keratinous substrates submitted to the action of a keratinase using an experimental design. Int J Pharm 224:115-122.

91) Casarin, F., F. Cladera-Olivera, and A. Brandelli. 2008. Use of poultry byproduct for production of keratinolytic enzymes. Food Bio-Process Technol 1:301-305.

92) Odetallah, N. H., J. J. Wang, J. D. Garlich, and J. C. H. Shih. 2005. Versazyme supplementation of broiler diets improves market growth performance. Poult. Sci. 84:858-864.

93) Angel, C. R., W. Saylor, S. L. Vieira, and N. Ward. 2011. Effects of a monocomponent protease on performance and protein utilization in 7- to 22- day-old broiler chickens. J. Poult. Sci. 90:2281-2286.

94) Freitas, D. M., S. L. Vieira, C. R. Angel, A. Favero, and A. Maiorka. 2011. Performance and nutrient utilization of broilers fed diets supplemented with a novel mono-component protease. J. Appl. Poult. Res. 20:322-334.

95) Ghazi, S., J. A. Rooke, H. Galbraith, and M. R. Bedford. 2002. The potential for the improvement of the nutritive value of soya-bean meal by different proteases in broiler chicks and broiler cockerels. Br. Poult. Sci. 43:70-77.

96) Parfrey, L.W., E. Barbero, E. Lasser, M. Dunthorn, D. Bhattacharya, D.J. Patterson, and L.A. Katz .2006. Evaluating Support for the Current Classification of Eukaryotic Diversity. PLoS Genet. 2 (12): e220.

97) Belay, A. 1997. Mass culture of Spirulina (Arthrospira) outdoors - The Earthrise Farms Experience. In: Vonshak, A. (ed.) Spirulina platensis (Arthrospira): Physiology, Cell-Biology and Biotechnology. Taylor and Francis. pp. 131-158.

98) Cohen Z. \& A. Vonshak. 1991. Fatty acid composition of Spirulina and Spirulinalike cyanobacteria in relation to their chemotaxonomy. Phytochem. 30: 205-206.

99) Belay, A. 2002. The potential application of Spirulina (Arthrospira) as a nutritional and therapeutic supplement in health management. Journal of the American Nutraceutical Association. 5: 27-48.

100) Mao T.K., J, Van de Water \& M.E. Gershwin 2005. Effects of a Spirulina-based dietary supplement on cytokine production from allergic rhinitis patients. J Med Food. 8(1):27-30.

101) Hirahashi T, M. Matsumoto, K. Hazeki, Y. Saeki, M. Ui, T. Seya. 2002. Activation of the human innate immune system by Spirulina: augmentation of interferon production and NK cytotoxicity by oral administration of hot water extract of Spirulina platensis. Int Immunopharmacol. 2(4):423-34.

102) Gershwin, M.E. \& Belay, A. (eds.) Spirulina in Human Nutrition and Health. CRC Press, 312pp.

103) Gemma, C., M.H. Mesches, B. Sepesi, K. Choo, D.B. Holmes \& P.C. Bickford. 2002. Diets enriched in foods with high antioxidant activity reverse age-induced decreases in cerebellar beta-adrenergic function and increases in proinflammatory cytokines. J Neurosci.15. 22(14):6114-20.

104) Ross, E., and W. Dominy. 1990. The nutritional value of dehydrated blue-green algae (Spirulina plantensis) for poultry. Poult. Sci. 69: 794 - 800. 
105) Drewery, M. L. 2012. Post-extraction algal residue as a protein source for cattle consuming forage. Master's Thesis, Texas A\&M University. Available electronically from http://hdl.handle.net/1969.1/148191.

106) Becker, E.W. 2007. Micro-algae as a source of protein. Biotech. Adv. 25: 207 210.

107) Belgiorno, V., G. De Feo, C. Della Rocca, and R.M. Napoli. 2003. Energy from gasification of solid wastes. Waste Manag. 23(1): 1-15.

108) Carlos, L. 2005. High temperature air/steam gasification of biomass in an updraft fixed batch type gasifier. PhD dissertation. Royal Institute of Technology, Energy Furnace and Technology, Stockholm, Sweden.

109) Redd, T.B., and A. Das. 1988. Handbook of biomass downdraft gasifier engine systems. Colorado: Solar Energy Research Institute.

110) Chopra, S. and A. Jain. 2007. A review of fixed bed gasification systems for biomass. Agricultural engineering international: the CIGR Ejournal. Invited overview No. 5 (9).

111) Codling, E., R. Chaney, and J. Sherwell. 2002. Poultry litter ash as a potential phosphorus source for agricultural crops. J. Environ. Qual. 31: 954-961.

112) Aviagen Global Nutrition Team. 2008. Global feed phosphate shortage. Aviagen.com

113) Akpe, M.P., P.E. Waibel, and R.V. Morey. 1984. Bioavailability of phosphorus in poultry litter biomass ash residue for turkeys. Poult. Sci. 63: 2100-2102.

114) Muir, F., R.M. Leach Jr., and B.S. Heinrichs. 1990. Bioavailability of phosphorus from broiler litter ash for chicks. Poult. Sci. 69: 1845-1850.

115) Blake, J.P., and J.B. Hess. 2014. Poultry litter ash as a replacement for dicalcium phosphate in broiler diets. J. Appl. Poult. Res. 23: 101-107. 
Manuscript submitted to Journal of Applied Poultry Research: Effects of Novel Phytase Enzymes on Activity Post-Pelleting, 3-21D Broiler Performance, and Bone Mineralization

\author{
A.M. Evans ${ }^{*}$ and J.S. Moritz ${ }^{* 1}$ \\ *Division of Animal and Nutritional Sciences, West Virginia University, Morgantown, \\ West Virginia, 26506-6108 \\ Phone: 304-293-1911
}

Fax: 304-293-2232

Metabolism and Nutrition

${ }^{1}$ Corresponding Author: Joe.Moritz@mail.wvu.edu

Primary Audience: Feed Manufacturers, Nutritionists, Researchers 
SUMMARY The majority of commercial broilers are fed pelleted diets containing exogenous phytase. This enzyme is used to decrease diet costs, increase performance, and reduce environmental impact. Technology exists to prevent denaturation of phytase during pelleting, however, the potential remains for the enzyme to lose efficacy in liberating phytate bound phosphorus. The objectives of the current study were to determine enzyme efficacy of four phytase variants $(\mathrm{A}-\mathrm{D})$ in vitro (Experiment 1$)$ as well as determine in vivo efficacy (Experiment 2). Positive control (PC) and negative control (NC) diets were formulated to 0.45 and $0.24 \%$ non-phytate phosphorus (nPP), respectively. Descriptive feed manufacture data from Experiment 1 demonstrated similarities among all treatments. As conditioning temperature increased, pellet durability increased for each phytase variant. Activity decreased in pellet samples and demonstrated the variability that can occur when testing enzyme thermostability. The $\mathrm{NC}+$ A treatment demonstrated one of the lowest activity levels of $290 \mathrm{FTU} / \mathrm{kg}$. In contrast, the NC + C treatment resulted in the highest activity of 1,100 FTU/kg. Feed conditioned at $90^{\circ} \mathrm{C}$ was fed to broilers in Experiment 2. Significant differences were observed for ending birds weight (EBW; P < 0.0001), feed intake (FI; P = 0.0002), live weight gain (LWG; P < 0.0001), feed conversion ratio corrected for mortality weight (FCR; $\mathrm{P}=0.0005)$, tibia ash (TA) \% $(\mathrm{P}<0.0001)$, TA mg/chick $(\mathrm{P}<0.0001)$, and TA $\mathrm{mg} / \mathrm{g}$ of gain $(\mathrm{P}<0.0001)$. The NC $+\mathrm{A}$ treatment was similar to the PC for EBW and all enzyme treatments were similar to the PC for FCR. All enzyme treatments were statistically similar to the NC for TA\% and TA mg/g of gain. For TA mg/chick, NC + A and NC + D were able to overcome some of the NC deficiency resulting in an increase in 
TA mg/chick. A linear and quadratic regression was performed to determine nPP sparing effects of the phytases. The NC + A resulted in the highest nPP sparing effects of 0.08 , 0.03, and $0.02 \%$ for FCR, EBW, and TA mg/chick, respectively. These data demonstrate the need for both in vitro and in vivo testing of enzymes due to the fact that high activity in vitro may not correlate to high in vivo efficacy.

KEYWORDS: phytase, broiler performance, enzyme efficacy, phosphorus sparing, enzyme activity

\section{DESCRIPTION OF PROBLEM}

Most commercially raised broilers consume a corn-soybean based diet. The majority of the phosphorus in these grains is in the form of phytate bound phosphorus that is unavailable to the bird. Phytase enzymes can be incorporated into diets in order to hydrolyze phytate bound phosphorus into bioavailable phosphorus that can be utilized by the bird. Commercially reared broilers are exclusively fed pelleted diets and the benefits of pelleting have been reported by multiple studies and include: increased intake [1], productive energy [2], and feed flow [1], as well as decreased feed wastage and ingredient segregation [2]. Pelleting requires feed to be exposed to conditions of high temperature, pressure, and moisture. These factors increase pellet quality by starch gelatinization $[3,4,5]$ and protein denaturation and gelation [6, 7]. Liquid phytases can be added post-pellet; however, this type of application has been associated with decreased pellet quality due to the blend lines associated with application [8]. Furthermore, if post-pellet liquid application provides phytase in only the outer layers of 
the pellet, then attrition associated with feed conveyance may reduce uniformity of phytase delivered throughout a poultry barn. Mixer-added phytases alleviate the issues associated with liquid phytases; however, thermostability becomes a concern, because phytases are proteins and proteins can denature during pelleting. Therefore, phytase enzymes added at the mixer must be able to withstand conditions associated with the pelleting process.

Multiple studies have shown that phytase enzymes lose activity at temperatures as low as $60^{\circ} \mathrm{C}[9,10]$ as determined using mild pelleting conditions and in vitro analysis. However, there are no standard conditions in feed manufacture. Variations in equipment, ingredients, ambient temperature, and manufacturing goals among commercial feed mills require more versatility from a mixer-added phytase. Therefore, biotechnology companies have attempted to produce phytases that are naturally heat stable and/or genetically modified to improve thermal stability [11]. It is important to determine phytase retained activity under the conditions of pelleting because, if the enzyme cannot survive the pelleting process, then nutritional and environmental benefits cannot be realized.

The objectives of the current study were to determine post-pelleted enzyme activity of four phytase variants in vitro (Experiment 1) as well as determine in vivo efficacy of the same four enzyme variants (Experiment 2). 


\section{MATERIALS AND METHODS}

\section{Experiment 1: in vitro enzyme activity}

All feed was manufactured at West Virginia University's pilot feed mill. Diets without phytase containing incrementally increasing amounts of inorganic phosphorus were used to provide standards for comparison. These standard diets consisted of a NC formulated to $0.25 \% \mathrm{nPP}$, a PC formulated to $0.45 \% \mathrm{nPP}$, a $3: 1$ ratio of PC: NC, and a 1:3 ratio of PC:NC (Table 1). The standard diets were included so that phosphorus sparing of the phytase variants could be determined. Dietary nPP levels were calculated using ingredient estimates of phosphorus availability. Diet formulations for PC and NC were kept as similar as possible with respect to ingredient inclusion (Table 1). In addition, values for ME, TSAA, lysine, and calcium were held constant. Soybean oil was included at 3\% and added at the mixer [12].

Four $794 \mathrm{~kg}$ allotments of the NC diet were mixed for ten minutes dry, and an additional ten minutes post soybean oil addition using a single screw vertical mixer [13]. In addition, $453.7 \mathrm{~kg}$ allotment of feed was batched in accordance to the PC and mixed in a similar manner as the NC. Each NC batch of $794 \mathrm{~kg}$ was then split into four allotments. Allotments from each batch were combined to create nutritionally uniform diets to be pelleted. Prior to pelleting, $4.5 \mathrm{~kg}$ of mash were premixed with the appropriate exogenous enzyme variant at a concentration such that would provide $500 \mathrm{FTU} / \mathrm{kg}$ (a common commercial phytase inclusion $[14,15])$ and mixed for 10 minutes using a small paddle mixer [16]. The $4.5 \mathrm{~kg}$ allotment was then placed back into the designated batch and mixed an additional twenty minutes prior to pelleting. All treatments were passed 
through a $1.3 \mathrm{~m}$ long conditioner with a diameter of $0.31 \mathrm{~m}$ and $10 \mathrm{sec}$ retention time [17]. Enzyme treatments were steam conditioned in a sequential manner, ie. 85, 88, $90^{\circ} \mathrm{C}$, while PC, NC, 3:1 PC:NC, and 1:3 PC:NC were steam conditioned at $90^{\circ} \mathrm{C}$. Pellets were formed using a 40-horsepower California Pellet Mill [18] equipped with a 38mm x 4.8mm pellet die. The pellets were cooled with ambient air utilizing a horizontal belt cooler [19]. Once conditioning temperature reached a steady state during pelleting, mash samples were taken from the feed screw auger that conveyed feed into the conditioner and corresponding pellet samples were taken from the cooler discharge. These samples were then analyzed for crude protein, calcium, total P, phytic acid, and phytase activity at a commercial laboratory [20]. In vitro activity and retention were determined using the Association of Official Agricultural Chemists (AOAC) 2000.12 method [21]. The nPP values were calculated for all diets using the following equation: total P of feed - (0.282 X phytic acid of feed) [22]. A pelleted sample was collected directly from the pellet die and placed into an insulated container to determine hot pellet temperature; temperature measurements were obtained using a thermocouple thermometer [23] and an 80PK-24 temperature probe. Pellet durability index (PDI) and modified pellet durability index (MPDI) were performed using a Pfost tumbling box on all treatments one day after pelleting [24]. In addition, pellet durability was also determined using a New Holmen Pellet Tester [25]. All batches of feed conditioned at $90^{\circ} \mathrm{C}$ were ground via a roller-mill prior to feeding; particle size [26] after grinding was performed to ensure feed form differences were eliminated [27, 28]. 


\section{Experiment 2: in vivo enzyme efficacy}

A total of 448 1-d old straight-run Hubbard X Cobb 500 [29] broiler chicks were obtained from a commercial hatchery [30]. For the first three days of life chicks were fed the NC diet as a pretest in a floor pen setting. On $\mathrm{d}$ 3, all chicks were individually weighed and allotted into 7 weigh groups. One bird from each group was placed in each of 64 raised wire battery cages to create the experimental unit. Each of the dietary treatments were randomly assigned to pens blocked by location, creating a randomized complete block design. Feed and water were provided for ad libitum consumption. Measured variables for the d3 - 21 experimental period included: starting pen weight, EBW, FI, LWG, and FCR, and mortality percentage. On d 21, birds were weighed by pen and killed via cervical dislocation and the left tibiae were extracted in order to determine bone mineralization. All animals were reared according to protocols established by the West Virginia University Animal Care and Use Committee [ACUC 12-0408].

\section{Statistical analysis}

Data was analyzed using one-way analysis of variance (ANOVA) using SAS software [31]. Significant differences were determined based on $\alpha \leq 0.05$. Means were separated using Fisher’s least significant difference test and letter superscripts were used to denote differences among treatment means. Variables measured included: EBW, LWG, FI, FCR, mortality percentage, TA\%, TA mg/chick, and TA mg/g of gain. Linear and quadratic regressions were performed on standard diets, to determine the $\mathrm{P}$ sparing of the phytase variants, if the ANOVA indicated significant differences. 


\section{RESULTS AND DISCUSSION}

\section{Experiment 1: in vitro enzyme activity}

In vitro enzyme efficacy data are shown in Tables 2 and 3. The descriptive feed manufacture results are presented in Table 2 and demonstrate that production rate, hot pellet temperature, New Holmen Pellet Tester, PDI, MPDI, and particle size were similar among all treatments. For enzyme treatments, as conditioning temperature increased, pellet durability also increased numerically. Particle size did not differ more than 120 $\mu \mathrm{m}$ between treatments, demonstrating that feed form would not be a confounding factor in Experiment 2. Analyzed phytase activity results are presented in Table 3. Mash and pellet samples were analyzed for each conditioning temperature and the target activity was $500 \mathrm{FTU} / \mathrm{kg}[14,15]$. The authors were successful in reaching the target activity goal in mash samples, while activity in pelleted samples decreased. Variations occurred between enzyme variants for both analyzed activity and retention. The NC + C demonstrated the highest activity above 1,000 FTU/kg in mash and pelleted samples and the highest overall retention percentage ranging between $55.6 \%$ for samples conditioned at $88^{\circ} \mathrm{C}$ to $100 \%$ for samples conditioned at $85^{\circ} \mathrm{C}$. Phytase activity and retention was lowest for NC $+\mathrm{D}$ with the lowest recorded activity of $120 \mathrm{FTU} / \mathrm{kg}$ and retention of only $17.4 \%$ for pelleted sample conditioned at $90^{\circ} \mathrm{C}$. These data demonstrate great variation in the thermostability of these phytase variants.

Determining in vivo enzyme activity in this study is important because high enzyme retention post pelleting determined in vitro may not translate to high efficacy in vivo [32]. Most past research has viewed in vitro post pellet activity and in vivo pelleted 
phytase efficacy as separate experiments; demonstrating high activity in vitro post pelleting without correlating in vivo testing of efficacy [33] or in vivo testing of efficacy using mash without corresponding in vitro post pelleting activity [34].

\section{Experiment 2: in vivo enzyme efficacy}

The data generated from in vivo testing is reported in Table 4. Significant differences were detected for d21 EBW ( $\mathrm{P}<0.0001)$, feed intake $(\mathrm{P}=0.0002)$, FCR ( $\mathrm{P}=$ 0.0005), LWG ( $\mathrm{P}<0.0001)$, TA\% $(\mathrm{P}<0.0001)$, and TA mg/chick $(\mathrm{P}<0.0001)$, and TA $\mathrm{mg} / \mathrm{g}$ of gain $(\mathrm{P}<0.0001)$. Birds fed the $\mathrm{NC}+\mathrm{A}$ resulted in a similar EBW compared to the PC, while $\mathrm{NC}+\mathrm{C}$ and $\mathrm{NC}+\mathrm{D}$ resulted in lower EBW similar to the $\mathrm{NC}$ and $\mathrm{NC}+\mathrm{B}$ was intermediate. Birds fed the $\mathrm{NC}+\mathrm{B}$ treatment consumed the least amount of feed and had similar intake to the NC $+\mathrm{C}$ and $\mathrm{NC}+\mathrm{D}$ treatments. Birds fed the NC obtained in the highest FCR, while all other treatments were similar to the PC. The PC treatment resulted in the highest $\mathrm{LWG}$, the $\mathrm{NC}+\mathrm{B}, \mathrm{NC}+\mathrm{C}$, and $\mathrm{NC}+\mathrm{D}$ treatments demonstrated lowered LWG similar to the NC, and the NC + A treatment was intermediate. The PC treatment demonstrated the highest TA\%, TA mg/chick, and TA mg/g of gain, while the NC resulted in the lowest values. For TA\% and TA mg/g of gain, all enzyme treatments were statistically similar to the $\mathrm{NC}$. The $\mathrm{NC}+\mathrm{B}$ and $\mathrm{NC}+\mathrm{C}$ were statistically similar to the NC for TA mg/chick, while NC + A and NC + D were intermediate.

A linear and quadratic regression of the standard curve was performed to obtain $\mathrm{nPP}$ sparing for the enzyme treatments; a linear regression was found to be the best fit model for TA\% and TA mg/g of gain (Table 5), while a quadratic regression was found 
to be the best fit model for FCR, LWG, EBW, and TA mg/chick (Table 6). The NC + A and $\mathrm{NC}+\mathrm{C}$ demonstrated the highest nPP sparing of $0.01 \%$ for TA\%, while NC + D demonstrated the highest sparing of $0.03 \%$ for TA mg/g of gain. The NC + A resulted in the highest nPP sparing effects of 0.08, 0.03, and 0.02\% for FCR, EBW, and TA mg/chick, respectively. The NC + B resulted in the highest nPP sparing effect of $0.14 \%$ for LWG. These data suggest that phosphorus requirements differ for each performance variable and each phytase variant spares this mineral differently for each variable. It should be noted that NC + A and NC + D contained the lowest activity levels at 290 and $120 \mathrm{FTU} / \mathrm{kg}$ and 45.3 and $17.4 \%$ retention, respectively. However, these enzymes demonstrated higher efficacy in vivo compared to the $\mathrm{NC}+\mathrm{B}$ and $\mathrm{NC}+\mathrm{C}$, and $\mathrm{NC}+\mathrm{A}$ resulted in the greatest nPP sparing effects for several performance variables. These results are similar to those observed by Loop and coauthors, who noted that phytase enzymes demonstrating a tested phytase with low activity in vitro translated to high efficacy in vivo [32]. Further product modifications are necessary to maximize these enzyme variants thermal stability prior to field testing.

\section{CONCLUSIONS AND APPLICATIONS}

1) In vitro activity revealed variation among phytase variants. Enzyme activity and retention differed dramatically between each of the four enzymes tested. NC $+\mathrm{A}$ and NC $+\mathrm{D}$ demonstrated the lowest activity and retention.

2) In vivo efficacy determined that $\mathrm{NC}+\mathrm{A}$ and $\mathrm{NC}+\mathrm{D}$ were able to overcome some of the NC deficiency in regards to performance. NC + A resulted in the greatest nPP sparing effects for most variables measured. 
3) Both in vitro post pellet activity and in vivo testing of phytases must be considered to properly determine the enzyme that best performs under the conditions associated with pelleting and can be targeted for commercialization.

\section{REFERENCES AND NOTES}

1) N.P. Buchanan, K.G.S. Lilly, C.K. Gehring, and J.S. Moritz. The effects of altering diet formulation and manufacturing technique on pellet quality. J. Appl. Poult. Res. 2010 19:112-120.

2) Behnke, K. C. 1996. Feed manufacturing technology: Current issues and challenges. Anim. Feed Sci. Technol. 62: 49 - 57.

3) Karim, A. A, M. H. Norziah, and C. C. Seow. 2000. Methods for the study of starch retrogradation. Food Chem. 71: 9 -36.

4) Zaritzky, N. E. 2000. Physical and microstructural properties of frozen gelatinized starch suspensions. Pages $15-28$ on Trends in Food Engineering. Lozano, J. E., C. Anon, E. Parada-Arias, and G. V. Barbosa-Canovas, eds. CRC press, Boca Raton, FL.

5) Lund, D. 1984. Influence of time, temperature, moisture, ingredients, and processing conditions on starch gelatinization. Crit. Rev. Food Sci. Nutr. 20: 249 - 273.

6) Briggs, J. L., D. E. Maier, B. A. Watkins, and K. C. Behnke. 1999. Effect of ingredients and processing parameters on pellet quality. Poult. Sci. 78: $1464-1471$.

7) Renkema, J. M. S., C. M. M. Lakemond, H. H. J. de Jongh, H. Gruppen, and T. van Vliet. 2000. The effect of $\mathrm{pH}$ on heat denaturation and gel performing properties of soy proteins. J. Biotech. 79: $223-230$.

8) Payne, R. L., T. K. Lavergne, and L. L. Southern. 2005. A comparison of two sources of phytase in liquid and dry forms in broilers. Poult. Sci. 84: 265 - 272.

9) Greiner R, U. Kontietzny, K.D. Jany. 1993. Purification and characterization of two phytases from Escherichia coli. Arch. Biochem. Biophys. 303: 107-113.

10) Golovan, S.P., G. Wang, J. Zhang, and C.W. Forsberg. 2000. Characterisation and overproduction of the Escherichia coli appA encoded bifunctional enzyme that exhibits both phytase and acid phosphatase activities. Can. J. Microbiol. 46: 59 - 71.

11) Lei, X., C. H. Stahl. 2001. Biotechnology development of effective phytases for mineral nutrition and environmental protection. Appl. Micro. Biotech. 57: 474 - 481.

12) Gehring, C. K., K. G. S. Lilly, L. K. Shires, K. R. Beaman, S. A. Loop, and J. S. Moritz. 2010. Increasing mixer-added fat reduces the electrical energy required for pelleting and improves exogenous enzyme efficacy for broilers. J. Appl. Poult. Res. (Accepted).

13) Vertical mixer, Avery Weigh-Tronix, Fairmont, MN.

14) Farzinpour, A., A. Karimi, and A. S. Ahmadi. 2011. Effects of dietary phytase and different levels of non-phytate phosphorus on serum minerals and biochemical parameters in broiler chickens. J. Anim. Vet. Adv. 10: 1317 - 1321.

15) Jones, C. K., M. D. Tokach, B. W. Ratliff, N. L. Horn, S. S. Dritz, R. D. Goodband, J. M. DeRouchey, and J. L. Nelssen. Efficacy of different commercial phytase sources 
and development of a phosphorus release curve. Nursery Pig Nutrit. And Manag. 106 $-121$.

16) Hobart paddle mixer (model 4146) Hobart Corp., Troy, OH.

17) A 4.25 feet length, 1.02 feet diameter short term California Pellet Mill conditioner (3 steam inlet ports), 429 rpm shaft speed; 21 picks; 10 -s feed retention time.

18) Master Model Pellet Mill, California Pellet Mills Company, Crawfordsville, IN.

19) A 10 feet length horizontal belt cooler.

20) Eurofins Scientific, Des Moines, IA.

21) AOAC. 2000. Method 2000.12. Phytase activity in feed: colorimetric enzymatic method. In official methods of analysis of AOAC international. $17^{\text {th }}$ ed. Assoc. Off. Anal. Chem., Arlington VA.

22) Jiang, S., Z. Jiang, G. Zhou, and Z. Chen. 2011. Non-phytate phosphorus requirements and efficacy of a genetically engineered yeast phytase in yellow broilers from 1 to 21 days of age. J. Anim. Phys. Anim. Nutr. 95: 47 - 55.

23) Fluke 51 II, Everette, WA.

24) American Society for Agricultural Engineers, 1983. Methods for determining and expressing fineness of feed materials by sieving. Page 325 in American Society of Agricultural Engineers Standard S 319. Am. Soc. Agric. Eng. Yearbook Standards, Am. Soc. Am. Eng., St. Joseph, MI. Pellet durability index was determined by sifting $500 \mathrm{~g}$ of pellets from a treatment through a No. 6 American Society for Testing and Materials (ASTM) screen before being deposited into a Pfost tumbler. The sifted pellets were then tumbled in the container, dimensions $5 \times 12 \times 12 \mathrm{in}$., with a $2 \times 9$ in. plate fixed diagonally along the $12 \times 12 \mathrm{in}$. side, for approximately $10 \mathrm{~min}$ at 50 rpm. The sample was then sifted again through the No. 6 (ASTM) mm screen, weighed, and the percentage of pellets was calculated by dividing the weight of pellets after tumbling by the weight of pellets before tumbling and then multiplying that value by 100 . Modified pellet durability index was similarly measured, with the exception of the addition of five, 13-mm hexagonal bolts to the $500 \mathrm{~g}$ of sample in the tumbler. Both analyses are meant to simulate the deleterious effects of transferring and handling the pellets.

25) Pellet quality was assessed one day following production using the New Holmen NHP Portable Pellet Durability Tester, Lignotech USA, INC., Rothschild, WI. 100 g of pellets were places in the chamber, blown about for 60 seconds by a jet of air, then weighed, giving a direct read of pellet durability. Fines are removed during the blowing process.

26) Ro-Tap particle size analyzer model RX-29 type 110V 60H2, WS Tyler, Mentor, OH. One hundred grams of each ground treatment was placed in a dust-tight enclosed series of stacked ( N0. 4, 6, etc.) American Society for Testing and Materials (ASTM) screens affixed to the Ro-Tap particle size analyzer and shaken for 10 minutes. The screens were then separated and weighed. Particle size was calculated by subtracting the weight of the screen from the final weight of screen and sample after shaking. The mean geometric particle size and log normal geometric SD were calculated as described by McEllhiney (McEllhiney, R. R. 1994. Determining and expressing 
particle size. Pages 545-547 in Feed Manufacture Technology IV. Am. Feed Ind. Assoc. Inc., Arlington, VA.)

27) Cutlip, S. E., Hott, J. M., Buchanan, N. P., Rack, A. L., Latshaw, J. D., and Moritz, J. S. 2008. The effect of steam-conditioning practices on pellet quality and growing broiler nutritional value. J. Appl. Poult. Res. 17:249-261.

28) W. A. Dozier, III, K. C. Behnke, C. K. Gehring and S. L. Branton. 2010. Effects of feed form on growth performance and processing yields of broiler chickens during a 42-day production period. J. Appl. Poult. Res. 19:219-226.

29) Cobb-Vantress, Siloam Springs, AR. 2008.

30) Pilgrim's Pride Hatchery, Moorefield, WV.

31) SAS Institute. 2000. The SAS System for Windows 2000. Release 8.1. SAS Inst. Inc., Cary, NC.

32) Loop, S. A., K. G. S. Lilly, L. K. Shires, C. K. Gehring, K. R. Beaman, M. E. Persia, and J. S. Moritz. 2012. The phytase analytical activity of pelleted diets may not adequately describe efficacy in the bird. J. Appl. Poult. Res. 21: 492 - 501.

33) Pasamontes, L., M. Haiker, M. Wyss, M. Tessier, and A. P. G. M. vanLoon. 1997. Gene cloning, purification, and characterization of a heat-stable phytase from the fungus Aspergillus fumigatus. Appl. Enivon. Microbio. 63: 1696 - 1700.

34) Timmons, J. R., R. Angel, J. M. Harter-Dennis, W. W. Saylor, and N. E. Ward. 2008. Evaluation of heat-stable phytases in pelleted diets fed to broilers from day zero to thirty five during the summer months. J. Appl. Poult. Res. 17: 482 - 489. 
Table 1. Diet formulations for positive and negative control diets differing in available phosphorus

\begin{tabular}{|c|c|c|}
\hline Ingredients & Positive control & Negative control \\
\hline & \multicolumn{2}{|c|}{ \% Inclusion } \\
\hline Corn & 53.19 & 53.12 \\
\hline Soybean meal (48\%) & 35.29 & 35.38 \\
\hline Corn DDGS & 5.00 & 5.00 \\
\hline Soybean oil & 3.00 & 3.00 \\
\hline Defluorinated phosphate & 1.74 & 0.63 \\
\hline Limestone & 0.68 & 1.64 \\
\hline DL-methionine & 0.29 & 0.29 \\
\hline Vitamin mineral premix $^{1}$ & 0.25 & 0.25 \\
\hline Lysine & 0.13 & 0.13 \\
\hline Salt & 0.2 & 0.33 \\
\hline Threonine & 0.11 & 0.11 \\
\hline Coban $60^{2}$ & 0.08 & 0.08 \\
\hline $\mathrm{BMD}^{3}$ & 0.05 & 0.05 \\
\hline \multicolumn{3}{|c|}{ Calculated Nutrients } \\
\hline ME (kcal/kg) & 3030.5 & 3030.5 \\
\hline Crude protein (\%) & 23.48 & 23.51 \\
\hline Lysine (\%) & 1.18 & 1.18 \\
\hline Methionine + cysteine (\%) & 0.89 & 0.89 \\
\hline Threonine (\%) & 0.75 & 0.75 \\
\hline Calcium (\%) & 0.91 & 0.91 \\
\hline Non-phytate phosphorus (\%) & 0.45 & 0.25 \\
\hline Sodium (\%) & 0.20 & 0.20 \\
\hline \multicolumn{3}{|c|}{ Analyzed Nutrients } \\
\hline Crude Protein (\%) & 21.80 & 21.80 \\
\hline Calcium (\%) & 0.86 & 0.87 \\
\hline Non-phytate phosphorus (\%) & 0.42 & 0.25 \\
\hline
\end{tabular}

${ }^{1}$ Supplied per kg of diet: manganese, $0.02 \%$; zinc $0.02 \%$; iron, $0.01 \%$; copper, $0.0025 \%$; iodine, $0.0003 \%$; selenium, $0.00003 \%$; folic acid, 0.69mg; choline, 386mg' riboflavin, 6.61mg; biotin, 0.03mg; vitamin B6, 1.38mg; niacin, 27.56mg; pantothenic acid, 6.61mg; thiamine, 2.20mg; manadione, 0.83mg; vitamin B12, 0.01mg; vitamin E, 16.53 IU; vitamin D3, 2133 ICU; vitamin A, 7716 IU. ${ }^{2}$ Active drug ingredient Monensin Sodium $60 \mathrm{gpb}$ (90 g/ton inclusion), Elanco Animal Health, Indianapolis, IN. As an aid in the prevention of coccidiosis caused by Eimerianecarix, Eimeriatenella, Eimeriaacervulina, Eimeria brunette, Eimeriamivati, and Eimeria maxima.

${ }^{3}$ Bacitracin Methylene Disalicylate $50 \mathrm{~g} / \mathrm{lb}$ (50 g/ton inclusion), Alpharma, Fort Lee, NJ. For increased rate of weight gain and improved feed efficiency. 
Table 2. Descriptive feed manufacture data for standard diets containing increasing levels of phosphorus and four phytase variants (Experiment 1)

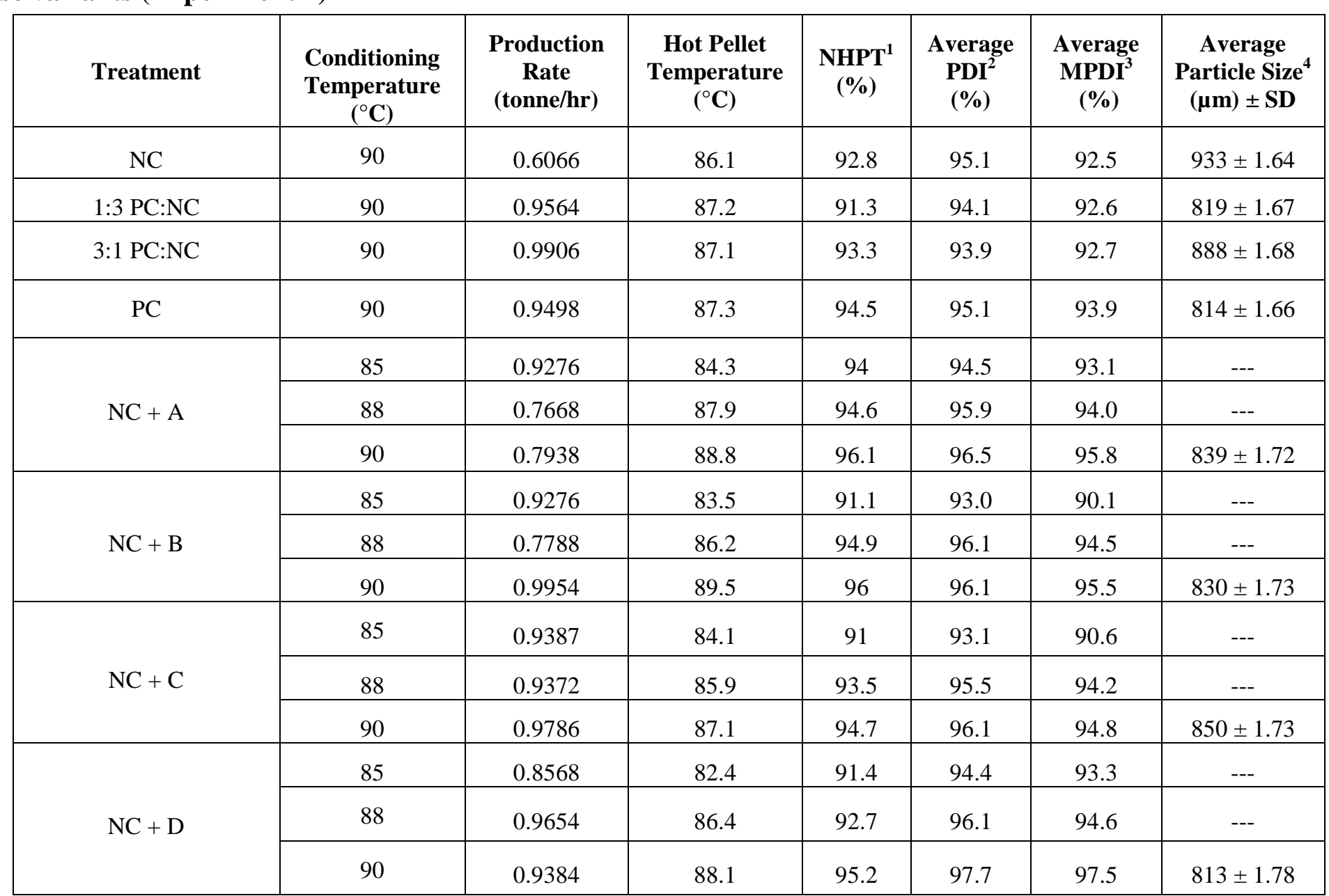

${ }^{1}$ New Holman Pellet Tester

${ }^{2}$ Pellet Durability Index (Pfost tumbler)

${ }^{3}$ Modified Pellet Durability Index (Pfost tumbler)

${ }^{4}$ Pellets were ground using a roller mill 
Table 3. Analyzed phytase activity of four phytase variants in mash and pelleted feed (Experiment 1)

\begin{tabular}{|c|c|c|c|c|}
\hline Treatment & $\begin{array}{c}\text { Conditioning } \\
\text { Temperature } \\
\left({ }^{\circ} \mathrm{C}\right)\end{array}$ & $\begin{array}{c}\text { Sample } \\
\text { Form }\end{array}$ & $\begin{array}{l}\text { Analyzed } \\
\text { Phytase }^{1} \\
\text { (FTU/kg) }\end{array}$ & $\begin{array}{c}\text { Retention } \\
\text { Percentage } \\
(\%) \\
\end{array}$ \\
\hline \multirow{6}{*}{$\mathrm{NC}+\mathrm{A}$} & \multirow[t]{2}{*}{85} & Mash & 450 & \multirow{2}{*}{104.4} \\
\hline & & Pellet & 470 & \\
\hline & \multirow[t]{2}{*}{88} & Mash & 650 & \multirow[b]{2}{*}{41.5} \\
\hline & & Pellet & 270 & \\
\hline & \multirow[t]{2}{*}{90} & Mash & 640 & \multirow{2}{*}{45.3} \\
\hline & & Pellet & 290 & \\
\hline \multirow{6}{*}{$\mathrm{NC}+\mathrm{B}$} & \multirow[t]{2}{*}{85} & Mash & 650 & \multirow[b]{2}{*}{56.9} \\
\hline & & Pellet & 370 & \\
\hline & \multirow[t]{2}{*}{88} & Mash & 470 & \multirow[b]{2}{*}{70.2} \\
\hline & & Pellet & 330 & \\
\hline & \multirow[t]{2}{*}{90} & Mash & 490 & \multirow[b]{2}{*}{59.2} \\
\hline & & Pellet & 290 & \\
\hline \multirow{6}{*}{$\mathrm{NC}+\mathrm{C}$} & \multirow[t]{2}{*}{85} & Mash & 1,300 & \multirow[b]{2}{*}{100.0} \\
\hline & & Pellet & 1,300 & \\
\hline & \multirow[t]{2}{*}{88} & Mash & 1,800 & \multirow{2}{*}{55.6} \\
\hline & & Pellet & 1,000 & \\
\hline & \multirow[t]{2}{*}{90} & Mash & 1,400 & \multirow[b]{2}{*}{78.6} \\
\hline & & Pellet & 1,100 & \\
\hline \multirow{6}{*}{$\mathrm{NC}+\mathrm{D}$} & \multirow[t]{2}{*}{85} & Mash & 760 & \multirow[b]{2}{*}{67.1} \\
\hline & & Pellet & 510 & \\
\hline & \multirow[t]{2}{*}{88} & Mash & 690 & \multirow[b]{2}{*}{30.4} \\
\hline & & Pellet & 210 & \\
\hline & \multirow[t]{2}{*}{90} & Mash & 690 & \multirow{2}{*}{17.4} \\
\hline & & Pellet & 120 & \\
\hline
\end{tabular}


Table 4. The effect of four phytase variants utilized in $90^{\circ} \mathrm{C}$ conditioned pelleted feed on live bird performance (Experiment 2)

\begin{tabular}{|c|c|c|c|c|c|c|c|c|c|}
\hline Treatment & $\begin{array}{c}\text { Day 3 } \\
\text { Starting } \\
\text { Pen } \\
\text { Weight }^{1} \\
\text { (kg) }\end{array}$ & $\begin{array}{c}\text { Day 2l } \\
\text { Ending } \\
\text { Bird } \\
\text { Weight } \\
\text { (kg) }\end{array}$ & $\begin{array}{c}\text { Pen Feed } \\
\text { Intake } \\
(\mathrm{kg})\end{array}$ & $\begin{array}{c}\mathrm{FCR}^{2} \\
(\mathrm{~kg} / \mathrm{kg})\end{array}$ & $\begin{array}{c}\mathrm{LWG}^{3} \\
(\mathrm{~kg})\end{array}$ & $\begin{array}{l}\text { Percent } \\
\text { Mortality } \\
(\%)\end{array}$ & $\begin{array}{l}\text { Tibia Ash } \\
\text { Percent }^{5} \\
(\%)\end{array}$ & $\begin{array}{l}\text { Tibia Ash } \\
\text { (mg/chick) }\end{array}$ & $\begin{array}{c}\text { Tibia Ash }{ }^{5,6} \\
\text { (mg/g of gain) }\end{array}$ \\
\hline $\mathrm{NC}$ & 0.326 & $0.476^{\circ}$ & $4.48^{\mathrm{abc}}$ & $1.59^{\mathrm{a}}$ & $0.435^{\circ}$ & 8.75 & $24.89^{\circ}$ & $451.58^{\circ}$ & $10.38^{\circ}$ \\
\hline $1: 3 \mathrm{PC}: \mathrm{NC}$ & 0.287 & $0.568^{\mathrm{bc}}$ & $4.93^{\circ}$ & $1.38^{b}$ & $0.532^{\mathrm{bc}}$ & 3.50 & $25.11^{\mathrm{bc}}$ & $566.35^{\circ}$ & $10.64^{\mathrm{bc}}$ \\
\hline $3: 1 \mathrm{PC}: \mathrm{NC}$ & 0.289 & $0.594^{\mathrm{ab}}$ & $4.85^{\mathrm{ab}}$ & $1.31^{\mathrm{b}}$ & $0.557^{\mathrm{ab}}$ & 5.25 & $26.86^{\mathrm{b}}$ & $615.62^{b}$ & $11.07^{\mathrm{b}}$ \\
\hline $\mathrm{PC}$ & 0.328 & $0.617^{\mathrm{a}}$ & $4.82^{\mathrm{ab}}$ & $1.28^{b}$ & $0.577^{\mathrm{a}}$ & 7.25 & $28.79^{\mathrm{a}}$ & $670.08^{\mathrm{a}}$ & $11.64^{\mathrm{a}}$ \\
\hline $\mathrm{NC}+\mathrm{A}$ & 0.287 & $0.539^{\mathrm{a}}$ & $4.26^{\mathrm{bc}}$ & $1.28^{b}$ & $0.502^{d \varepsilon}$ & 5.38 & $24.49^{\circ}$ & $520.65^{\circ}$ & $10.36^{\mathrm{c}}$ \\
\hline $\mathrm{NC}+\mathrm{B}$ & 0.325 & $0.468^{\mathrm{cd}}$ & $3.54^{\mathrm{d}}$ & $1.30^{\mathrm{b}}$ & $0.427^{\circ}$ & 8.88 & $23.27^{\circ}$ & $435.36^{\circ}$ & $10.27^{\mathrm{c}}$ \\
\hline $\mathrm{NC}+\mathrm{C}$ & 0.326 & $0.479^{\circ}$ & $4.04^{d \varepsilon}$ & $1.39^{\mathrm{b}}$ & $0.438^{\circ}$ & 5.38 & $24.60^{\circ}$ & $450.14^{\circ}$ & $10.27^{\circ}$ \\
\hline $\mathrm{NC}+\mathrm{D}$ & 0.289 & $0.504^{d s}$ & $3.97^{\mathrm{ds}}$ & $1.31^{\mathrm{b}}$ & $0.468^{8 s}$ & 8.76 & $23.98^{\circ}$ & $494.92^{\circ}$ & $10.58^{\mathrm{bc}}$ \\
\hline ANOVA P-value & 0.7716 & $<0.0001$ & 0.0002 & 0.0005 & $<0.0001$ & 0.9282 & $<0.0001$ & $<0.0001$ & $<0.0001$ \\
\hline $\mathrm{SEM}^{?}$ & 0.0266 & 0.0134 & 0.2164 & 0.0485 & 0.0148 & 3.4735 & 0.6564 & 12.2313 & 0.1851 \\
\hline Fisher's LSD ${ }^{8}$ & $\ldots$ & 0.0383 & 0.6151 & 0.1379 & 0.0409 & $\ldots$ & 1.8655 & 34.761 & 0.5263 \\
\hline
\end{tabular}

${ }^{1}$ Starting pen weights were based on 7 birds per pen

${ }^{2}$ Feed Conversion Ratio (Feed: Gain) calculated using mortality weight

${ }^{4}$ Mortality percentage is based on 7 birds per pen, so if 2 birds died the mortality percentage would be $29 \%$ in that pen

${ }^{5}$ Tibiae were ether extracted to remove residual fat prior to being ashed

${ }^{6}$ Tibia ash $\mathrm{mg} / \mathrm{g}$ of gain = tibia ash (mg/chick) $/$ LWG (g)

8 Standard Error of the Mean

ae

a common superscript differ $(\mathrm{P}<0.05)$ 
Table 5. Sparing effects for enzyme variants A - D calculated from standard curve linear regression using tricalcium phosphorus (Experiment 2)

\begin{tabular}{|c|c|c|c|c|}
\hline Treatment & $\begin{array}{c}\text { Linear derived } \\
\text { Calc nPP (\%) } \\
\text { Tibia Ash } \\
\text { Percent }^{1}\end{array}$ & $\begin{array}{c}\text { Tibia Ash } \\
\text { Percent nPP } \\
\text { Sparing } \\
\text { Effect }\end{array}$ & $\begin{array}{c}\text { Linear derived } \\
\text { Calc nPP (\%) } \\
\text { Tibia Ash } \\
\text { (mg/g of gain) }\end{array}$ & $\begin{array}{c}\text { Tibia Ash (mg/g } \\
\text { of gain) nPP } \\
\text { Sparing Effect }\end{array}$ \\
\hline NC + A & 0.24 & $\mathbf{0 . 0 1}$ & 0.24 & $\mathbf{0 . 0 1}$ \\
\hline NC + B & 0.18 & $\mathbf{0 . 0 0}$ & 0.22 & $\mathbf{0 . 0 0}$ \\
\hline NC + C & 0.24 & $\mathbf{0 . 0 1}$ & 0.22 & $\mathbf{0 . 0 0}$ \\
\hline NC + D & 0.21 & $\mathbf{0 . 0 0}$ & 0.26 & $\mathbf{0 . 0 3}$ \\
\hline
\end{tabular}

${ }^{1}$ Calculated nPP values derived from the linear regression of Tibia Ash Percent for the standard curve (Tibia Ash Percent -8.53555$) / 7.99093=$ calc. $\mathrm{nPP}, \mathrm{R}^{2}=0.0 .5451$ ${ }^{2}$ Calculated nPP values derived from the linear regression of Tibia Ash mg/g of gain for the standard curve (Tibia Ash mg/g of gain -18.60229$) / 26.05517=\mathrm{calc}$. $\mathrm{nPP}$, $\mathrm{R}^{2}=0.0 .3642$ 
Table 6. Sparing effects for enzyme variants A - D calculated from standard curve quadratic regression using tricalcium phosphorus (Experiment 2)

\begin{tabular}{|c|c|c|c|c|c|c|c|c|}
\hline Treatment & $\begin{array}{c}\text { Quadratic } \\
\text { derived } \\
\text { Calc nPP } \\
\text { (\%) FCR }{ }^{1}\end{array}$ & $\begin{array}{c}\text { FCR } \\
\text { nPP } \\
\text { Sparing } \\
\text { Effect }\end{array}$ & $\begin{array}{c}\text { Quadratic } \\
\text { derived } \\
\text { Calc nPP } \\
\text { (\%) LWG }\end{array}$ & $\begin{array}{c}\text { LWG } \\
\text { nPP } \\
\text { Sparing } \\
\text { Effect }\end{array}$ & $\begin{array}{c}\text { Quadratic } \\
\text { derived Calc } \\
\text { nPP (\%) } \\
\text { Ending Bird } \\
\text { Weight }^{3} \\
\end{array}$ & $\begin{array}{c}\text { Ending } \\
\text { Bird } \\
\text { Weight nPP } \\
\text { Sparing } \\
\text { Effect } \\
\end{array}$ & $\begin{array}{c}\text { Quadratic } \\
\text { derived Calc nPP } \\
\text { (\%) Tibia Ash } \\
\text { mg/chick }\end{array}$ & $\begin{array}{c}\text { Tibia Ash } \\
\text { mg/chick } \\
\text { nPP Sparing } \\
\text { Effect }\end{array}$ \\
\hline $\mathrm{NC}+\mathrm{A}$ & 0.31 & 0.08 & 0.36 & 0.13 & 0.26 & 0.03 & 0.25 & 0.02 \\
\hline $\mathrm{NC}+\mathrm{B}$ & 0.30 & 0.07 & 0.37 & 0.14 & 0.22 & 0.00 & 0.23 & 0.00 \\
\hline $\mathrm{NC}+\mathrm{C}$ & 0.27 & 0.04 & 0.32 & 0.09 & 0.24 & 0.01 & 0.23 & 0.00 \\
\hline $\mathrm{NC}+\mathrm{D}$ & 0.30 & 0.07 & 0.34 & 0.11 & 0.24 & 0.01 & 0.24 & 0.01 \\
\hline
\end{tabular}

${ }^{1}$ Calculated nPP values derived from the quadratic regression of Feed Conversion Ratio percent for the standard curve

$\left[15.73 \pm \sqrt{15.73^{2}-4(22.381)(4.0209-F C R)}\right] / 2(22.381)=$ calc. $\mathrm{nPP}, \mathrm{R}^{2}=0.4423$

${ }^{2}$ Calculated nPP values derived from the quadratic regression of Live Weight Gain percent for the standard curve

$\left[6.687 \pm \sqrt{6.687^{2}-4(-9.4295)(0.599-L W G)}\right] / 2(-9.4295)=$ calc. $\mathrm{nPP}, \mathrm{R}^{2}=0.6815$

${ }^{3}$ Calculated nPP values derived from the quadratic regression of Ending Bird Weight percent for the standard curve

$\left[-6.188 \pm \sqrt{6.188^{2}-4(-8.616)(-0.4867-\text { Ending Bird Weight })}\right] / 2(-8.616)=$ calc. $\mathrm{nPP}, \mathrm{R}^{2}=0.7157$

${ }^{4}$ Calculated nPP values derived from the quadratic regression of Tibia Ash mg/chick percent for the standard curve

$\left[-7,310.297 \pm \sqrt{7,310.297^{2}-4(-9,644.036)\left(715.46-\text { Tibia Ash } \frac{m g}{\text { chick }}\right)}\right] / 2(-9,644.036)=$ calc. nPP, $\mathrm{R}^{2}=0.8617$ 
Manuscript submitted to Journal of Applied Poultry Research: Effects of Enzyme Supplementation on Nutrient Digestibility and Growth Performance of Chicks Fed Diets Containing Meat and Bone Meal

\author{
A.M. Evans ${ }^{*}$, B.G. Glover ${ }^{*}$, and J.S. Moritz ${ }^{* 1}$ \\ *Division of Animal and Nutritional Sciences, West Virginia University, Morgantown, \\ West Virginia, 26506 \\ Phone: 304-293-1911 \\ Fax: 304-293-2232
}

Metabolism and Nutrition

${ }^{1}$ Corresponding Author: Joe.Moritz@mail.wvu.edu

Primary Audience: Nutritionists, Researchers, Feed Mill Managers 
SUMMARY Feed ingredient price has have influenced nutritionists to use alternative ingredients to reduce cost and the use of exogenous enzymes may help to increase nutrient availability of these new formulations. The current study was accomplished by conducting two separate experiments. The objective of Experiment 1 was to determine the effect of Allzyme SSF and VegPro (separately and in combination) on the digestibility and growth performance of broilers fed complete diets containing $8 \%$ meat and bone meal (MBM). The objective of Experiment 2 was to determine the digestibility of the same diets as Experiment 1 as well as MBM with or without enzyme supplementation using a cecectomized rooster model. A positive control (PC) diet was formulated to meet Agristat levels for all nutrients, while a negative control (NC) diet was formulated to $85 \%$ crude protein and digestible amino acids of Agristat levels. The enzymes were supplemented into NC diets and were referred to as NC + SSF, NC + VegPro, and NC + SSF + VegPro. In Experiment 1, significant differences were observed for all performance variables ( $\mathrm{P}<0.0001)$, indicating that both enzymes (separately or in combination) were able to overcome part of the NC deficiency for ending bird weight (EBW), feed conversion ratio (FCR), and live weight gain (LWG). Apparent ileal amino acid digestibility (AIAAD) demonstrated that the NC + SSF + VegPro diet was able to overcome a portion of the NC deficiency, resulting in an increase in digestible amino acids $(\mathrm{P}<0.0001)$. In Experiment 2, NC + SSF demonstrated improved digestibility compared to NC for threonine, methionine, and lysine $(\mathrm{P}<$ 0.0001), while the NC + VegPro demonstrated increased digestibility compared to NC for isoleucine, leucine, and lysine $(\mathrm{P}<0.0001)$ for complete diet digestibility. The 
digestibility of MBM per se did not improve with enzyme supplementation $(\mathrm{P}<0.05)$. The current study demonstrates benefit to supplementing diets containing 8\% MBM with Allzyme SSF and VegPro; however, the target substrate was likely of vegetable origin.

KEYWORDS: broiler, cecectomized rooster, performance, amino acid digestibility, meat and bone meal, Allzyme SSF, Allzyme VegPro

\section{DESCRIPTION OF PROBLEM}

The majority of commercial broilers raised in the United States are fed cornsoybean meal based diets. These diets can be expensive due to the rising price of ingredients, particularly soybean meal. This ingredient is important because it is used to meet amino acid requirements of broilers. However, cell wall components of soybean meal are poorly digestible [1, 2, 3]. Broilers lack the endogenous enzymes required to digest cell wall components, especially non-starch polysaccharides (NSP) [4, 5].

Therefore, alternative protein sources, such as animal by-product meals, may be attractive for feed formulation. These sources have favorable amino acid profiles, lack NSPs, and may be cost effective.

Commercially available enzyme cocktails have demonstrated efficacy in corn and soybean meal based diets [6, 7]. Diet formulations containing high levels of MBM may also benefit from incorporation of these particular cocktails. However, research concerning enzyme cocktails designed for vegetable substrates on formulations containing high levels of MBM is lacking. Two such commercially available enzyme cocktails are Allzyme SSF and Allzyme VegPro. Allzyme SSF is produced by solid state 
fermentation and contains multiple enzymes, including: phytase, protease, cellulase, and NSP-ase [8]. Allzyme VegPro is an enzymatic complex comprised of dried Aspergillus niger and Trichoderma longibrachiatum fermentation extracts and contains the enzymes protease, amylase, and cellulase [9]. The current study was accomplished by conducting two separate experiments. The objective of Experiment 1 was to determine the effect of Allzyme SSF and VegPro (separately and in combination) on the digestibility and growth performance of broilers fed complete diets containing 8\% MBM. The objective of Experiment 2 was to determine the digestibility of the same diets as Experiment 1 as well as MBM with or without enzyme supplementation using a cecectomized rooster model.

\section{MATERIALS AND METHODS}

\section{Experiment 1}

\section{Diet preparation}

Dietary treatments consisted of a nutritionally adequate PC diet that was least-cost formulated and contained ingredients and nutrients that met Agristat levels [10]. An NC was formulated to $85 \%$ crude protein and digestible amino acids compared to the PC (Table 1). All feed was manufactured at West Virginia University’s pilot feed mill. A $453.7 \mathrm{~kg}$ allotment of feed was batched in accordance to the NC. An additional $113.4 \mathrm{~kg}$ allotment of feed was batched in accordance to the PC. All batches were mixed for ten minutes with dry ingredients, and an additional ten minutes post soybean oil addition using a single screw vertical mixer [11]. The NC batch was divided into four $113.4 \mathrm{~kg}$ allotments. Each allotment received one of the enzyme treatments, and were referred to as NC + SSF, NC + VegPro, and NC + SSF + VegPro. There were a total of five dietary treatments. Appropriate exogenous enzymes were introduced into $4.5 \mathrm{~kg}$ of mash and 
mixed for 10 minutes using a small paddle mixer [12]. The small batch was then introduced back to the designated $113.4 \mathrm{~kg}$ batch and mixed an additional ten minutes [11]. A 300 gram sample was analyzed for crude protein, total lysine, total methionine, total cysteine, total threonine, calcium, total P, and phytic acid at commercial laboratories $[13,14]$. Diets were not pelleted and fed as a mash.

\section{Live Bird Performance}

A total of 360 one day old straight-run Hubbard X Cobb 500 [15] broiler chicks were obtained from a commercial hatchery [16]. All chicks were individually weighed and allotted into 8 weigh groups. One bird from each group was placed in each of 45 raised wire battery cages to create the experimental unit. Each of the dietary treatments were randomly assigned to pens blocked by location, creating a randomized complete block design. Feed and water were provided for ad libitum consumption. Measured variables for the 1 - 21d experimental period included: starting pen weight, EBW, feed intake (FI), LWG, and FCR corrected for mortality weight. On d 21, birds were weighed by pen and killed via cervical dislocation and the ileum (defined as the portion of the small intestine extending from the Meckel's diverticulum to the ileal-cecal junction) was excised [17]. This section was cut in half and the lower section used for collection. The lower ileum was gently flushed with distilled water and the digesta washing was collected. The digesta collected was lyophilized at $-40^{\circ} \mathrm{C}$ for 72 hours. Once dry, all digesta was ground and analyzed for total amino acid concentration. A portion of the digesta was ashed at $600^{\circ} \mathrm{C}$ for 16 hours, acidified using sulfuric acid, diluted with $\mathrm{ddH}_{2} \mathrm{O}$, filtered, and titanium dioxide levels were determined using inductively coupled 
plasma mass spectrometry (ICP) [18]. These data were used to calculate AIAAD; this term is defined as the percentage of digestible amino acid within the total amount of amino acid contained in the feed.

Apparent ileal amino acid digestibility was calculated using the following equation:

$$
A I A A D(\%)=\left[\left(\left(A A_{\text {diet }} / T i_{\text {diet }}\right)-\left(A A_{\text {digesta }} / T i_{\text {digesta }}\right)\right) /\left(A A_{\text {diet }} / T i_{\text {diet }}\right)\right] X 100
$$

\section{Experiment 2}

\section{Part 1: TAAD of complete diets}

The five dietary treatments from Experiment 1 were precision fed to 30 week old cecectomized Single Comb White Leghorn (SCWL) roosters to determine TAAD [19]. A cornstarch control was used to account for endogenous amino acid losses. A total of 48 SCWL roosters were used, with eight replications per treatment and control. Roosters were fasted for 24 hours prior to precision feeding. A 30 gram sample of each treatment was placed directly into the rooster's crop, and excreta was collected for 48 hours [20]. Excreta was then dried and sent to a commercial laboratory for total amino acid content [13].

\section{Part 2: TAAD of meat and bone meal}

Meat and bone meal or this ingredient with the addition of SSF, VegPro, or SSF + VegPro (total of four treatments) were precision fed to 30 week old cecectomized SCWL roosters to determine TAAD [19] using similar methodologies as described above in Part 1: TAAD of complete diets. All animals were reared according to protocols established 
by the West Virginia University Animal Care and Use Committee [ACUC 11-0301, 110703].

\section{Statistical analysis}

Data was analyzed using one-way analysis of variance (ANOVA) using SAS software [21]. Significant differences were determined based on $\alpha \leq 0.05$. Means were separated using Fisher's least significant difference test and letter superscripts were used to denote differences among treatment means. Variables measured included: EBW, LWG, FI, FCR, mortality percentage, AIAAD, and TAAD.

\section{RESULTS AND DISCUSSION}

\section{Experiment 1}

Live bird performance results can be found in Table 2. Significant differences were observed for all performance variables $(\mathrm{P}<0.0001)$. Birds fed the PC resulted in the highest EBW and LWG, birds fed the NC resulted in the lowest EBW and LWG, and diets supplemented with enzyme were intermediate $(\mathrm{P}<0.0001)$. Birds fed NC + SSF + VegPro consumed the most feed, birds fed NC and NC + VegPro consumed the least amount of feed, and birds fed the PC and NC + SSF were intermediate $(\mathrm{P}<0.0001)$. For FCR, birds fed NC demonstrated the highest or worst FCR, birds fed the PC resulted in the lowest or best FCR, while birds fed diets supplemented with enzyme were intermediate $(\mathrm{P}<0.0001)$. The NC treatment was created by decreasing crude protein and digestible amino acids by $15 \%$ compared to the PC; it was not expected that the enzymes would overcome this drastic decrease. Furthermore, these data support past research. Allzyme VegPro demonstrated improved weight gain, feed conversion, and 
digestibility of fat and crude protein when added to corn-soybean based diets [8]. Allzyme SSF has also been shown to increase metabolizable energy, improve feed conversion, and improve overall performance of broiler chicks [9].

The AIAAD results are located in Table 3. Significant differences were found for all amino acids $(\mathrm{P}<0.0001)$. The PC diet resulted in the highest digestible values for all amino acids reported. For lysine, leucine, isoleucine, valine, cysteine, proline, glutamic acid, and aspartic acid, the NC + SSF + VegPro diet was able to overcome part of the NC deficiency, resulting in an increase in digestibility. For the same amino acids listed previously, the NC + SSF and NC + VegPro diets were statistically similar to the NC (P $<0.0001)$.

\section{Experiment 2}

\section{Part 1: TAAD of complete diets}

The TAAD of complete diets from Experiment 2 can be found in Table 4. Significant differences were observed for threonine $(\mathrm{P}<0.0001)$, glutamic acid $(\mathrm{P}=$ 0.0034), methionine $(\mathrm{P}<0.0001)$, isoleucine $(\mathrm{P}=0.0057)$, leucine $(\mathrm{P}<0.0001)$, and lysine $(\mathrm{P}<0.0001)$. The PC diet resulted in the highest digestible values for glutamic acid, methionine, isoleucine, leucine, and lysine. The PC and NC diets were statically similar for digestible threonine. The NC + SSF diet was able to overcome part of the NC deficiency for threonine, methionine, and lysine, resulting in an increase in digestibility of these amino acids. The NC + VegPro diet was able to overcome some of the NC deficiency for isoleucine, leucine, and lysine, also resulting in a increase of digestibility for these amino acids. The NC + SSF + VegPro was statistically similar to the NC for the 
listed amino acids. These data are different from observations in Experiment 1, where the NC + SSF + VegPro diet demonstrated an increase in amino acid digestibility. This may likely be due to the differences in assays; AIAAD is determined using continually fed growing broilers, whereas TAAD is determined using a 30 gram bolus of feed and a mature rooster. Previous research conducted by Kadim and others observed significant differences between ileal and excreta-based digestibility values [22] and in some cases amino acid digestibility was underestimated by excreta analysis [23].

\section{Part 2: TAAD of meat and bone meal}

The TAAD of MBM results from Experiment 2 can be found in Table 5. Significant differences were observed for all amino acids tested $(\mathrm{P}<0.0001)$. For all amino acids, MBM alone resulted in the highest digestible values and supplementing enzymes, either separately or in combination, did not improve digestibility. The authors speculate that the presence of the exogenous enzymes may have decreased endogenous secretions, thus decreasing overall digestibility of the MBM. This may be supported by Jiang and others who reported a reduction in pancreatic secretions by approximately $20 \%$ when diets were supplemented with amylase and protease [24]. Mahagna and cohorts also reported depressed digestive enzyme activity when broilers were fed diets containing meat meal supplemented with amylase and protease [25]. The current study demonstrates value in supplementing Allzyme SSF and VegPro into complete diets containing 8\% MBM; however, the target substrate was likely of vegetable origin. 


\section{CONCLUSIONS AND APPLICATIONS}

1) Birds fed the diets supplemented with enzyme (separately or in combination) were able to overcome some of the NC deficiency, demonstrating improved EBW, LWG, and FCR.

2) The combination of enzymes (NC + SSF + VegPro) demonstrated improved AIAAD compared to the NC for lysine, leucine, isoleucine, valine, cysteine, proline, glutamic acid, and aspartic acid.

3) When examining complete diet TAAD, the NC + SSF diet demonstrated improved digestibility for threonine, methionine, and lysine compared to the NC diet. The NC + VegPro diet demonstrated greater digestible isoleucine, leucine, and lysine values compared to the NC.

4) The digestibility of MBM did not improve with enzyme supplementation.

5) Based on the current study, Allzyme SSF and Allzyme VegPro demonstrate some value in increasing digestibility of complete diets containing 8\% MBM; however, the target substrate was likely of vegetable origin.

\section{REFERENCES AND NOTES}

1) Nitsan, Z. 1991. Influence of antinutritional compounds on dietary protein utilization in various species, as affected by age, diet and feeding regime. in: B.O. Eggum, S. Boisen, C. Børsting, A. Danfær, T. Hvelplund (Eds.) Proceedings of the VIth International Symposium on Protein Metabolism and Nutrition. EAAP Publication No. 59: 103-126.

2) Noy, Y. and D. Sklan. 1995. Digestion and absorption in the young chick. Poult. Sci. 74 (2): 366-373.

3) Jin, C. F., I. H. Kim, K. Han, and S. H. Bae. 1998. Effects of supplemental synthetic amino acids to the low protein diets on the performance of growing pigs. Asian-australas. J. Anim. Sci. 11:1-7.

4) Bedford, M.R. 1995. Mechanism of action and potential environmental benefits from the use of feed enzymes. Animal Feed Science and Technology. 53: 145-155.

5) Marsman, G.J.P., H. Gruppen, A.F.B. Van der Poel, R.P. Kwakkel, M.W.A. Vertegen, and A.G.J. Voragen. 1997. The effect of thermal processing and enzyme treatments of soybean meal on growth performance, ileal nutrient digestibilities, and chime characteristics in broiler chicks. Poult. Sci. 76: 864-872.

6) Wu, Y. B., J. Pierce, W. H. Hendricks, and V. Ravindran. 2003. Comparison of in vitro nutrient release by three enzyme preparations in wheat- and maize-based diets. Proc. Australian Poult. Sci. Symp. 5:114-118. 
7) Ristanovic, B., M. Drinic, M. Milenkovic, T. Radovanovic, V. Kalpacina, and G. Cilev. 2011. The effects of the use of the Allzyme VegPro enzyme cocktail on the daily weight gain and feed conversion in weaned piglets. Macedonian J. of Animal Sci. 1(1): 117-122.

8) Gippert, T., A. Abouzeid, and K.E. Sherif. 1997. The effect of Allzyme VegPro on the digestibility of broiler feeds and on the production. Proc. Aust. Poult. Sci. Sym. No. 9: 179-182.

9) Ao, T., J.L. Pierce, M. Paul, A.J. Pescatore, A.H. Cantor, K.A. Dawson and M.J. Ford. 2011. Effects of supplementing Allzyme SSF and Allzyme PT in wheat based diet on the performance of chicks. Poultry Sci. Vol. 90 (Suppl. 1): 510.

10) AgriStats Inc., Fort Wayne, IN; year 2013.

11) Vertical mixer, Avery Weigh-Tronix, Fairmont, MN.

12) Hobart paddle mixer (model 4146) Hobart Corp., Troy, OH.

13) University of Missouri, Agricultural Experiment Station, Columbia, MO.

14) Eurofins Scientific, Des Moines, IA.

15) Cobb-Vantress, Siloam Springs, AR. 2008.

16) Pilgrims Pride Hatchery. Moorefield, WV

17) Ravindran, V., L. I. Hew, G. Ravindran, and W. L. Bryden. 1999. A Comparison of ileal digesta and excreta analysis for the determination of amino acid digestibility in food ingredients for poultry. Bri. Poult. Sci. Vol. 40: 266 - 274.

18) Gigliotti, J. C., A. L. Smith, J. Jaczynski, and J. C. Tou. 2011. Consumption of krill protein concentrate prevents early renal injury and nephrocalcinosis in female Sprague-Dawley rats. Urol. Res. 39: 59 - 67.

19) Parsons, C.M. 1985. Influence of cecectomy on digestibility of amino acid by roosters fed distillers dried grains with solubles. J. Anim. Sci. 104:469 - 472.

20) Sibbald, I. R., and P. M. Morse. 1982. Effects of the nitrogen correction and the feed intake on true metabolizable energy values. Poult. Sci. 62: 138 - 142

21) SAS Institute. 2000. The SAS System for Windows 2000. Release 8.1. SAS Inst. Inc., Cary, NC.

22) Kadim, I.T., P.J. Maughan, and V. Ravindran. 2002. Ileal amino acid digestibility assay for the growing meat chicken- comparison of ileal and excreta amino acid digestibility in the chicken. British Poult. Sci. 44: 588-597.

23) Ravindran, V., L.I. Hew, G. Ravindran, and W.I. Bryden. 1999. A comparison of ileal digesta and excreta analysis for the determineation of amino acid digestibility in food ingredients for poultry. British Poult. Sci. 40: 266-274.

24) Jiang, Z., Y. Zhou, F. Lu, Z. Han, and T. Wang. 2008. Effects of different levels of supplementary alpha-amylase on digestive enzyme activities and pancreatic amylase mPNA expression of young broilers.

25) Mahagna, M., I. Nir, M. Larbier, and Z. Nitsan. 1995. Effect of age and exogenous amylase and protease on development of the digestive tract, pancreatic enzyme activities and digestibility of nutrients in young meat-type chicks. Reprod. Nutr. Dev. 35: 201-212. 
Table 1. Diet composition for the negative and positive control diets

\begin{tabular}{|c|c|c|}
\hline Ingredient (\%) & Positive Control & Negative Control \\
\hline Corn & 61.99 & 67.88 \\
\hline Soybean Meal (48\%) & 26.06 & 17.96 \\
\hline Porcine Meat and Bone Meal & 7.93 & 7.93 \\
\hline Animal and Vegetable Blend & 1.91 & 1.91 \\
\hline Limestone & 0.38 & 0.40 \\
\hline Dicalcium Phosphorus & 0.00 & 0.07 \\
\hline DL-Methionine & 0.35 & 0.30 \\
\hline Vitamin/Trace Mineral Premix & 0.25 & 0.25 \\
\hline Lysine $\mathrm{HCl}$ & 0.29 & 0.32 \\
\hline Titanium Dioxide & 0.20 & 0.20 \\
\hline Threonine & 0.13 & 0.13 \\
\hline Salt & 0.21 & 0.20 \\
\hline Sodium Bicarbonate & 0.17 & 0.17 \\
\hline Coban $60^{2}$ & 0.08 & 0.08 \\
\hline BMD $90^{3}$ & 0.05 & 0.05 \\
\hline \multicolumn{3}{|c|}{ Calculated Nutrients } \\
\hline Metabolizable Energy (kcal/kg) & 3,031 & 3,031 \\
\hline Crude Protein (\%) & 21.95 & 18.50 \\
\hline Digestible Lysine (\%) & 1.18 & 1.00 \\
\hline Digestible TSAA (\%) & 0.89 & 0.76 \\
\hline Digestible Threonine (\%) & 0.77 & 0.65 \\
\hline Calcium (\%) & 0.96 & 0.96 \\
\hline Available Phosphorus (\%) & 0.45 & 0.45 \\
\hline Sodium (\%) & 0.20 & 0.20 \\
\hline
\end{tabular}

${ }^{1}$ Supplied per kg of diet: manganese, $0.02 \%$; zinc 0.02\%; iron, 0.01\%; copper, $0.0025 \%$; iodine, $0.0003 \%$; selenium, 0.00003\%; folic acid, 0.69mg; choline, 386mg' riboflavin, 6.61mg; biotin, 0.03mg; vitamin B6, 1.38mg; niacin, 27.56mg; pantothenic acid, 6.61mg; thiamine, 2.20mg; manadione, 0.83mg; vitamin B12, 0.01mg; vitamin E, 16.53 IU; vitamin D3, 2133 ICU; vitamin A, 7716 IU.

${ }^{2}$ Active drug ingredient Monensin Sodium $60 \mathrm{gpb}$ (90 g/ton inclusion), Elanco Animal Health, Indianapolis, IN. As an aid in the prevention of coccidiosis caused by Eimerianecarix, Eimeriatenella, Eimeriaacervulina, Eimeria brunette, Eimeriamivati, and Eimeria maxima.

${ }^{3}$ Bacitracin Methylene Disalicylate 50 g/lb (50 g/ton inclusion), Alpharma, Fort Lee, NJ. For increased rate of weight gain and improved feed efficiency. 
Table 2. The effects of Alltech SSF and VegPro on live bird performance of Hubbard x Cobb 500 broiler chickens (Experiment 1)

\begin{tabular}{|c|c|c|c|c|c|}
\hline Treatment & $\begin{array}{c}\text { Starting Pen } \\
\text { Weight }^{1} \\
\text { (kg) }\end{array}$ & $\begin{array}{c}\text { Ending Pen } \\
\text { Weight } \\
\text { (kg) }\end{array}$ & $\begin{array}{c}\text { LWG/bird }^{2} \\
\text { (kg) }\end{array}$ & $\begin{array}{c}\text { Pen Feed } \\
\text { Intake } \\
\text { (kg) } \\
\end{array}$ & $\begin{array}{c}\text { FCR }^{3} \\
(\mathrm{~kg} / \mathrm{kg})\end{array}$ \\
\hline $\begin{array}{c}\text { Positive Control } \\
\text { (PC) }\end{array}$ & 0.363 & $5.985^{\mathrm{a}}$ & $0.703^{\mathrm{a}}$ & $7.48^{\mathrm{b}}$ & $1.32^{\mathrm{d}}$ \\
\hline $\begin{array}{l}\text { Negative Control } \\
\text { (NC) }\end{array}$ & 0.362 & $4.801^{d}$ & $0.555^{d}$ & $7.22^{\mathrm{C}}$ & $1.62^{\mathrm{a}}$ \\
\hline $\mathrm{NC}+\mathrm{SSF}$ & 0.366 & $5.636^{b}$ & $0.659^{b}$ & $7.49^{b}$ & $1.42^{\mathrm{C}}$ \\
\hline NC + Veg Pro & 0.365 & $5.160^{\mathrm{C}}$ & $0.599^{c}$ & $7.21^{\mathrm{c}}$ & $1.50^{\mathrm{bc}}$ \\
\hline $\begin{array}{c}\text { NC + SFF + } \\
\text { VegPro }\end{array}$ & 0.365 & $5.506^{\mathrm{b}}$ & $0.643^{b}$ & $7.55^{\mathrm{a}}$ & $1.47^{\mathrm{bc}}$ \\
\hline ANOVA P-Value & 0.5294 & $<0.0001$ & $<0.0001$ & $<0.0001$ & $<0.0001$ \\
\hline SEM $^{4}$ & 0.0014 & 0.0787 & 0.0783 & 0.1251 & 0.0266 \\
\hline Fisher's LSD ${ }^{5}$ & --- & 0.2271 & 0.2190 & 0.3606 & 0.0768 \\
\hline
\end{tabular}

${ }^{1}$ Starting pen weights were based on 8 birds per pen

${ }^{2}$ Live Weight Gain

${ }^{3}$ Feed Conversion Ratio (Feed: Gain); there was no mortality in this study.

${ }^{4}$ Standard Error of the Mean

${ }^{5}$ Fisher's Least Significant Difference

${ }^{\mathrm{a}-\mathrm{d}}$ Means within a column not sharing a common superscript differ $(\mathrm{P}<0.05)$ 
Table 3. Percent Digestible Amino Acid ${ }^{1}$ for Positive and Negative Control Diets and Diets Containing SSF, VegPro, or SSF + VegPro using Hubbard x Cobb 500 Straight-Run Broiler Apparent Ileal Digestibility (Experiment 1)

\begin{tabular}{|c|c|c|c|c|c|c|c|c|c|c|c|c|}
\hline Treatment & $\begin{array}{c}\text { Aspartic } \\
\text { Acid } \\
(\%)\end{array}$ & $\begin{array}{l}\text { Threonine } \\
(\%)\end{array}$ & $\begin{array}{c}\text { Glutamic } \\
\text { Acid } \\
(\%)\end{array}$ & $\begin{array}{c}\text { Proline } \\
(\%)\end{array}$ & $\begin{array}{c}\text { Glycine } \\
(\%)\end{array}$ & $\begin{array}{c}\text { Alanine } \\
(\%)\end{array}$ & $\begin{array}{c}\text { Cysteine } \\
(\%)\end{array}$ & $\begin{array}{c}\text { Valine } \\
(\%)\end{array}$ & $\begin{array}{c}\text { Methionine } \\
(\%)\end{array}$ & $\begin{array}{c}\text { Isoleucine } \\
(\%)\end{array}$ & $\begin{array}{c}\text { Leucine } \\
(\%)\end{array}$ & $\begin{array}{l}\text { Lysine } \\
(\%)\end{array}$ \\
\hline $\begin{array}{c}\text { Positive Control } \\
\text { (PC) }\end{array}$ & $1.23^{\mathrm{a}}$ & $0.61^{3}$ & $2.72^{a}$ & $0.85^{\mathrm{a}}$ & $0.56^{\mathrm{a}}$ & $0.75^{\mathrm{a}}$ & $0.13^{\mathrm{a}}$ & $0.61^{\mathrm{a}}$ & $0.42^{2}$ & $0.54^{2}$ & $1.31^{\mathrm{a}}$ & $0.98^{2}$ \\
\hline $\begin{array}{c}\text { Negative Control } \\
\text { (NC) }\end{array}$ & $0.39^{\circ}$ & $0.34^{b}$ & $1.53^{\circ}$ & $0.42^{\circ}$ & $0.30^{\mathrm{bc}}$ & $0.37^{\mathrm{bc}}$ & $0.08^{\mathrm{c}}$ & $0.23^{\mathrm{c}}$ & $0.36^{b}$ & $0.20^{\mathrm{cd}}$ & $0.64^{c}$ & $0.54^{\mathrm{c}}$ \\
\hline $\mathrm{NC}+\mathrm{SSF}$ & $0.37^{\circ}$ & $0.23^{\mathrm{e}}$ & $1.66^{\mathrm{be}}$ & $0.41^{\mathrm{c}}$ & $0.23^{\text {ce }}$ & $0.32^{\circ}$ & $0.08^{\mathrm{c}}$ & $0.21^{\mathrm{c}}$ & $0.29^{\circ}$ & $0.22^{\circ}$ & $0.67^{\circ}$ & $0.54^{\mathrm{c}}$ \\
\hline $\mathrm{NC}+$ VegPro & $0.33^{\mathrm{c}}$ & $0.23^{\mathrm{c}}$ & $1.48^{\circ}$ & $0.38^{\circ}$ & $0.21^{\mathrm{b}}$ & $0.33^{\mathrm{c}}$ & $0.09^{\mathrm{bc}}$ & $0.21^{\mathrm{c}}$ & $0.30^{c}$ & $0.17^{\mathrm{d}}$ & $0.57^{\circ}$ & $0.57^{\circ}$ \\
\hline $\begin{array}{c}\text { NC + SSF + } \\
\text { VegPro }\end{array}$ & $0.58^{b}$ & $0.24^{\mathrm{c}}$ & $1.82^{b}$ & $0.53^{b}$ & $0.33^{b}$ & $0.44^{b}$ & $0.11^{\mathrm{ab}}$ & $0.30^{5}$ & $0.37^{b}$ & $0.26^{b}$ & $0.79^{b}$ & $0.68^{b}$ \\
\hline ANOVA P-Value & $<0.0001$ & $<0.0001$ & $<0.0001$ & $<0.0001$ & $<0.0001$ & $<0.0001$ & 0.0018 & $<0.0001$ & $<0.0001$ & $<0.0001$ & $<0.0001$ & $<0.0001$ \\
\hline $\mathrm{SEM}^{2}$ & 0.0453 & 0.0218 & 0.0634 & 0.0321 & 0.0248 & 0.0289 & 0.0100 & 0.0193 & 0.0081 & 0.0134 & 0.0407 & 0.0254 \\
\hline Fisher's LSD ${ }^{3}$ & 0.1295 & 0.0624 & 0.1814 & 0.0917 & 0.0710 & 0.0827 & 0.0286 & 0.0554 & 0.0234 & 0.0384 & 0.1165 & 0.0727 \\
\hline
\end{tabular}

${ }^{1}$ Pecent digestible amino acid refers to the percentage of digestible amino acid within the total amount of amino acid contained in the feed

${ }^{2}$ Standard Error of the Mean

${ }^{3}$ Fisher's Least Significant Difference

${ }^{\mathrm{a}-\mathrm{d}}$ Means within a column not sharing a common superscript differ $(\mathrm{P}<0.05)$ 
Table 4. Percent Digestible Amino Acid ${ }^{1}$ for Positive and Negative Control Diets and Diets Containing SSF, VegPro, or SSF + VegPro using cecectomized Single Comb White Leghorn Roosters (Experiment 2, Part 1)

\begin{tabular}{|c|c|c|c|c|c|c|c|c|c|c|c|c|}
\hline Treatment & $\begin{array}{c}\text { Aspartic } \\
\text { Acid } \\
(\%)\end{array}$ & $\begin{array}{c}\text { Threonine } \\
(\%)\end{array}$ & $\begin{array}{c}\text { Glutamic } \\
\text { Acid } \\
(\%)\end{array}$ & $\begin{array}{c}\text { Proline } \\
(\%)\end{array}$ & $\begin{array}{c}\text { Glycine } \\
(\%)\end{array}$ & $\begin{array}{c}\text { Alanine } \\
(\%)\end{array}$ & $\begin{array}{c}\text { Cysteine } \\
(\%)\end{array}$ & $\begin{array}{c}\text { Valine } \\
(\%)\end{array}$ & $\begin{array}{c}\text { Methionine } \\
(\%)\end{array}$ & $\begin{array}{c}\text { Isoleucine } \\
(\%)\end{array}$ & $\begin{array}{c}\text { Leucine } \\
(\%)\end{array}$ & $\begin{array}{c}\text { Lysine } \\
(\%)\end{array}$ \\
\hline $\begin{array}{l}\text { Positive Control } \\
\text { (PC) }\end{array}$ & 1.47 & $0.835^{\mathrm{ab}}$ & $3.07^{\mathrm{a}}$ & 1.16 & 1.08 & 1.03 & 0.292 & 0.807 & $0.630^{\mathrm{a}}$ & $0.682^{\mathrm{a}}$ & $1.67^{\mathrm{a}}$ & $1.26^{\mathrm{a}}$ \\
\hline $\begin{array}{l}\text { Negative Control } \\
\text { (NC) }\end{array}$ & 1.59 & $0.798^{\mathrm{bc}}$ & $2.93^{\mathrm{bc}}$ & 1.21 & 1.39 & 1.02 & 0.301 & 0.831 & $0.508^{\mathrm{C}}$ & $0.646^{b}$ & $1.48^{\mathrm{c}}$ & $1.10^{\circ}$ \\
\hline $\mathrm{NC}+\mathrm{SSF}$ & 1.58 & $0.855^{a}$ & $2.84^{\circ}$ & 1.24 & 1.30 & 1.04 & 0.300 & 0.816 & $0.605^{b}$ & $0.643^{\circ}$ & $1.48^{\circ}$ & $1.16^{b}$ \\
\hline $\mathrm{NC}+$ VegPro & 1.62 & $0.741^{\mathrm{d}}$ & $2.97^{\mathrm{ab}}$ & 1.20 & 1.16 & 1.02 & 0.320 & 0.852 & $0.497^{\circ}$ & $0.690^{2}$ & $1.55^{\mathrm{b}}$ & $1.19^{b}$ \\
\hline $\begin{array}{c}\text { NC + SSF + } \\
\text { VegPro }\end{array}$ & 1.55 & $0.783^{\text {cd }}$ & $2.87^{\mathrm{be}}$ & 1.22 & 1.27 & 1.03 & 0.300 & 0.832 & $0.502^{\circ}$ & $0.6487^{b}$ & $1.51^{\mathrm{bc}}$ & $1.14^{\mathrm{be}}$ \\
\hline
\end{tabular}

${ }^{1}$ Pecent digestible amino acid refers to the percentage of digestible amino acid within the total amount of amino acid contained in the feed (Table 1 )

${ }^{2}$ Standard Error of the Mean

${ }^{3}$ Fisher's Least Significant Difference

${ }^{\mathrm{a}-\mathrm{c}}$ Means within a column not sharing a common superscript differ $(\mathrm{P}<0.05)$ 
Table 5. Percent Digestible Amino Acid ${ }^{1}$ for Meat and Bone Meal (MBM), MBM + SSF, MBM + VegPro, or MBM + SSF + VegPro using cecectomized Single Comb White Leghorn Roosters (Experiment 2, Part 2)

\begin{tabular}{|c|c|c|c|c|c|c|c|c|c|c|c|c|}
\hline Treatment & $\begin{array}{c}\text { Aspartic } \\
\text { Acid } \\
(\%)\end{array}$ & $\begin{array}{l}\text { Threonine } \\
(\%)\end{array}$ & $\begin{array}{c}\text { Glutamic } \\
\text { Acid } \\
(\%)\end{array}$ & $\begin{array}{c}\text { Proline } \\
(\%)\end{array}$ & $\begin{array}{c}\text { Glycine } \\
(\%)\end{array}$ & $\begin{array}{c}\text { Alanine } \\
(\%)\end{array}$ & $\begin{array}{l}\text { Cysteine } \\
(\%)\end{array}$ & $\begin{array}{c}\text { Valine } \\
(\%)\end{array}$ & $\begin{array}{l}\text { Methionine } \\
(\%)\end{array}$ & $\begin{array}{c}\text { Isoleucine } \\
(\%)\end{array}$ & $\begin{array}{c}\text { Leucine } \\
(\%)\end{array}$ & $\begin{array}{l}\text { Lysine } \\
(\%)\end{array}$ \\
\hline $\begin{array}{c}\text { Meat \& Bone Meal } \\
\text { (MBM) }\end{array}$ & $3.37^{\mathrm{a}}$ & $1.64^{3}$ & $6.38^{2}$ & $3.81^{\mathrm{a}}$ & $4.90^{2}$ & $3.30^{2}$ & $0.53^{2}$ & $2.04^{3}$ & $0.85^{2}$ & $1.46^{\mathrm{a}}$ & $3.78^{\mathrm{a}}$ & $2.34^{2}$ \\
\hline $\mathbf{M B M}+\mathrm{SSF}$ & $2.35^{b}$ & $1.29^{\mathrm{b}}$ & $5.03^{b}$ & $3.00^{\mathrm{b}}$ & $3.64^{b}$ & $2.60^{b}$ & $0.27^{b}$ & $1.62^{b}$ & $0.72^{\mathrm{b}}$ & $1.18^{b}$ & $3.12^{b}$ & $1.84^{b}$ \\
\hline MBM + VegPro & $2.33^{\circ}$ & $1.31^{\mathrm{b}}$ & $5.09^{\circ}$ & $3.08^{b}$ & $3.75^{b}$ & $2.66^{b}$ & $0.30^{6}$ & $1.64^{b}$ & $0.71^{\circ}$ & $1.20^{\mathrm{b}}$ & $3.13^{\mathrm{b}}$ & $1.90^{\mathrm{b}}$ \\
\hline $\begin{array}{c}\text { MBM + SSF + } \\
\text { VegPro }\end{array}$ & $2.12^{\mathrm{b}}$ & $1.17^{\circ}$ & $4.79^{\mathrm{b}}$ & $2.92^{\mathrm{b}}$ & $3.48^{b}$ & $2.52^{b}$ & $0.22^{\circ}$ & $1.49^{\circ}$ & $0.63^{\circ}$ & $1.09^{\circ}$ & $2.96^{\circ}$ & $1.66^{\mathrm{c}}$ \\
\hline ANOVA P-Value & $<0.0001$ & $<0.0001$ & $<0.0001$ & $<0.0001$ & $<0.0001$ & $<0.0001$ & $<0.0001$ & $<0.0001$ & $<0.0001$ & $<0.0001$ & $<0.0001$ & $<0.0001$ \\
\hline $\mathrm{SEM}^{2}$ & 0.1082 & 0.0275 & 0.1056 & 0.1057 & 0.1820 & 0.0678 & 0.0195 & 0.0350 & 0.0092 & 0.0213 & 0.0427 & 0.0502 \\
\hline Fisher's LSD ${ }^{3}$ & 0.3136 & 0.0798 & 0.3061 & 0.3065 & 0.5274 & 0.1966 & 0.0566 & 0.1015 & 0.0268 & 0.0619 & 0.1238 & 0.1455 \\
\hline
\end{tabular}

${ }^{1}$ Pecent digestible amino acid refers to the percentage of digestible amino acid within the total amount of amino acid contained in the feed ${ }^{2}$ Standard Error of the Mean

${ }^{3}$ Fisher's Least Significant Difference

${ }^{\mathrm{a}-\mathrm{c}}$ Means within a column not sharing a common superscript differ $(\mathrm{P}<0.05$ 
Manuscript submitted to Journal of Applied Poultry Research: Effects of Algae Incorporation into Broiler Starter Diet Formulations on Nutrient Digestibility and 3-21D Bird Performance

\author{
A.M. Evans ${ }^{*}$, D.L. Smith ${ }^{\dagger}$, and J.S. Moritz ${ }^{* 1}$ \\ *Division of Animal and Nutritional Sciences, West Virginia University, Morgantown, \\ West Virginia, 26506; and ${ }^{\dagger}$ Division of Animal Sciences, Eastern New Mexico \\ University, Portales, New Mexico, 88130 \\ Phone: 304-293-1911 \\ Fax: 304-293-2232
}

Metabolism and Nutrition

${ }^{1}$ Corresponding Author: Joe.Moritz@mail.wvu.edu

Primary Audience: Nutritionists, Researchers, Feed Mill Managers 
SUMMARY Algae, a human supplement and alternative fuel source, has potential as a feed ingredient for poultry. Three studies were conducted with the following objectives: determine digestible nutrient values for a commercially available Spirulina algae (Study 1), formulate and pellet a practical broiler starter diet using these data (Study 2), and assess feeding diet formulations with varying levels of algae on Hubbard X Cobb 500 broiler performance and apparent ileal amino acid digestibility (AIAAD; Study 3). Spirulina algae true metabolizable energy (TMEn; 2,839 kcal/kg) and true amino acid digestibility (TAAD) values (2.10, 1.07, 0.42, 1.97\%, lysine, methionine, cysteine, threonine, respectively) from Study 1 were used to formulate a practical broiler starter diet containing $21 \%$ algae. A diet containing $0 \%$ algae was also formulated. Both diets were pelleted, ground, and mixed at different ratios to create diets containing 6,11 , and $16 \%$ algae. The $21 \%$ algae diet resulted in lowered production rate and increased hot pellet temperature and pellet durability compared to the $0 \%$ algae diet. Diets containing up to $16 \%$ algae were statistically similar to the $0 \%$ algae diet for ending bird weight, live weigh gain, and feed intake ( $\mathrm{P}>0.05)$. The $16 \%$ algae diet demonstrated the highest level of digestible cysteine and lysine $(\mathrm{P}<0.0001)$. All diets containing algae demonstrated higher digestible methionine values compared to the $0 \%$ algae diet $(\mathrm{P}<$ 0.0001). Descriptive feed manufacture, performance, and AIAAD data demonstrated value in algae incorporation into practical diet formulations.

KEYWORDS: algae, broiler performance, true metabolizable energy, true amino acid digestibility, apparent ileal amino acid digestibility 


\section{DESCRIPTION OF PROBLEM}

Crude oil prices have influenced the development of next generation alternative fuel sources. Algae is a leading candidate as an alternative fuel due to its short growing cycle, lack of requirement for arable land or potable water, and photosynthetic efficiency [1]. The extraction of oil from algae for fuel generates a co-product, that when dried, could be used as a feed ingredient. This algae co-product has potential to be used in various animal feeds including: poultry, swine, and cattle; however, several variables are associated with production, thus necessitating research that compares method of production and feeding value. Variables for consideration include the extraction, drying, and storage of the co-product. For example, the algae may be grown in outdoor ponds, collected and passed through a series of cleaning screens, and spray dried to remove the moisture, resulting in a dry algae product [1]. Algae, in general, is high in several nutrients including: crude protein, beta carotene, gamma linolenic acid, vitamin $\mathrm{B}_{12}$, and iron $[2,3]$.

As a human supplement, the effect of algae has been documented. Several studies have shown that algae supports the immune function in humans $[3,4,5,6]$. Algae was found to decrease inflammation and contain antioxidant agents in several studies [3, 6, 7]. Little research exists testing algae’s effects in animal production. Ross and Dominy reported no detrimental effects by feeding broiler chickens up to 12\% Spirulina algae [8]. Drewery and cohorts reported no significant differences in forage intake, digestion, or nitrogen balance with steers fed algae [9]. Becker named algae as a novel source of protein. Becker compared algae's amino acid profile to egg and soybean and 
demonstrated similarities with an egg profile; the author also cited poultry as the target domestic animal [10]. These data demonstrate potential for algae as an animal feed ingredient.

The objectives of this research were to determine digestible nutrient values for a commercially available Spirulina algae (Study 1), formulate and pellet a practical broiler starter diet using these data (Study 2), and assess feeding diet formulations with varying levels of algae on Hubbard X Cobb 500 broiler performance and AIAAD (Study 3).

\section{MATERIALS AND METHODS}

The algae used in these studies was a dried commercial Spirulina algae source that was not fat extracted and had a powdery consistence (Table 1).

\section{Study 1}

Three treatments, $100 \%$ corn, 100\% algae, and 50:50 corn: algae were precision fed to 30 week old intact Single Comb White Leghorn (SCWL) roosters to determine TMEn [11]. The 50:50 corn: algae treatment was used to account for potential passage rate or viscosity detriments of feeding the finely powdered algae. A non-feed control was used (roosters were not precision fed) to account for endogenous energy losses. A total of 24 SCWL roosters were used, with six replications per treatment and control. These same treatments were precision fed to a total of 24 cecectomized SCWL roosters also 30 weeks of age, with six replications per treatment and control, to determine TAAD [12]. A cornstarch control was used to account for endogenous amino acid losses. Roosters 
were fasted for 24 hours prior to precision feeding. A 30 gram sample of each treatment was placed directly into the rooster's crop, and excreta was collected for 48 hours [13]. Excreta was then dried and sent to a commercial laboratory for gross energy and nitrogen analysis [14] or total amino acid content [15].

\section{Study 2}

The data from Study 1 as well as nutrient composition (Table 1) obtained from a commercial laboratory [16] was utilized to formulate a diet with $21 \%$ algae. A $0 \%$ algae control diet was also formulated utilizing similar ingredients as well as ME, TSAA, digestible lysine, digestible threonine, sodium, calcium, and available phosphorus (Table 2).

All feed was manufactured at West Virginia University’s pilot feed mill. A $340 \mathrm{~kg}$ allotment of the $21 \%$ algae diet was mixed for ten minutes dry, and an additional ten minutes post fat addition using a single screw vertical mixer [17]. A $340 \mathrm{~kg}$ allotment of feed was also batched in accordance to the $0 \%$ algae diet formulation. In addition, a 230 $\mathrm{kg}$ allotment of feed was batched in accordance to the $0 \%$ algae diet with the addition of 2.9\% green gel food coloring [18]. The food coloring treatment was created to explore potential feed intake effects that may result from the vibrant green color of the feed due to algae inclusion. All batches of feed were steam conditioned and pelleted. Initially feed was passed through a $1.3 \mathrm{~m}$ long conditioner with a diameter of $0.31 \mathrm{~m}$ and $10 \mathrm{sec}$ retention time [19]. Treatments were steam conditioned at $82^{\circ} \mathrm{C}$ and pellets were formed using a 40-horsepower California Pellet Mill [20] equipped with a 4.8mm x 38mm pellet 
die. The pellets were cooled with ambient air utilizing a horizontal belt cooler [21]. Once conditioning temperature reached a steady state during pelleting, mash samples were taken from the feed screw auger that conveyed feed into the conditioner and corresponding pellet samples were taken from the cooler discharge. These samples were analyzed for crude protein, calcium, and total P at a commercial laboratory [22]. Samples were also collected for dry matter analysis at several stages in the pelleting process, including: at the end of the conditioning barrel prior to pelleting (hot mash) and immediately after extrusion from the pellet die (hot pellet). A pelleted sample was collected directly from the pellet die and placed into an insulated container to determine hot pellet temperature; temperature measurements were obtained using a thermocouple thermometer [23] and an 80PK-24 temperature probe. Pellet durability index (PDI) and modified pellet durability index (MPDI) were performed using a Pfost tumbling box on all treatments one day after pelleting [24]. In addition, pellet durability was determined using a New Holmen Pellet Tester [25]. All batches of feed were ground with a rollermill to eliminate potentially confounding feed form effects and the 0 and $21 \%$ algae batches were mixed in different ratios to create three additional diets that contained 6, 11, and $16 \%$ algae.

\section{Study 3}

A total of 1,000 1-d old straight-run Hubbard X Cobb 500 [26] broiler chicks were obtained from a commercial hatchery [27]. On day 3, all chicks were individually weighed and allotted into 10 weigh groups. One bird from each group was placed in each of 96 raised wire battery cages to create the experimental unit. Each of the dietary 
treatments were randomly assigned to pens blocked by location, creating a randomized complete block design. Each treatment was replicated 16 times. Feed and water were provided for ad libitum consumption. Measured variables for the $\mathrm{d} 3-21$ experimental period included: day 3 starting bird weight, day 21 ending bird weight (EBW), feed intake (FI), live weight gain (LWG), mortality percentage, and feed conversion ratio corrected for mortality weight (FCR). On d 21, birds were weighed by pen and killed via cervical dislocation and the ileum (defined as the portion of the small intestine extending from the Meckel's diverticulum to the ileal-cecal junction) was excised [28]. This section was cut in half and the lower section used for collection. The lower ileum was gently flushed with distilled water and the digesta washing was collected. The digesta collected was lyophilized at $-40^{\circ} \mathrm{C}$ for 72 hours. Once dry, all digesta was ground and analyzed for total amino acid concentration. A portion of the digesta was ashed at $600^{\circ} \mathrm{C}$ for 16 hours, acidified using sulfuric acid, diluted with $\mathrm{ddH}_{2} \mathrm{O}$, filtered, and titanium dioxide levels were determined using inductively coupled plasma mass spectrometry (ICP) [29]. These data were used to calculate AIAAD. All animals were reared according to protocols established by the West Virginia University Animal Care and Use Committee [ACUC 11-0301, 11-0703].

Apparent ileal amino acid digestibility was calculated using the following equation:

$$
A I A A D(\%)=\left[\left(\left(A A_{\text {diet }} / T i_{\text {diet }}\right)-\left(A A_{\text {digesta }} / T i_{\text {digesta }}\right)\right) /\left(A A_{\text {diet }} / T i_{\text {diet }}\right)\right] X 100
$$




\section{Statistical analysis}

Data was analyzed using one-way analysis of variance (ANOVA) with SAS software [30]. Significant differences were determined based on $\alpha \leq 0.05$. Means were separated using Fisher's least significant difference test and letter superscripts were used to denote differences among treatment means.

\section{RESULTS AND DISCUSSION}

\section{Study 1}

The TMEn and TAAD values can be found in Table 3. All treatments were significantly different from one another $(\mathrm{P}<0.0001)$. The $100 \%$ corn treatment demonstrated the highest TMEn value of 3,335 kcal/kg, the $100 \%$ algae treatment resulted in the lowest TMEn value of 2,839 $\mathrm{kcal} / \mathrm{kg}$, and the 50:50 corn: algae treatment was intermediate with a TMEn value of 3,057 kcal/kg. Soybean meal TMEn was added as a descriptive comparison and was not included in statistical analysis. The TMEn value for soybean meal was obtained from Dale and Batal and was reported as 2,461 kcal/kg [31]. These data suggests that algae has an energy value above soybean meal and approximately $90 \%$ the energy of corn.

The $100 \%$ algae treatment resulted in the highest percent digestible amino acid values, the $100 \%$ corn treatment resulted in the lowest values, and the 50:50 corn: algae treatment was intermediate for all amino acids analyzed $(\mathrm{P}<0.0001)$. Digestible lysine, 
methionine, cysteine, and threonine values for algae were determined to be 2.10, 1.07, 0.42, and $1.97 \%$, respectively. The same amino acid values for corn were determined to be $0.22,0.11,0.13$, and $0.28 \%$, respectively. Again, soybean meal TAAD was added as a descriptive comparison and was not included in statistical analysis. The soybean meal TAAD values were obtained from AminoDat 4.0 [32]. Digestible lysine, methionine, cysteine, and threonine values for soybean meal were reported as $2.23,0.65,0.68$, and $1.85 \%$, respectively. These data suggest that algae percent digestible amino acid values are most similar to soybean meal, indicating that algae has potential to replace this ingredient in diet formulation.

\section{Study 2}

Nutrient levels obtained from Study 1 were used to incorporate algae into broiler starter diets at the highest practical inclusion of $21 \%$. A diet containing $0 \%$ algae was formulated to contain similar ingredients and calculated nutrients. Algae inclusion into diet formulation was accomplished by replacing approximately $60 \%$ of the soybean meal and $40 \%$ of the animal/vegetable blend fat compared to the $0 \%$ algae diet (Table 2). These two diets were pelleted using similar conditions and descriptive feed manufacture data can be found in Table 4. This data was not replicated and should be considered descriptive. The $21 \%$ algae diet decreased production rate and increased hot pellet temperature as compared to the 0 and $0 \%$ algae with food coloring diets. Production rate decreased from 0.72 to 0.53 tonne/hour for the 0 and $21 \%$ algae diets, respectively. The $0 \%$ algae with food coloring diet was similar to the $0 \%$ algae diet at 0.70 tonne/hour. Hot pellet temperature increased from 79.4 to $84.0^{\circ} \mathrm{C}$ for the 0 and $21 \%$ algae diets, 
respectively. The $0 \%$ algae with food coloring diet was similar to the $0 \%$ algae diet at $79.2^{\circ} \mathrm{C}$. Pellet durability was increased for the $21 \%$ algae diet. The PDI determined with a Pfost tumbling box resulted in $97.7 \%$ durable pellets for the $21 \%$ algae diet compared to 73 and $77.9 \%$ durable pellets for the 0 and $0 \%$ algae with food coloring diets, respectively. The MPDI showed a similar effect with the $21 \%$ algae diet resulting in 97.5\% durable pellets while the 0 and $0 \%$ algae with food coloring diets resulted in 62.8 and 68.1\% durable pellets, respectively. The New Holmen Pellet Tester was also used to determine pellet durability [33]. Percent durable pellet for this test was 45.5, 48.8, and 97.4\% for the 0 , 0 with food coloring, and $21 \%$ algae diets, respectively. All assays demonstrated a remarkably high durability for the $21 \%$ algae diet. The authors speculate that algae may be a pellet binder. The powdery consistency of algae may have filled interstitial spaces within the pellet, while the high crude protein value could have resulted in protein gelation. These factors likely contributed to increased retention time in the die, thus decreasing production rate, increasing hot pellet temperature and ultimately improving pellet durability. This concept can be supported by past research conducted by Gehring and coauthors, who demonstrated decreased pellet mill production rate and increased pellet durability with a $5 \%$ inclusion of a trout protein paste (crude protein $=$ 85.77\%) [34]. Similarly, Buchanan and Moritz reported improved pellet quality with a 5\% inclusion of soy protein isolate or cellulose [35].

\section{Study 3}

Data for bird performance can be found in Table 5. Day 3 starting pen weight was not significantly different $(\mathrm{P}>0.05)$. Day $21 \mathrm{EBW}$ was significantly different $(\mathrm{P}=$ 
0.0310). The $16 \%$ algae diet resulted in the highest numerical EBW and was statistically similar to the 0,6 , and $11 \%$ algae diets, while the $21 \%$ algae diet resulted in the lowest numerical EBW and was statistically similar to the $0 \%$ algae with food coloring diet. Significant differences were observed for LWG $(P=0.0269)$ demonstrating that birds fed the $16 \%$ algae diet resulted in the largest numerical weight gain and were statistically similar to birds fed the 0, 6, and $11 \%$ algae diets, while birds fed the $21 \%$ algae diet gained the least amount of weight and were statistically similar to birds fed the $0 \%$ algae and $0 \%$ algae with food coloring diets. There was also a significant difference for FI (P = 0.0024) demonstrating that birds fed the $0,6,11$, and $16 \%$ algae diets consumed similar amounts of feed, while the birds fed the $21 \%$ algae diet consumed the least amount of feed and were statistically similar to birds fed the $0 \%$ algae with food coloring diet. While not significant, there was a trend towards a lowered FCR for the $21 \%$ algae diet (P $=0.0636)$. This trend was associated with the lowered EBW and FI for this diet and not particularly noteworthy.

These findings are similar to results observed by Ross and Dominy who found no detrimental effects to feeding broiler chicks diets containing Spirulina algae up to $12 \%$ [8]. As with other ingredients (i.e. corn DDGS and soybean meal), processing specifics can influence nutrient composition and ultimately affect performance [36, 37, 38]. The algae product used by Ross and Dominy contained similar total nutrient compositions as the algae used in the current study. The algae product nutrient similarities and performance results from the Ross and Dominy study support the findings of the studies presented in this paper. 
The AIAAD data can be found in Table 6. Significant differences were observed for all amino acids analyzed except for isoleucine $(\mathrm{P}<0.0001)$. The diets containing 6 , 11 , and $16 \%$ algae were statistically similar to the $0 \%$ algae diet for digestible threonine and valine. The diets containing 6 and 16\% algae resulted in the highest digestible proline and alanine values that were statistically higher than the $0 \%$ algae and $0 \%$ algae with food coloring treatments. The diets containing 6,11 , and $16 \%$ algae resulted in the highest digestible glycine and leucine values that were statistically higher than other dietary treatments $(\mathrm{P}<0.0001)$. All diets containing algae demonstrated greater digestible methionine values than the $0 \%$ algae treatment $(\mathrm{P}<0.0001)$. The $16 \%$ algae diet resulted in the highest digestible aspartic acid $(\mathrm{P}<0.0001)$, cysteine $(\mathrm{P}=0.0254)$, and lysine $(\mathrm{P}<0.0001)$ values compared to all other dietary treatments.

The authors speculate that TAAD data may have underestimated AIAAD. This may be supported by previous research conducted by Kadim and others where significant differences were observed between ileal and excreta-based digestibility values [39] and in some cases found amino acid digestibility was underestimated by excreta analysis [40].

Broilers fed the $21 \%$ algae diet demonstrated a decrease in performance and amino acid digestibility. The authors speculate this may have been caused by the same process that increased pellet durability. Protein gelation during pelleting may have increased viscosity of digesta, preventing endogenous enzymes access to substrates in the gastrointestinal tract, thus decreasing performance and amino acid digestibility. However, increased algae inclusions up to $16 \%$ may have slowed digesta passage rate and improved digestibility. 
The authors emphasize that the algae used in these studies was a commercially available, full-fat product. Further research should be conducted to compare the effects of full-fat and fat-extracted algae products on broiler performance, as well as a pelleting study to determine the minimum level of algae required to induce the binding effect observed in Study 2. Overall, these data demonstrate value for Spirulina algae inclusion in practical starter diet formulations.

\section{CONCLUSIONS AND APPLICATIONS}

1) Algae contained a TMEn value intermediate of corn and soybean meal and TAAD values similar to soybean meal and was incorporated into practical broiler diets by replacing approximately $60 \%$ soybean meal and $40 \%$ animal vegetable blended fat.

2) Algae inclusion decreased production rate and increased hot pellet temperature and pellet durability during feed manufacture. This suggests that algae has potential as a pellet binder.

3) Diets containing $0,6,11$, and $16 \%$ algae were statistically similar in broiler starter performance variables and contained similar or higher digestible AIAAD compared to the $0 \%$ algae diet. 
4) Overall, these data suggest that up to $16 \%$ algae can be incorporated into practical broiler starter diets and utilized by broiler chicks without causing detriment to performance or AIAAD.

\section{REFERENCES AND NOTES}

1. Belay, A. 1997. Mass culture of Spirulina (Arthrospira) outdoors - The Earthrise Farms Experience. In: Vonshak, A. (ed.) Spirulina platensis (Arthrospira): Physiology, Cell-Biology and Biotechnology. Taylor and Francis. pp. 131-158.

2. Cohen Z. \& A. Vonshak. 1991. Fatty acid composition of Spirulina and Spirulinalike cyanobacteria in relation to their chemotaxonomy. Phytochem. 30: 205-206.

3. Belay, A. 2002. The potential application of Spirulina (Arthrospira) as a nutritional and therapeutic supplement in health management. Journal of the American Nutraceutical Association. 5: 27-48.

4. Mao T.K., J, Van de Water \& M.E. Gershwin. 2005. Effects of a Spirulina-based dietary supplement on cytokine production from allergic rhinitis patients. J Med Food. 8(1):27-30.

5. Hirahashi T, M. Matsumoto, K. Hazeki, Y. Saeki, M. Ui, T. Seya. 2002. Activation of the human innate immune system by Spirulina: augmentation of interferon production and NK cytotoxicity by oral administration of hot water extract of Spirulina platensis. Int Immunopharmacol. 2(4):423-34.

6. Gershwin, M.E. \& Belay, A. 1997. (eds.) Spirulina in Human Nutrition and Health. CRC Press, 312pp.

7. Gemma, C., M.H. Mesches, B. Sepesi, K. Choo, D.B. Holmes \& P.C. Bickford. 2002. Diets enriched in foods with high antioxidant activity reverse age-induced decreases in cerebellar beta-adrenergic function and increases in proinflammatory cytokines. J Neurosci.15; 22(14): 6114-20.

8. Ross, E., and W. Dominy. 1990. The nutritional value of dehydrated blue-green algae (Spirulina plantensis) for poultry. Poult. Sci. 69: 794 - 800.

9. Drewery, M. L. 2012. Post-extraction algal residue as a protein sourec for cattle consuming forage. Master’s Thesis, Texas A\&M University. Available electronically from http://hdl.handle.net/1969.1/148191.

10. Becker, E.W. 2007. Micro-algae as a source of protein. Biotech. Adv. 25: 207 210.

11. Latshaw, J.D., and K. Freeland. 2008. Metabolizable energy values determined with intact and cecectomized roosters. Poult Sci. 87:101 - 103.

12. Parsons, C.M. 1985. Influence of cecectomy on digestibility of amino acid by roosters fed distillers dried grains with solubles. J. Anim. Sci. 104:469 - 472. 
13. Sibbald, I. R., and P. M. Morse. 1982. Effects of the nitrogen correction and the feed intake on true metabolizable energy values. Poult. Sci. 62: 138 - 142.

14. University of Arkansas, Central Analytical Laboratory, Fayetteville, AR.

15. University of Missouri, Agricultural Experiment Station, Columbia, MO.

16. Cumberland Valley Analytical Services, Maugansville, MD.

17. Vertical mixer, Avery Weigh-Tronix, Fairmont, MN.

18. AmeriColor. Placentia, CA .

19. A 4.25 feet length, 1.02 feet diameter short term California Pellet Mill conditioner (3 steam inlet ports), 429 rpm shaft speed; 21 picks; 10-s feed retention time.

20. Master Model Pellet Mill, California Pellet Mills Company, Crawfordsville, IN.

21. A 10 feet length horizontal belt cooler.

22. Eurofins Scientific, Des Moines, IA.

23. Fluke 51 II, Everette, WA.

24. American Society for Agricultural Engineers. 1983. Methods for determining and expressing fineness of feed materials by sieving. Page 325 in American Society of Agricultural Engineers Standard S 319. Am. Soc. Agric. Eng. Yearbook Standards, Am. Soc. Am. Eng., St. Joseph, MI. Pellet durability index was determined by sifting $500 \mathrm{~g}$ of pellets from a treatment through a No. 6 American Society for Testing and Materials (ASTM) screen before being deposited into a Pfost tumbler. The sifted pellets were then tumbled in the container, dimensions $5 \times 12 \times 12$ in., with a $2 \times 9$ in. plate fixed diagonally along the $12 \times 12$ in. side, for approximately $10 \mathrm{~min}$ at $50 \mathrm{rpm}$. The sample was then sifted again through the No. 6 (ASTM) $\mathrm{mm}$ screen, weighed, and the percentage of pellets was calculated by dividing the weight of pellets after tumbling by the weight of pellets before tumbling and then multiplying that value by 100 . Modified pellet durability index was similarly measured, with the exception of the addition of five, 13-mm hexagonal bolts to the $500 \mathrm{~g}$ of sample in the tumbler. Both analyses are meant to simulate the deleterious effects of transferring and handling the pellets.

25. Pellet quality was assessed one day following production using the New Holmen Portable Pellet Durability Tester, Lignotech USA, INC., Rothschild, WI. $100 \mathrm{~g}$ of pellets were places in the chamber, blown about for 60 seconds by a jet of air, then weighed, giving a direct read of pellet durability. Fines are removed during the blowing process.

26. Cobb-Vantress, Siloam Springs, AR. 2008.

27. Pilgrims Pride Hatchery. Moorefield, WV

28. Ravindran, V., L. I. Hew, G. Ravindran, and W. L. Bryden. 1999. A Comparison of ileal digesta and excreta analysis for the determination of amino acid digestibility in food ingredients for poultry. Bri. Poult. Sci. Vol. 40: 266 - 274.

29. Gigliotti, J. C., A. L. Smith, J. Jaczynski, and J. C. Tou. 2011. Consumption of krill protein concentrate prevents early renal injury and nephrocalcinosis in female Sprague-Dawley rats. Urol. Res. 39: 59 - 67.

30. SAS Institute. 2000. The SAS System for Windows 2000. Release 8.1. SAS Inst. Inc., Cary, NC. 
31. Dale, N., and A. Batal. 2009. Metabolizable energy value of soybean meal. University of Georgia, Department of Poultry Science Presentation.

32. Amino Dat. 4.0. 2010. Published by Evonik Degussa GmbH.

33. New Holmen Pellet Tester, NHP100, TekPro Limited, Norfolk, UK.

34. Gehring, C.K., J. Jaczynski, and J.S. Moritz. 2009. Improvement of pellet quality with proteins recovered from whole fish using isoelectric solubilizationprecipitation. J. Appl. Poult. Res. 18: 418-431.

35. Buchanan, N.P., and J.S. Moritz. 2009. Main effects and interactions of varying formulation protein, fiber, and moisture on feed manufacture and pellet quality. J. Appl. Poult. Res. 18: 274-283.

36. Batal, A.B, and N.M. Dale. 2006. True metabolizable energy and amino acid digestibility of distillers dried grains with solubles. J. Appl. Poult. Res. 15: 89-93.

37. Waldroup, P.W., Z. Wang, C. Coto, S. Cerrate, F. Yan. 2007. Development of standardized nutrient matrix for corn distillers dried grains with solubles. Inter. J. Poult. Sci. 6(7): 478-483.

38. Fastinger, N.D., J.D. Latshaw, and D.C. Mahan. 2006. Amino acid availability and true metabolizable energy content of corn distillers dried grains with solubles in adult cecectomized roosters. Poult. Sci. 85: 1212-1216.

39. Kadim, I.T., P.J. Maughan, and V. Ravindran. 2002. Ileal amino acid digestibility assay for the growing meat chicken- comparison of ileal and excreta amino acid digestibility in the chicken. British Poult. Sci. 44: 588-597.

40. Ravindran, V., L.I. Hew, G. Ravindran, and W.I. Bryden. 1999. A comparison of ileal digesta and excreta analysis for the determineation of amino acid digestibility in food ingredients for poultry. British Poult. Sci. 40: 266-274. 
Table 1. Algae ${ }^{1}$ nutrient composition used for diet formulation

\begin{tabular}{|c|c|}
\hline Nutrient & Value \\
\hline True Metabolizable Energy (kcal/kg) & 2,839 \\
\hline Moisture $^{2}(\%)$ & 5.10 \\
\hline Crude Protein ${ }^{2}(\%)$ & 76.0 \\
\hline Crude Fat $^{2}(\%)$ & 4.95 \\
\hline Digestible Lysine (\%) & 2.10 \\
\hline Digestible Methionine (\%) & 1.07 \\
\hline Digestible Cysteine (\%) & 0.42 \\
\hline Digestible Threonine (\%) & 1.97 \\
\hline Calcium $^{2}(\%)$ & 1.20 \\
\hline $\operatorname{Sodium}^{2}(\%)$ & 0.28 \\
\hline Total Phosphorus ${ }^{2}(\%)$ & 1.36 \\
\hline Phytic Acid ${ }^{2}$ (\%) & 1.01 \\
\hline Non-Phytate Phosphorus ${ }^{2,3}$ (\%) & 1.08 \\
\hline
\end{tabular}

\footnotetext{
${ }^{1}$ Algae was obtained from Earthrise Nutritionals (Calipatria, CA). This is a full fat product grown in outdoor ponds.

${ }^{2}$ Analysis was performed by Eurofins Scientific, Des Moines, IA.

${ }^{3}$ Non-phytate phosphorus $=$ total phosphorus $-(0.282 \mathrm{X}$ phytic acid $)$
} 
Table 2. Diet composition for the 0 and $21 \%$ algae diets

\begin{tabular}{|c|c|c|}
\hline Ingredient (\%) & 0\% Algae & 21\% Algae \\
\hline Corn & 54.49 & 59.07 \\
\hline Soybean Meal (48\%) & 31.62 & 9.55 \\
\hline Algae & 0.00 & 21.00 \\
\hline Animal and Vegetable Blend & 4.18 & 1.50 \\
\hline Wheat Middlings & 4.93 & 4.93 \\
\hline Limestone & 1.38 & 0.98 \\
\hline Dicalcium Phosphorus & 1.71 & 1.46 \\
\hline DL-Methionine & 0.34 & 0.26 \\
\hline Vitamin/Trace Mineral Premix ${ }^{1}$ & 0.25 & 0.25 \\
\hline Lysine $\mathrm{HCl}$ & 0.26 & 0.43 \\
\hline Titanium Dioxide & 0.20 & 0.20 \\
\hline Threonine & 0.12 & 0.04 \\
\hline Salt & 0.31 & 0.27 \\
\hline Sodium Bicarbonate & 0.21 & 0.05 \\
\hline \multicolumn{3}{|c|}{ Calculated Nutrients } \\
\hline Metabolizable Energy (kcal/kg) & 3,031 & 3,031 \\
\hline Crude Protein (\%) & 20.66 & 22.84 \\
\hline Digestible Lysine (\%) & 1.18 & 1.18 \\
\hline Digestible TSAA (\%) & 0.89 & 0.89 \\
\hline Digestible Threonine (\%) & 0.77 & 0.77 \\
\hline Calcium (\%) & 0.96 & 0.96 \\
\hline Available Phosphorus (\%) & 0.45 & 0.45 \\
\hline Sodium (\%) & 0.20 & 0.20 \\
\hline
\end{tabular}

\footnotetext{
${ }^{1}$ Supplied per kg of diet: manganese, $0.02 \%$; zinc $0.02 \%$; iron, $0.01 \%$; copper, $0.0025 \%$; iodine, $0.0003 \%$; selenium, $0.00003 \%$; folic acid, 0.69mg; choline, 386mg' riboflavin, 6.61mg; biotin, 0.03mg; vitamin B6, 1.38mg; niacin, 27.56mg; pantothenic acid, 6.61mg; thiamine, 2.20mg; manadione, 0.83mg; vitamin B12, 0.01mg; vitamin E, 16.53 IU; vitamin D3, 2133 ICU; vitamin A, 7716 IU.
} 
Table 3. True metabolizable energy (TMEn) and true amino acid digestibility (TAAD) value for treatments $100 \%$ corn, $100 \%$ algae, $100 \%$ soybean meal and 50:50 corn: algae (Study 1)

\begin{tabular}{|c|c|c|c|c|c|c|c|c|c|c|c|c|c|}
\hline Treatment & $\begin{array}{c}\text { TMEn }{ }^{1} \\
(\mathrm{kcal} / \mathrm{kg}) \pm \mathrm{SD}^{2}\end{array}$ & $\begin{array}{c}\text { Aspartic } \\
\text { Acid } \\
(\%)\end{array}$ & $\begin{array}{c}\text { Threonine } \\
(\%)\end{array}$ & $\begin{array}{c}\text { Glutamic } \\
\text { Acid } \\
(\%)\end{array}$ & $\begin{array}{c}\text { Proline } \\
(\%)\end{array}$ & $\begin{array}{c}\text { Glycine } \\
(\%)\end{array}$ & $\begin{array}{c}\text { Alanine } \\
(\%)\end{array}$ & $\begin{array}{c}\text { Cysteine } \\
(\%)\end{array}$ & $\begin{array}{c}\text { Valine } \\
(\%)\end{array}$ & $\begin{array}{l}\text { Methionine } \\
(\%)\end{array}$ & $\begin{array}{c}\text { Isoleucine } \\
(\%)\end{array}$ & $\begin{array}{c}\text { Leucine } \\
(\%)\end{array}$ & $\begin{array}{c}\text { Lysine } \\
(\%)\end{array}$ \\
\hline $100 \%$ corn & $3,335^{2}=40.18$ & $0.53^{\mathrm{c}}$ & $0.28^{\mathrm{c}}$ & $1.28^{\mathrm{c}}$ & $0.57^{\circ}$ & $0.61^{\circ}$ & $0.44^{\circ}$ & $0.13^{\mathrm{c}}$ & $0.40^{\circ}$ & $0.11^{\mathrm{c}}$ & $0.22^{\circ}$ & $0.73^{\mathrm{c}}$ & $0.22^{\mathrm{c}}$ \\
\hline 50:50 corn: algae & $3,057^{b}=40.63$ & $2.75^{\mathrm{b}}$ & $1.12^{\mathrm{b}}$ & $4.11^{\mathrm{b}}$ & $1.24^{b}$ & $1.58^{b}$ & $1.99^{\mathrm{b}}$ & $0.31^{b}$ & $1.94^{b}$ & $0.63^{b}$ & $1.51^{\mathrm{b}}$ & $2.48^{b}$ & $1.27^{b}$ \\
\hline $100 \%$ algae & $2,839^{\circ}=41.90$ & $4.58^{\mathrm{a}}$ & $1.97^{\mathrm{a}}$ & $6.12^{\mathrm{a}}$ & $1.72^{\mathrm{a}}$ & $2.32^{\mathrm{a}}$ & $3.21^{\mathrm{a}}$ & $0.42^{\mathrm{a}}$ & $2.94^{3}$ & $1.07^{\mathrm{a}}$ & $2.55^{\mathrm{a}}$ & $3.88^{\mathrm{a}}$ & $2.10^{2}$ \\
\hline $100 \%$ soybean meal* & 2,461 & 5.37 & 1.85 & 8.47 & 2.34 & 1.98 & 2.03 & 0.68 & 2.21 & 0.65 & 2.11 & 3.55 & 2.89 \\
\hline ANOVA P-Value & $<0.0001$ & $<0.0001$ & $<0.0001$ & $<0.0001$ & $<0.0001$ & 0.0023 & $<0.0001$ & $<0.0001$ & $<0.0001$ & $<0.0001$ & $<0.0001$ & $<0.0001$ & $<0.0001$ \\
\hline $\mathrm{SEM}^{3}$ & 16.67 & 0.0341 & 0.0140 & 0.0564 & 0.0057 & 0.4246 & 0.0166 & 0.0011 & 0.0184 & 0.0022 & 0.0089 & 0.0225 & 0.0057 \\
\hline Fisher's LSD ${ }^{4}$ & 39.546 & 0.0890 & 0.0459 & 0.1412 & 0.1029 & 0.0984 & 0.1191 & 0.0934 & 0.0567 & 0.0129 & 0.1489 & 0.0325 & 0.0329 \\
\hline
\end{tabular}

${ }^{1}$ True Metabolizable Energy corrected for nitrogen

${ }^{2}$ Standard Deviation

${ }^{3}$ Standard Error of the Mean

${ }^{4}$ Fisher's Least Significant Difference

${ }^{\mathrm{a}-\mathrm{c}}$ Means within a column not sharing a common superscript differ $(\mathrm{P}<0.05)$

*Soybean meal was used as a comparison was not included in statistical analysis. The TMEn value was obtained from Dale and Batal (2009). The TAAD values was obtained from AminoDat 4.0 (2010) 
Table 4. Descriptive feed manufacture data for diets containing 0 and $21 \%$ algae and $0 \%$ algae with a green food coloring addition (Study 2)

\begin{tabular}{cccccc}
\hline Treatment & $\begin{array}{c}\text { Production } \\
\text { Rate } \\
\text { (tonne/hr) }\end{array}$ & $\begin{array}{c}\text { Hot Pellet } \\
\text { Temperature } \\
\left({ }^{\circ} \mathbf{C}\right)\end{array}$ & $\begin{array}{c}\text { New Holmen } \\
\text { Pellet Tester } \\
(\%)\end{array}$ & $\begin{array}{c}\text { PDI }^{\mathbf{1}} \\
\mathbf{( \% )}\end{array}$ & $\begin{array}{c}\text { MPDI }^{2} \\
\mathbf{( \% )}\end{array}$ \\
\hline 0\% Algae & 0.72 & 79.4 & 45.5 & 73.0 & 62.8 \\
\hline 0\% Algae with green food coloring & 0.70 & 79.2 & 48.8 & 77.9 & 68.1 \\
\hline 21\% Algae & 0.53 & 84.0 & 97.4 & 97.7 & 97.5 \\
\hline
\end{tabular}

${ }^{1}$ Pellet Durability Index

${ }^{2}$ Modified Pellet Durability Index 
Table 5. Effects on performance variables for 3-21 day Hubbard X Cobb 500 broilers when fed diets containing 0, 6, 11, 16, $21 \%$ algae and a diet containing $0 \%$ algae and a green food coloring (Study 3 )

\begin{tabular}{|c|c|c|c|c|c|c|}
\hline Treatment & $\begin{array}{c}\text { Day } 3 \text { Starting } \\
\text { Pen Weight } \\
\text { (kg/pen) }\end{array}$ & $\begin{array}{c}\text { Day } 21 \text { EBW } \\
\text { (kg/bird) }\end{array}$ & $\begin{array}{c}\mathrm{LWG}^{2} \\
\text { (kg/bird) }\end{array}$ & $\begin{array}{c}\mathrm{FI}^{3} \\
\text { (kg/pen) }\end{array}$ & $\begin{array}{c}\text { FCR }^{4} \\
(\mathrm{~kg} / \mathrm{kg})\end{array}$ & $\begin{array}{l}\text { Mortality } \\
\text { (\%) }\end{array}$ \\
\hline $0 \%$ algae & 0.394 & $0.664^{\mathrm{ab}}$ & $0.625^{\mathrm{abc}}$ & $8.76^{\mathrm{ab}}$ & 1.42 & 2.50 \\
\hline $6 \%$ algae & 0.373 & $0.673^{\mathrm{ab}}$ & $0.636^{\mathrm{ab}}$ & $9.05^{\mathrm{a}}$ & 1.45 & 1.87 \\
\hline $11 \%$ algae & 0.395 & $0.676^{\mathrm{ab}}$ & $0.637^{\mathrm{ab}}$ & $8.73^{\mathrm{ab}}$ & 1.41 & 3.12 \\
\hline $16 \%$ algae & 0.395 & $0.682^{\mathrm{a}}$ & $0.642^{\mathrm{a}}$ & $8.72^{\mathrm{ab}}$ & 1.40 & 3.12 \\
\hline $21 \%$ algae & 0.393 & $0.645^{\mathrm{c}}$ & $0.606^{\mathrm{c}}$ & $8.25^{c}$ & 1.38 & 1.87 \\
\hline 0\% algae with green food coloring & 0.393 & $0.654^{\mathrm{bc}}$ & $0.614^{\mathrm{bc}}$ & $8.44^{\mathrm{bc}}$ & 1.40 & 1.87 \\
\hline ANOVA P-Value & 0.4881 & 0.0310 & 0.0269 & 0.0024 & 0.0636 & 0.9316 \\
\hline SEM $^{5}$ & 0.0091 & 0.0086 & 0.0086 & 0.1369 & 0.0159 & 1.1971 \\
\hline Fisher's LSD 6 & --- & 0.0244 & 0.0244 & 0.3858 & --- & --- \\
\hline $\begin{array}{l}\text { bird weight } \\
\text { eight gain } \\
\text { take } \\
\text { nnversion ratio corrected for mortality weight } \\
\text { d Error of the Mean } \\
\text { L Least Significant Difference } \\
\text { within a column not sharing a common superscript }\end{array}$ & 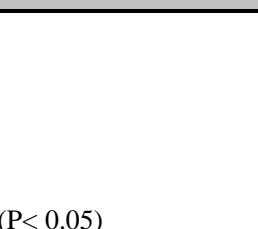 & & & & & \\
\hline
\end{tabular}


Table 6. Percent digestible amino acid ${ }^{1}$ for diets containing $0,6,11,16,21 \%$ algae, and a diet containing $0 \%$ algae with a green food coloring addition using Hubbard X Cobb 500 straight-run broiler ileal digestibility (Study 3)

\begin{tabular}{|c|c|c|c|c|c|c|c|c|c|c|c|c|}
\hline Treatment & $\begin{array}{c}\text { Aspartic } \\
\text { Acid } \\
(\%)\end{array}$ & $\begin{array}{c}\text { Threonine } \\
(\%)\end{array}$ & $\begin{array}{c}\text { Glutamic } \\
\text { Acid } \\
(\%)\end{array}$ & $\begin{array}{c}\text { Proline } \\
(\%)\end{array}$ & $\begin{array}{c}\text { Glycine } \\
(\%)\end{array}$ & $\begin{array}{c}\text { Alanine } \\
(\%)\end{array}$ & $\begin{array}{c}\text { Cysteine } \\
(\%)\end{array}$ & $\begin{array}{c}\text { Valine } \\
(\%)\end{array}$ & $\begin{array}{c}\text { Methionine } \\
(\%)\end{array}$ & $\begin{array}{c}\text { Isoleucine } \\
(\%)\end{array}$ & $\begin{array}{c}\text { Leucine } \\
(\%)\end{array}$ & $\begin{array}{c}\text { Lysine } \\
(\%)\end{array}$ \\
\hline $0 \%$ algae & $0.663^{\mathrm{bc}}$ & $0.391^{\mathrm{ab}}$ & $1.91^{\mathrm{b}}$ & $0.609^{b}$ & $0.425^{b}$ & $0.607^{\mathrm{bc}}$ & $0.164^{b}$ & $0.465^{\mathrm{ab}}$ & $0.375^{\circ}$ & 0.477 & $1.15^{b}$ & $0.97^{\circ 0}$ \\
\hline $6 \%$ algae & $0.695^{b}$ & $0.418^{a}$ & $2.07^{\mathrm{a}}$ & $0.704^{\mathrm{a}}$ & $0.547^{\mathrm{a}}$ & $0.664^{\mathrm{a}}$ & $0.159^{\circ}$ & $0.445^{b}$ & $0.416^{\mathrm{ab}}$ & 0.498 & $1.21^{\mathrm{a}}$ & $1.03^{\mathrm{b}}$ \\
\hline $11 \%$ algae & $0.602^{\text {bed }}$ & $0.390^{2 b}$ & $1.87^{b}$ & $0.640^{\mathrm{sb}}$ & $0.529^{\mathrm{a}}$ & $0.648^{\mathrm{ab}}$ & $0.167^{b}$ & $0.471^{\mathrm{ab}}$ & $0.418^{\mathrm{ab}}$ & 0.476 & $1.19^{\mathrm{a}}$ & $1.01^{\mathrm{bc}}$ \\
\hline $16 \%$ algae & $0.798^{\mathrm{a}}$ & $0.423^{\mathrm{a}}$ & $1.97^{\mathrm{ab}}$ & $0.700^{\mathrm{a}}$ & $0.544^{\mathrm{a}}$ & $0.672^{\mathrm{a}}$ & $0.195^{\mathrm{a}}$ & $0.486^{\mathrm{a}}$ & $0.421^{\mathrm{a}}$ & 0.486 & $1.20^{\mathrm{a}}$ & $1.07^{\mathrm{a}}$ \\
\hline $21 \%$ algae & $0.558^{\circ}$ & $0.359^{b}$ & $1.65^{\circ}$ & $0.522^{\circ}$ & $0.419^{b}$ & $0.593^{\circ}$ & $0.159^{b}$ & $0.414^{\circ}$ & $0.402^{b}$ & 0.453 & $1.14^{b}$ & $0.98^{\text {cd }}$ \\
\hline $\begin{array}{l}0 \% \text { algae }+ \text { green food } \\
\text { coloring }\end{array}$ & $0.595^{\text {cd }}$ & $0.388^{\mathrm{ab}}$ & $1.73^{\mathrm{e}}$ & $0.609^{b}$ & $0.400^{\mathrm{b}}$ & $0.596^{\mathrm{bc}}$ & $0.158^{\circ}$ & $0.413^{\mathrm{c}}$ & $0.381^{\circ}$ & 0.451 & $1.13^{\mathrm{b}}$ & $0.97^{\circ}$ \\
\hline ANOVA P-Value & $<0.0001$ & 0.0085 & $<0.0001$ & 0.0002 & $<0.0001$ & 0.0057 & 0.0254 & $<0.0001$ & $<0.0001$ & 0.0746 & $<0.0001$ & $<0.0001$ \\
\hline $\mathrm{SEM}^{2}$ & 0.0352 & 0.0127 & 0.0492 & 0.0293 & 0.0257 & 0.0189 & 0.0086 & 0.0107 & 0.0061 & 0.0128 & 0.0137 & 0.0139 \\
\hline Fisher's LSD ${ }^{3}$ & 0.0990 & 0.0359 & 0.1383 & 0.0825 & 0.0722 & 0.0532 & 0.0243 & 0.0302 & 0.0173 & $\ldots$ & 0.0387 & 0.0392 \\
\hline
\end{tabular}

${ }^{1}$ Pecent digestible amino acid refers to the percentage of digestible amino acid within the total amount of amino acid contained in the feed ${ }^{2}$ Standard Error of the Mean

${ }^{3}$ Fisher's Least Significant Difference

${ }^{\text {a-d }}$ Means within a column not sharing a common superscript differ $(\mathrm{P}<0.05)$ 
Manuscript submitted to Journal of Applied Poultry Research : The Effect of Poultry Litter Biochar Diet Inclusion on Feed Manufacture and Performance Variables in 4-21D Broilers

\author{
A.M. Evans ${ }^{*}$, S.A. Loop ${ }^{*}$, and J. S. Moritz ${ }^{* 1}$ \\ *Department of Animal and Nutritional Sciences, Davis College of Agriculture, \\ Natural Resources and Design, West Virginia University, Morgantown, WV 26506
}

Metabolism and Nutrition

${ }^{1}$ Corresponding author: jsmoritz@mail.wvu.edu

Primary Audience: Nutritionists, Researchers, Feed Mill Managers 
SUMMARY Decreasing diet cost and minimizing environmental impact are current issues that can affect the success of poultry production. In the eastern U.S., much concern has been generated surrounding eutrophication of the Chesapeake Bay from excess nitrogen and phosphorus. Gasification of poultry litter and feeding the resultant poultry litter biochar (PLB) may be an alternative to traditional land application of manure. In addition, PLB may provide a cost effective source of essential nutrients for poultry by the partial or complete replacement of rock phosphorus in poultry diets and may also provide a mechanism for improving feed manufacture variables. The objectives of this study were to assess effects of diet incorporation of PLB on feed manufacture and pellet quality (Experiment 1) and subsequent feeding effects on broiler performance and tibia ash (Experiment 2). Seven diets were formulated to compare the replacement of rock phosphorus with PLB. Inclusion of PLB was high, 6.2 or 6.9\%, in order to maximize rock phosphorus replacement but also to assess potential detriments. Four diets were chosen to generate replicated feed manufacture and pellet quality data. The addition of PLB to diets was shown to improve pellet quality at $6.9 \%(\mathrm{P}<0.05)$. Diets containing PLB decreased live weight gain (LWG) and feed conversion ratio (FCR), however some contribution to bone mineralization was demonstrated $(\mathrm{P}<0.0001)$. These results indicate that PLB contains aP and calcium, but the bioavailability of these minerals relative to rock phosphorus was not equivalent. Furthermore, the particular PLB tested decreased broiler performance.

Key words: gasification, poultry litter biochar, rock phosphorus, feed manufacture, broilers 


\section{DESCRIPTION OF THE PROBLEM}

Most broilers raised in the U.S. consume a corn-soybean based diet in which up to $70 \%$ of the ingredient phosphorus is present as phytate and largely unavailable to the bird [1]. In order to increase phytate phosphorus availability, exogenous phytase enzymes are utilized in diet formulations and rock phosphates are included to meet the remaining available phosphorus requirement. Rock phosphates, especially dicalcium phosphorus or tricalcium phosphorus-like products, are also utilized in diets to maintain high feed production rate due to perceived die scouring properties [2, 3]. Rock phosphates have also been shown to affect pellet mill production rate, electrical energy use of the pellet mill, and pellet quality; all of which are important economic factors associated with feed manufacture $[4,5,6]$. However, increasing the amount of rock phosphorus in the diet can be costly and does not address the potential negative environmental impact of land application of phosphorus rich litter [7, 8].

Gasification of poultry litter and utilizing the resultant PLB as a feed ingredient may be an alternative to rock phosphate ingredients. During the gasification process, poultry litter is subjected to temperatures greater than $400^{\circ} \mathrm{C}$ in an oxygen controlled environment producing PLB and syngas (which may be utilized to heat poultry houses) [9]. At these elevated temperatures, pathogens are destroyed and the majority of organic matter is consumed, leaving behind various minerals that may be available nutritionally. In addition to the possible nutritional benefits, PLB may have the potential to enhance feed manufacture similar to that of rock phosphorus. Even though PLB represents a potential replacement for rock phosphorus, limited research has been conducted on this 
product. Only three studies have been published assessing PLB and poultry feeding and all reported that this ingredient could be used as a phosphorus source without compromising performance $[10,11,12]$. The objectives of this study were to assess effects of diet incorporation of PLB on several manufacture and pellet quality (Experiment 1) and subsequent feeding effects on broiler performance and tibia ash (Experiment 2).

\section{MATERIALS AND METHODS}

\section{Experiment 1 - Feed Manufacture}

Prior to diet formulation, PLB samples were obtained and sent to a commercial laboratory in order to obtain proximate analysis values, mineral content, total phosphorus levels, and heavy metal content (Table 1) [13]. Seven dietary treatments, formulated to meet AgriStats recommendations [14], were manufactured at West Virginia University's Pilot Feed Mill (Table 3). The negative control (NC) and positive control (PC) diets were formulated to contain $0.23 \%$ and $0.45 \% \mathrm{aP}$ and $0.80 \%$ and $0.91 \%$ Ca, respectively. Additional standard diets (Diets 2 and 3) were created by mixing different ratios of the NC and PC diets. Sand was included in these diets in order to maintain similar ingredient inclusions among diets and to better assess the effects of the PLB incorporation per se. Diet 5 (PC with PLB) was formulated to be as similar as possible to the PC. The calculated aP and Ca levels in Diet 5 were $0.37 \%$ and $0.91 \%$, respectively. This dietary treatment was created through the substitution of limestone, salt, tricalcium phosphorus and the majority of sand with PLB. Diet 6 (COM) was formulated as a more commercial 
type diet with a decreased amount of fat, no sand, and phytase. Diet 7 (COM with PLB) was formulated to be similar to the COM treatment with PLB replacing limestone, salt, and tricalcium phosphorus. The calculated aP and Ca levels in Diet 7 were $0.45 \%$ and 0.91\%, respectively. The NC, Diet 2, and Diet 3 were pelleted and ground (feed manufacture was not replicated with these treatments). The PC and Diets 5, 6, and 7 were pelleted each day for four days in order to obtain replicated feed manufacture and pellet quality data. Diets were steam conditioned at $77^{\circ} \mathrm{C}$ and pellets were formed utilizing a California Pellet Mill [15] equipped with a 38mm X 4.8mm die with a production rate of approximately 1.2 tonne per hour. The pilot pellet mill is rated for one tonne per hour, thus we exceeded capacity to mimic production practices of many commercial feed mills. Pellet durability index (PDI) and modified pellet durability index (MPDI) were performed on all replicated treatments one day post-pelleting [16]. Cool pellet samples were taken at the feed surge bin and dry matter analyses were performed. Feed manufacture variables measured included conditioner and pellet mill relative electrical energy usage, production rate, and bulk density (Table 4). Pelleted feed was ground via a roller mill prior to bird feeding in order to eliminate potentially confounding feed form effects $[17,18]$. Calcium and non-phytate phosphorus (nPP) analyses were conducted on amalgamated, cool pellet samples of each treatment [13].

\section{Experiment 2 - Live Bird Performance}

A total of 700 male and 700 female, Cobb 500 chicks [19] were obtained from a commercial hatchery at hatch [20] and placed on a three day NC pretest. Six hundred sixteen males and 616 females were selected based on weight to create uniformity in 
initial pen weight. Weighing occurred on day three and groups of 11 males and 11 females were randomly allotted to one of 56 floor pens $[0.69 \times 2.44 \mathrm{~m}(2.26 \times 8.00 \mathrm{ft})]$ located in two rooms joined by a woven wire barrier that allowed heat and ventilation to move freely between rooms. Rooms were located in a cross-ventilated negative-pressure house with forced-air brooders. Temperature during week one was held at approximately $35^{\circ} \mathrm{C}$, and decreased gradually to approximately $29^{\circ} \mathrm{C}$. Broilers were placed at a stocking density of 22 birds/pen [0.065 m²/bird $\left.\left(0.70 \mathrm{ft}^{2} / \mathrm{bird}\right)\right]$ and were provided with feed and water, supplied through Kuhl feed pans adapted to hoppers and Ziggity nipple drinkers, for ad libitum consumption [21, 22]. Broilers received 24h of light for the first week and were then reduced to $20 \mathrm{~h}$ of light per day for the remaining two weeks. On d21, birds were weighed on a per pen basis and five birds were selected from each pen within the range of 100 grams plus or minus the mean pen weight, regardless of sex. Broilers were then killed via cervical dislocation and left tibiae were excised in order to determine bone mineralization [23]. Feed intake (FI), LWG, FCR, and tibia ash percentage were calculated for the 4-21d experimental period (Table 5). All animals were reared according to protocols established by the West Virginia University Animal Care and Use Committee.

Statistical Analysis

Analyses were completed using GLM ANOVA procedure from the SAS Institute [24] and when significant differences were detected, treatment means were separated and compared using Fisher’s Least Significant Difference. Means were considered significantly different at $\alpha \leq 0.05$. 


\section{RESULTS AND DISCUSSION}

\section{Experiment 1 - Feed Manufacture}

Feed manufacture results are presented in Table 4. The PC with PLB treatment (Diet 5) demonstrated similar pellet mill relative electrical energy usage to the PC and both of these treatments demonstrated decreased energy usage when compared to the COM (Diet 6) and COM with PLB (Diet 7) $(\mathrm{P}=0.0018)$. The decrease in energy usage for the PC and PC with PLB treatments was likely due to their 3.96\% inclusion of fat compared to $0.88 \%$ and $2.55 \%$ in the COM and COM with PLB treatments, respectively [25]. Gehring and coauthors demonstrated that increasing mixer added fat from 1 to $4 \%$ of the diet reduced pellet mill relative electrical energy usage by $2.97 \mathrm{~kW} \cdot \mathrm{h} /$ metric ton [26]. The high fat inclusion in the standard curve diets was necessary in order to use sand to isolate PLB effects without changing other ingredient inclusions in Diet 5. The addition of PLB to diets did not improve production rate $(\mathrm{P}>0.05)$. In fact, the $\mathrm{PC}$ with PLB (Diet 5) reduced production rate relative to the PC $(\mathrm{P}<0.05)$. The inclusion of PLB likely increased retention time in the pellet die and did not show die scouring properties similar to that of tricalcium phosphorus. The PDI and MPDI were improved for the PC with PLB (Diet 5) and COM with PLB (Diet 7) compared to PC (P = 0.0001) despite their high fat additions (3.96\%, Diet 5 and 2.55\%, Diet 7). This improvement may be due to increased retention time in the pellet die with the addition of PLB or from a binding effect as PLB was analyzed to contain approximately $11.8 \%$ crude protein. The crude protein of PLB was likely associated with an incomplete burn during gasification $[27,28,29]$. 


\section{Experiment 2 - Live Bird Performance}

Live bird performance results are presented in Table 5. Diets containing PLB demonstrated negative effects for all performance variables $(\mathrm{P}<0.0001)$. These results may be explained by possible arsenic contamination associated with the PLB. The PLB used in this study was derived from four cycles of built-up commercial broiler litter and upon analysis, the PLB was found to contain approximately 99 ppm of arsenic (Table 2). Past research has demonstrated a maximum tolerable level for chicks of $30 \mathrm{ppm}$ arsenic [30]. It is also speculated that diets containing PLB with increased levels of fat may have slowed down gut transit time, thus exacerbating any negative effects associated with PLB [31]. A similar mechanism may have been responsible for the performance difference between COM (Diet 6) and PC with the slowed passage rate benefiting nutrient digestion and absorption. Despite negative performance effects of PLB containing diets, some bone mineralization was demonstrated in that PC with PLB and COM with PLB had similar tibia ash percentages as Diet 3 of the standard curve $(\mathrm{P}<0.0001)$. The use of PLB as a replacement of P in poultry diets has been previously studied with turkeys [10] and broilers $[11,12]$. These authors concluded that PLB could be used as a replacement for rock phosphates without compromising bird growth or performance. Production of PLB, ingredient analysis, and dietary inclusion differed among these previous studies and the current study. Muir and others utilized a gasified PLB and included it in diet formulations up to 4.8\% [11], while Blake and Hess utilized fluidized PLB up to $3.2 \%$ of diet formulations [12]. Akpe and others did not provide diet formulations, however, did utilize a fluidized product [10]. The PLB used in previous research was analyzed for nutrient content; however, analysis did not include arsenic content. These differences in 
product production, dietary inclusion, and nutrient analysis could explain the performance differences observed in previous studies and the current study. The results of the current study indicate that PLB contains available phosphorus and calcium, but the bioavailability of these minerals relative to rock phosphorus is unclear due to the undefined anti-nutritional effects of this particular PLB.

\section{CONCLUSIONS AND APPLICATIONS}

1. For feed manufacture, PLB increased feed retention time in the pellet die and was unable to demonstrate die scouring properties similar to those of tricalcium phosphorus. However, inclusion of PLB significantly improved pellet quality perhaps due to increased retention time in the die or via a binding effect associated with the crude protein content of this particular PLB.

2. Poultry litter biochar demonstrated detrimental effects on live bird performance that may be due to possible arsenic contamination of the PLB. However, PLB phosphorus and calcium was shown to be partially available with respect to bone mineralization.

\section{REFERENCES AND NOTES}

1. Angel, R., and S. D. Dhanhu, T. J. Applegate, and M. Christman. 2001. Nonphytin phosphorus requirement of broilers fed a four-phytase feeding program. Pages 416-427 in Addressing Anim. Prod. Environ. Issues. Research Triangle Park, Durham, NC. 
2. Wamsley, K.G.S., K.G. Gehring, A. Corzo, E. A. Fontana, and J. S. Moritz. 2012. Effects of inorganic feed phosphate on feed quality and manufacturing efficiency. J. Appl. Poult. Res. 21:823 - 829.

3. Personal Communication; Eddy Fontana, Mosaic Company.

4. Behnke, K.C., 1981. Pellet mill performance as affected by mineral source. Feedstuffs. 53: 34-36.

5. Verner, W.A. 1988. Phosphates in pelleting: Best cost vs least cost. Feed Manage. 39: 56-58.

6. Lowe, R., and S. Zwart. 2007. Does the choice of feed phosphate affect pelleting behavior? Feed Compound. 27: 20-23.

7. Fritts, C.A. and P. Waldroup. 2006. Modified Phosphorus Program for Broilers Based on Commercial Feeding Intervals to Sustain Live Performance and Reduce Total and Water-Soluble Phosphorus in Litter. J. Appl. Poult. Sci . 15:207-218.

8. Waldroup, P.W. , J.H. Kersey, E.A. Saleh, C.A. Fritts, F. Yan, H.L. Stilborn, R.C. Crum Jr, and V. Raboy. 2000. Nonphytate phosphorus requirement and phosphorus excretion of broiler chicks fed diets composed of normal or high available phosphate corn with and without microbial phytase. Poult. Sci.79:14511459.

9. Zublena, J.P., J. C. Barker, and T. A. Carter. 1997. Poultry Manure as a Fertilizer Source. North Carolina Cooperative Extension Service. 2010. $<$ http://www.soil.ncsu.edu/publications/Soilfacts/AG-439-05/>.

10. Apke, M.P., P.E. Waibel, and R.V. Morey. 1984. Bioavailability of phosphorus in poultry litter biomass ash residues for turkeys. Poult. Sci. 63: 2100-2102.

11. Muir, F., R.M. Leach Jr., and B.S. Heinrichs. 1990. Bioavailability of phosphorus from broiler litter ash for chicks. Poult. Sci. 69: 1845-1850.

12. Blake, J.P., and J.B. Hess. 2014. Poultry litter ash as a replacement for dicalcium phosphate in broiler diets. J. Appl. Poult. Res. 23: 101-107.

13. New Jersey Feed Lab Inc, Trenton, NJ.

14. California Pellet Mills Inc., Crawfordsville, IN.

15. Agri Stats Inc., Fort Wayne, IN, 46825

16. American Society for Agricultural Engineers, 1983. Methods for determining and expressing fineness of feed materials by sieving. Page 325 in American Society of Agricultural Engineers Standard S 319. Am. Soc. Agric. Eng. Yearbook

Standards, Am. Soc. Am. Eng., St. Joseph, MI. Pellet durability index was determined by sifting $500 \mathrm{~g}$ of pellets from a treatment through a No. 6 American Society for Testing and Materials (ASTM) screen before being deposited into a Pfost tumbler. The sifted pellets were then tumbled in the container, dimensions 5 $\times 12 \times 12$ in., with a $2 \times 9$ in. plate fixed diagonally along the $12 \times 12$ in. side, for approximately $10 \mathrm{~min}$ at $50 \mathrm{rpm}$. The sample was then sifted again through the No. 6 (ASTM) mm screen, weighed, and the percentage of pellets was calculated by dividing the weight of pellets after tumbling by the weight of pellets before tumbling and then multiplying that value by 100 . Modified pellet durability index was similarly measured, with the exception of the addition of five, 13-mm 
hexagonal bolts to the $500 \mathrm{~g}$ of sample in the tumbler. Both analyses are meant to simulate the deleterious effects of transferring and handling the pellets.

17. Cutlip, S. E., Hott, J. M., Buchanan, N. P., Rack, A. L., Latshaw, J. D., and Moritz, J. S. 2008. The effect of steam-conditioning practices on pellet quality and growing broiler nutritional value. J. Appl. Poult. Res. 17:249-261.

18. W. A. Dozier, III, K. C. Behnke, C. K. Gehring and S. L. Branton. 2010. Effects of feed form on growth performance and processing yields of broiler chickens during a 42-day production period. J. Appl. Poult. Res. 19:219-226.

19. Cobb-Vantress, Siloam Springs, AR

20. Matterns Hatchery, Beaver Springs, PA

21. Kuhl Corporation, Flemington, NJ.

22. Ziggity Systems Inc., Middlebury, IN.

23. Tibiae were placed in a soxhlet apparatus with petroleum ether for 16 hours. All fat-extracted bones were ashed in a $600^{\circ} \mathrm{C}$ ashing oven for 18 hours.

24. SAS Institute. 2008. The SAS System for Windows. Cary, IN.

25. Firman, J.D., A. Kamyab and H. Leigh. 2008. Comparison of Fat Sources in Rations of Broilers from Hatch to Market. International Journal of Poultry Science 12: 1152-1155.

26. Gehring, C.K, Lilly, K.G.S., Shires, L.K., Beaman, K.R., Loop, S.A., Moritz, J.S., Increasing mixer-added fat reduces the electrical energy required for pelleting and improves exogenous enzyme efficacy for broilers. 2011. J. Appl. Poult. Res. 2011 20: 75-89.

27. Akpe, M.P., P.E. Waibel, and R.V. Morey. 1984. Bioavailability of phosphorus in poultry litter biomass ash residue for turkeys. Poult. Sci. 63:2100-2102.

28. International Biochar Initiative. Practitioners Profile: Using Chicken Litter for Biochar. 2009. <http://www.biochar-international.org/Frye/Poultry>.

29. Personal Communication; Johannes Lehmann, Cornell University.

30. Merck Veterinary Manual. 2008.

31. Golian, A. and D.V. Maurice. 1992. Dietary poultry fat and gastrointestinal transit time of feed and fat utilization in broiler chickens. Poult. Sci. 71: 1357-1363. 
Table 1. Proximate analysis values, mineral content, and heavy metal composition of PLB derived from built-up broiler litter.

\begin{tabular}{|cc|}
\hline Nutrient $^{1}$ & Value \\
\hline Moisture & $2.16 \%$ \\
\hline Crude Protein & $11.40 \%$ \\
\hline Crude Fat & $0.23 \%$ \\
\hline Crude Fiber & $11.60 \%$ \\
\hline Calcium & $9.12 \%$ \\
\hline Phosphorus & $5.52 \%$ \\
\hline Sodium & $2.64 \%$ \\
\hline Non-phytate phosphorus ${ }^{2}$ & $2.80 \%$ \\
\hline Aluminum & $1.2 \%$ \\
\hline Arsenic & $99 \mathrm{ppm}$ \\
\hline Nickel & $48 \mathrm{ppm}$ \\
\hline Chromium & $29 \mathrm{ppm}$ \\
\hline Cobalt & $5 \mathrm{ppm}$ \\
\hline Lead & $2 \mathrm{ppm}$ \\
\hline Cadmium & $0.4 \mathrm{ppm}$ \\
\hline
\end{tabular}

${ }^{1}$ New Jersey Feed Labs, Inc. Trenton, NJ.

${ }^{2} \mathrm{nPP}=$ Total Phosphorus $-(0.282 \mathrm{X}$ Total Phytic Acid $)$ 
Table 2. Ingredient and calculated nutrient composition of diets provided to Cobb $\mathbf{x}$ Cobb 500 broilers from 4-21 d of age.

\begin{tabular}{|c|c|c|c|c|c|}
\hline Ingredient & $\begin{array}{l}\text { Diet } 1 \\
\text { (NC) }\end{array}$ & $\begin{array}{c}\text { Diet } 4 \\
\text { (PC) }\end{array}$ & $\begin{array}{c}\text { Diet } 5 \\
\text { (PC w/ PLB) } \\
\end{array}$ & $\begin{array}{c}\text { Diet } 6 \\
(\mathrm{COM}) \\
\end{array}$ & $\begin{array}{c}\text { Diet } 7 \\
\text { (COM w/ PLB) } \\
\end{array}$ \\
\hline & $\%$ & $\%$ & $\%$ & $\%$ & $\%$ \\
\hline Corn & 51.46 & 51.46 & 51.47 & 63.09 & 58.19 \\
\hline Soybean Meal & 31.56 & 31.56 & 31.56 & 29.49 & 28.71 \\
\hline Soybean Oil & 3.96 & 3.96 & 3.96 & 0.88 & 2.55 \\
\hline MBM & 3.00 & 3.00 & 3.00 & 3.00 & 3.00 \\
\hline Limestone & 1.29 & 1.07 & --- & 1.33 & 0.20 \\
\hline Salt & 0.39 & 0.26 & --- & 0.32 & 0.001 \\
\hline Methionine & 0.36 & 0.36 & 0.36 & 0.34 & 0.37 \\
\hline $\mathrm{NB}^{3000^{\mathrm{a}}}$ & 0.25 & 0.25 & 0.25 & 0.25 & 0.25 \\
\hline Lysine & 0.17 & 0.17 & 0.17 & 0.21 & 0.26 \\
\hline Threonine & 0.15 & 0.15 & 0.15 & 0.15 & 0.18 \\
\hline Tricalcium Phosphorus & 0.25 & 1.30 & --- & 0.80 & --- \\
\hline Coban ${ }^{b}$ & 0.08 & 0.08 & 0.08 & 0.08 & 0.08 \\
\hline BMD $^{c}$ & 0.05 & 0.05 & 0.05 & 0.05 & 0.05 \\
\hline Sand & 7.04 & 6.33 & 2.07 & --- & --- \\
\hline PLB & --- & --- & 6.89 & --- & 6.16 \\
\hline Phytase $^{d}$ (mixer added) & --- & --- & --- & 0.01 & 0.01 \\
\hline \multicolumn{6}{|c|}{ Calculated Nutrient Analysis } \\
\hline ME (kcal/kg) & 1394 & 1394 & 1394 & 1394 & 1394 \\
\hline CP (\%) & 21.94 & 21.94 & 22.73 & 21.94 & 21.94 \\
\hline Lysine (\%) & 1.28 & 1.28 & 1.28 & 1.28 & 1.28 \\
\hline Meth+Cys (\%) & 0.98 & 0.98 & 0.98 & 0.98 & 0.98 \\
\hline Calcium (\%) & 0.80 & 0.91 & 0.91 & 0.91 & 0.91 \\
\hline Available Phosphorus (\%) & 0.23 & 0.45 & 0.37 & 0.45 & 0.45 \\
\hline
\end{tabular}

${ }^{\text {A }}$ Supplied per kg of diet: manganese, $0.02 \%$; zinc $0.02 \%$; iron, $0.01 \%$; copper, $0.0025 \%$; iodine, $0.0003 \%$; selenium, $0.00003 \%$; folic acid, $0.69 \mathrm{mg}$; choline, $386 \mathrm{mg}$ ' riboflavin, 6.61mg; biotin, $0.03 \mathrm{mg}$; vitamin $\mathrm{B}_{6}, 1.38 \mathrm{mg}$; niacin, $27.56 \mathrm{mg}$; pantothenic acid, 6.61mg; thiamine, 2.20mg; manadione, 0.83mg; vitamin $\mathrm{B}_{12}, 0.01 \mathrm{mg}$; vitamin E, $16.53 \mathrm{IU}$; vitamin $\mathrm{D}_{3}, 2133 \mathrm{ICU}$; vitamin $\mathrm{A}, 7716 \mathrm{IU}$.

${ }^{B}$ Active drug ingredient Monensin Sodium $60 \mathrm{gpb}$ (90 g/ton inclusion), Elanco Animal Health, Indianapolis, IN. As an aid in the prevention of coccidiosis caused by Eimeria necarix, Eimeria tenella, Eimeria acervulina, Eimeria brunette, Eimeriamivati, and Eimeria maxima.

${ }^{C}$ Bacitracin Methylene Disalicylate $50 \mathrm{~g} / \mathrm{lb}$ (50 g/ton inclusion), Alpharma, Fort Lee, NJ. For increased rate of weight gain and improved feed efficiency. ${ }^{\mathrm{D}}$ Phytase (Optiphos, JBS United Inc., Sheridan, IN). 
Table 3. Effects on feed manufacture variables when PC (Diet 4), PC with PLB (Diet 5), COM (Diet 6), and COM with PLB (Diet 7) were pelleted.

\begin{tabular}{|c|c|c|c|c|c|c|}
\hline Treatment $^{1}$ & $\begin{array}{c}\text { Production } \\
\text { Rate } \\
\text { (tonne/hour) }\end{array}$ & $\begin{array}{c}\text { Conditioner } \\
\text { Relative Electrical } \\
\text { Energy Usage } \\
\text { (KWH/tonne) } \\
\end{array}$ & $\begin{array}{c}\text { Pellet Mill Relative } \\
\text { Electrical Energy } \\
\text { Usage } \\
\text { (KWH/tonne) } \\
\end{array}$ & $\begin{array}{c}\text { PDI }^{2} \\
(\%)\end{array}$ & $\begin{array}{c}\text { MPDI }^{3} \\
(\%)\end{array}$ & $\begin{array}{c}\text { Bulk } \\
\text { Density }\end{array}$ \\
\hline PC (Diet 4) & $1.18^{\mathrm{a}}$ & 0.761 & $6.58^{\mathrm{b}}$ & $51.07^{\mathrm{C}}$ & $23.88^{\mathrm{C}}$ & 40.32 \\
\hline PC with PLB (Diet 5) & $1.13^{\mathrm{b}}$ & 0.786 & $7.26^{\mathrm{b}}$ & $67.72^{\mathrm{b}}$ & $42.18^{\mathrm{b}}$ & 40.07 \\
\hline COM (Diet 6) & $1.14^{\mathrm{ab}}$ & 0.718 & $8.34^{\mathrm{a}}$ & $86.52^{\mathrm{a}}$ & $77.85^{\mathrm{a}}$ & 38.88 \\
\hline COM with PLB (Diet 7) & $1.11^{\mathrm{b}}$ & 0.734 & $8.86^{\mathrm{a}}$ & $88.38^{\mathrm{a}}$ & $81.00^{\mathrm{a}}$ & 40.33 \\
\hline ANOVA P-Value & 0.0319 & 0.3895 & 0.0018 & $<0.0001$ & $<0.0001$ & 0.0933 \\
\hline $\mathrm{LSD}^{4}$ & 0.0410 & -- & 0.9591 & 4.91 & 6.96 & -- \\
\hline SEM $^{5}$ & 0.013 & 0.028 & .300 & 1.53 & 2.18 & 0.128 \\
\hline
\end{tabular}

${ }^{\mathrm{a}-\mathrm{e}}$ Means within a column without a common superscript differ significantly $(\mathrm{P} \leq 0.05)$.

${ }^{1}$ Treatments were replicated over a period of four days in order to obtain four replications.

${ }^{2}$ Pellet Durability Index

${ }^{3}$ Modified Pellet Durability Index

${ }^{4}$ Fisher's Least Significant Difference

${ }^{5}$ Pooled Standard Error $(n=4)$. 
Table 4. Effects on performance variables for 4-21 day broilers when fed NC (Diet 1), Diet 2, Diet 3, PC (Diet 4), PC with PLB (Diet 5), COM (Diet 6), or COM with PLB (Diet 7).

\begin{tabular}{cccccc} 
Treatment $^{\mathbf{1}}$ & $\begin{array}{c}\text { FI } \\
\text { Kg/pen }\end{array}$ & $\begin{array}{c}\text { LWG } \\
\text { Kg/bird }\end{array}$ & $\begin{array}{c}\text { FCR } \\
\text { Kg:kg }\end{array}$ & $\begin{array}{c}\text { Mortality } \\
\mathbf{( \% )}\end{array}$ & $\begin{array}{c}\text { Tibia Ash } \\
\text { Percentage } \\
\mathbf{( \% )}\end{array}$ \\
\hline NC (Diet 1) & $17.77^{\mathrm{c}}$ & $0.509^{\mathrm{d}}$ & $1.59^{\mathrm{c}}$ & 0.568 & $28.69^{\mathrm{d}}$ \\
Diet 2 & $19.47^{\mathrm{b}}$ & $0.564^{\mathrm{c}}$ & $1.59^{\mathrm{c}}$ & 2.27 & $29.59^{\mathrm{d}}$ \\
Diet 3 & $21.58^{\mathrm{a}}$ & $0.613^{\mathrm{b}}$ & $1.61^{\mathrm{c}}$ & 0.568 & $35.04^{\mathrm{bc}}$ \\
\hline PC (Diet 4) & $22.14^{\mathrm{a}}$ & $0.657^{\mathrm{a}}$ & $1.54^{\mathrm{c}}$ & 0.568 & $37.73^{\mathrm{a}}$ \\
\hline PC with PLB (Diet 5) & $17.72^{\mathrm{c}}$ & $0.460^{\mathrm{e}}$ & $1.78^{\mathrm{a}}$ & 1.705 & $33.71^{\mathrm{c}}$ \\
\hline COM (Diet 6) & $20.05^{\mathrm{b}}$ & $0.545^{\mathrm{c}}$ & $1.69^{\mathrm{b}}$ & 0.568 & $36.68^{\mathrm{ab}}$ \\
\hline COM with PLB (Diet 7) & $19.16^{\mathrm{b}}$ & $0.499^{\mathrm{d}}$ & $1.76^{\mathrm{ab}}$ & 1.136 & $34.12^{\mathrm{c}}$ \\
\hline ANOVA P-Value $^{\mathrm{b}}$ & $<\mathbf{0 . 0 0 0 1}$ & $<\mathbf{0 . 0 0 0 1}$ & $<\mathbf{0 . 0 0 0 1}$ & 0.5034 & $<\mathbf{0 . 0 0 0 1}$ \\
\hline LSD $^{\mathbf{1}}$ & 1.05 & 0.031 & -- & -- & 1.790 \\
\hline SEM $^{2}$ & 0.366 & 0.011 & 0.027 & 0.840 & 0.627 \\
\hline
\end{tabular}

${ }^{\mathrm{a}-\mathrm{e}}$ Means within a column without a common superscript differ significantly $(\mathrm{P} \leq 0.05)$.

${ }^{1}$ Fisher's Least Significant Difference

${ }^{2}$ Pooled Standard Error $(\mathrm{n}=8)$ 
Manuscript prepared for Journal of Applied Poultry Research: The Effect of Poultry Litter Biochar on Pellet Quality, 1-21D Broiler Performance, and Digesta Viscosity

A.M. Evans ${ }^{*}$ and J.S. Moritz ${ }^{* 1}$
*Division of Animal and Nutritional Sciences, West Virginia University, Morgantown,
West Virginia, 26506-6108
Phone: $304-293-1911$

Fax: 304-293-2232

Metabolism and Nutrition

${ }^{1}$ Corresponding Author: Joe.Moritz@mail.wvu.edu

Primary Audience: Researchers, Nutritionists, Feed Mill Managers 
SUMMARY Current issues that affect the success of poultry production include decreasing diet cost and minimizing environmental impact. Gasification of poultry litter and feeding the resultant poultry litter biochar (PLB) may be one alternative to traditional land application of manure. This PLB may also provide a cost effective source of essential nutrients for poultry by the partial replacement of rock phosphorus in diet formulation as well as improve feed manufacture. Past research has suggested PLB improved pellet quality but decreased broiler performance due to potential digesta viscosity challenges and heavy metal adulteration. The objectives of this study were to assess a low arsenic PLB on descriptive feed manufacture in Experiment 1, as well as broiler performance and digesta viscosity in Experiment 2. Treatments were arranged in a 4 (Diet Formulation) X 2 (Phytase Inclusion) factorial design. The four dietary treatments consisted of a positive control (PC) formulated to $0.45 \%$ non-phytate phosphorus (nPP), a negative control (NC) formulated to $0.23 \%$ nPP, 2\% PLB, and 4\% PLB. Diets containing PLB (with or without phytase) demonstrated numerical improvement in pellet quality. Multiple comparison of treatment means revealed that diets containing PLB with phytase resulted in similar feed intake (FI), ending bird weight (EBW), live weight gain (LWG), and feed conversion ratio corrected for mortality weight (FCR), and mortality percentage compared to the PC $(\mathrm{P}<0.0001)$. Diet Formulation x Phytase interactions were observed for EBW, LWG, FI, and mortality percentage. These interactions demonstrated lowered performance for birds fed the NC diet without phytase and improved performance with this diet supplemented with phytase. No differences were observed for digesta viscosity measurements $(\mathrm{P}>0.05)$. 
These data demonstrate improved pellet quality and bird performance with diets containing PLB and phytase that suggest PLB can partially replace rock phosphorus in diet formulations.

Key words: gasification, poultry litter biochar, rock phosphorus, feed manufacture, broiler, viscosity

\section{DESCRIPTION OF THE PROBLEM}

The majority of U.S. raised broilers consume a corn-soybean based diet with approximately $2 / 3$ of the phosphorus being present as unavailable phytate bound

phosphorus [1]. Rock phosphorus is typically added to broiler diet formulations to increase dietary available phosphorus. However, high amounts of dietary rock phosphorus can be costly and does not address the environmental impact of litter phosphorus [2, 3]. Phytases can be added to diets to improve plant phosphorus digestibility and reduce environmental impact, but rock phosphorus sources, particularly tricalcium phosphorus, are still incorporated to increase pellet mill production rate [4, 5], electrical energy use of the pellet mill, and pellet quality [6, 7, 8]; all of which are important economic factors associated with feed manufacture.

One alternative to rock phosphorus sources is poultry litter biochar, or PLB. This product is created through gasification of poultry litter. During gasification, poultry litter is subjected to pyrolysis, where temperatures reach $400^{\circ} \mathrm{C}$ and higher in an oxygen controlled environment [9]. In this process, pathogens are destroyed and organic matter is consumed, leaving behind an ash containing minerals that may be available nutritionally, specifically phosphorus that can be liberated from a phytate molecule under 
these high temperatures. O’Dell reported approximately $88 \%$ of phytate in soybean meal could be degraded at $115^{\circ} \mathrm{C}$ [10]. In addition to the possible nutritional benefits, PLB may have the potential to enhance feed manufacture similar to that of rock phosphorus. In a previous study, PLB addition to diets demonstrated improved pellet quality; however, broiler performance upon feeding was not maximized, though some contribution to bone mineralization was observed [11]. The authors speculated that performance detriments may have been a result of arsenic contamination of the PLB or detrimental effects of PLB on digesta viscosity. The objectives of the current study were to obtain a PLB product with a lower arsenic content and assess its effects on descriptive feed manufacture in Experiment 1, as well as broiler performance and digesta viscosity in Experiment 2.

\section{MATERIALS AND METHODS}

\section{Experiment 1 - Feed Manufacture}

Prior to diet formulation, PLB samples were obtained and sent to a commercial laboratory to determine proximate analysis and mineral content (Table 1) [12]. This experiment was conducted at West Virginia University’s pilot feed mill using a 4 Diet Formulation X 2 Phytase (included or not) factorial design. The four levels of Diet Formulation were: NC (formulated with $0.23 \% \mathrm{nPP}$ ), PC (formulated with $0.45 \% \mathrm{nPP}$ ), 2\% PLB (0.45\% nPP), and 4\% PLB (0.45\% nPP). Batching was accomplished by creating $544.5 \mathrm{~kg}$ allotments of each diet formulation (without phytase) that were mixed for ten minutes dry, and an additional ten minutes post fat addition using a single screw 
vertical mixer. Each batch of feed was split into two equal aliquots $(272.25 \mathrm{~kg})$ with one aliquot receiving the addition of phytase [13]. Prior to pelleting, $4.5 \mathrm{~kg}$ of mash from each aliquot receiving phytase were mixed for 10 minutes using a small paddle mixer [14]. The $4.5 \mathrm{~kg}$ allotment was then placed back into the designated batch and mixed an additional twenty minutes prior to pelleting. This batching technique created a total of eight dietary treatments.

All batches of feed were passed through a $1.3 \mathrm{~m}$ long conditioner with a diameter of $0.31 \mathrm{~m}$ and $10 \mathrm{sec}$ retention time [15]. Treatments were steam conditioned at $82^{\circ} \mathrm{C}$ and pellets formed using a 40-horsepower California Pellet Mill equipped with a 38mm x 4.8mm pellet die [16]. Pellets were cooled with ambient air utilizing a horizontal belt cooler [17]. Once conditioning temperature reached a steady state during pelleting, mash samples were taken from the feed screw auger that conveys feed into the conditioner and corresponding pellet samples were taken from the cooler discharge. These samples were then analyzed for crude protein, calcium, total P, phytic acid, and phytase activity at a commercial laboratory [18]. In vitro phytase activity and retention were determined using the Association of Official Agricultural Chemists (AOAC) 2000.12 method [19]. The nPP values were calculated for all diets using the following equation: total $\mathrm{P}$ of feed - (0.282 X phytic acid of feed) [20]. A pelleted sample was collected directly from the pellet die and placed into an insulated container to determine hot pellet temperature; temperature measurements were obtained using a thermocouple thermometer [21] and an 80PK-24 temperature probe. Pellet durability index (PDI) and modified pellet durability index (MPDI) were performed using a Pfost tumbling box on all treatments one day after 
pelleting [22]. In addition, pellet durability was determined using a New Holmen Pellet Tester [23]. All batches of feed were ground with a roller-mill prior to feeding; particle size after grinding was performed to ensure feed form differences were eliminated [24, 25].

\section{Experiment 2 - Live Bird Performance}

A total of 1,472 1-d old straight-run Hubbard X Cobb 500 [26] broiler chicks were obtained from a commercial hatchery [27]. A total of 23 chicks were randomly allocated to one of 64 pens to create the experimental unit. Each of the dietary treatments were randomly assigned to pens blocked by location, creating a randomized complete block design. Feed and water were provided for ad libitum consumption. Measured variables for the 21d experimental period included: starting pen weight, EBW, LWG, FI, FCR, and mortality percentage. On day 21, all birds were killed via cervical dislocation. Birds were weighed by pen and ten birds were chosen in each pen whose weights were 100 grams \pm the pen mean weight. The left tibia was excised from all ten birds; the birds were then randomly allocated for lower ileum (five birds) and total GI tract collection (five birds). Contents of the entire GI tract were squeezed out by hand into a $50 \mathrm{~mL}$ centrifuge tube [28]. The digesta was centrifuged [29] at 12,700 RPM for 5 min at $4{ }^{\circ} \mathrm{C}$ [30]. A pipette was utilized to transport $1 \mathrm{~mL}$ of supernatant into a microcentrifuge tube. The microcentrifuge tube was placed in a $25^{\circ} \mathrm{C}$ water bath [31] for approximately $10 \mathrm{~min}$. After, $0.5 \mathrm{~mL}$ of supernatant was placed in a Brookfield Cone and Plate Viscometer [32] with a CPE-40 cone and a CPE-44Y cup. Measurements were taken at $30 \mathrm{sec}$ and $1 \mathrm{~min}$ at both speeds of 10 and 20 RPM. Similar methodologies were utilized by Lee and 
coauthors [33]. All animals were reared according to protocols established by the West Virginia University Animal Care and Use Committee [ACUC 12-0408].

\section{Statistical analysis}

Diet Formulation x Phytase factorial analyses were performed to explore main effects and interactions. Multiple comparisons were also performed with all treatment means using Fisher's least significant difference test. All data were statistically analyzed using the GLM procedure of Statistical Analysis System [34]. Alpha was designated as 0.05 , and letter superscripts were used to denote differences among treatment means. Variables measured included: EBW, LWG, FI, FCR, mortality percentage, and digesta viscosity.

\section{RESULTS AND DISCUSSION}

\section{Experiment 1 - Feed Manufacture}

The proximate analysis and mineral content of the PLB used in this study are

presented in Table 1. The authors were successful in obtaining a PLB product with a lower arsenic level (22 ppm) than the product used in previous research (99 ppm) [11]. Descriptive feed manufacture results are presented in Table 2. Production rate and hot pellet temperature were similar among treatments. The addition of PLB to diets without phytase at either 2 or $4 \%$ numerically increased pellet durability compared to the PC (63.3 and 68.0 vs 58.0\% PDI, respectively). When phytase was included in diet formulation, PDI was also increased for diets containing 2 or 4\% PLB compared to the 
PC (60.7 and 69.1 vs 55.4\% PDI, respectively). Similar results were observed for New Holmen Pellet Tester and MPDI.

\section{Experiment 2 - Live Bird Performance}

Live bird performance results are presented in Table 4. Multiple comparison of treatment means demonstrated significant differences for EBW, LWG, FI, mortality percentage, and FCR $(\mathrm{P}<0.0001)$. The NC diet without phytase supplementation resulted in the lowest EBW and LWG. Birds fed the PC (with or without phytase), NC with phytase, 2\% PLB with phytase, and 4\% PLB with phytase diets resulted in the greatest EBW and LWG. It should be noted that the phytase dose utilized was considered a super-dose and therefore could have enhanced performance by decreasing gut irritation of phytate phosphorus in addition to meeting phosphorus requirement. Birds fed the NC without phytase consumed the least amount of feed and demonstrated the highest mortality percentage, while all other treatments were similar. The NC without phytase treatment demonstrated the highest or worst FCR and supplementing diets containing PLB with phytase revealed an improvement to FCR to a similar level as PC (with or without phytase). Diet Formulation x Phytase interactions were observed for EBW, LWG, FI, and mortality percentage $(\mathrm{P}<0.0001)$. These interactions revealed that birds fed the NC diet without phytase demonstrated a decrease in performance and supplementing this diet formulation with phytase balanced the phosphorus deficiency and performance was improved. No differences were observed for digesta viscosity measurements $(\mathrm{P}>0.05)$. Increased digesta viscosity was speculated to be in part responsible for reduced broiler performance in a previous PLB experiment. Additional 
research had been conducted to assess PLB as a replacement for phosphorus in turkey [35] and broiler diets [36, 37]. While PLB production, nutrient content, and dietary inclusion differ among these studies and the current study, all agree that PLB can be used as a replacement for rock phosphorus without compromising bird performance. For the current study, bone mineralization and amino acid digestibility are presently being analyzed and may provide more evidence for PLB's use in broiler diet formulations. Performance and digesta viscosity suggest that diet formulations containing PLB and phytase can be used without causing a detriment to broiler performance.

The authors would like to thank Northeast SARE for providing funding for this study.

\section{CONCLUSIONS AND APPLICATIONS}

1) PLB numerically improved pellet quality compared to diets that did not contain PLB, regardless of phytase supplementation.

2) Diet formulations containing PLB and phytase demonstrated EBW, LWG, FI, mortality percentage, and FCR similar to the PC diet.

3) No differences were observed for digesta viscosity.

4) Diet formulations containing modest incorporations of PLB (2 and 4\%) and phytase can be used without detriment to broiler growth or performance. 


\section{REFERENCES AND NOTES}

1. Angel, R., and S. D. Dhanhu, T. J. Applegate, and M. Christman. 2001. Nonphytin phosphorus requirement of broilers fed a four-phytase feeding program. Pages 416-427 in Addressing Anim. Prod. Environ. Issues. Research Triangle Park, Durham, NC.

2. Fritts, C.A. and P. Waldroup. 2006. Modified Phosphorus Program for Broilers Based on Commercial Feeding Intervals to Sustain Live Performance and Reduce Total and Water-Soluble Phosphorus in Litter. J. Appl. Poult. Sci . 15:207-218.

3. Waldroup, P.W. , J.H. Kersey, E.A. Saleh, C.A. Fritts, F. Yan, H.L. Stilborn, R.C. Crum Jr, and V. Raboy. 2000. Nonphytate phosphorus requirement and phosphorus excretion of broiler chicks fed diets composed of normal or high available phosphate corn with and without microbial phytase. Poult. Sci.79:1451-1459.

4. Wamsley, K.G.S., K.G. Gehring, A. Corzo, E. A. Fontana, and J. S. Moritz. 2012. Effects of inorganic feed phosphate on feed quality and manufacturing efficiency. J. Appl. Poult. Res. 21:823 - 829.

5. Personal communication; Eddy Fontana, Mosaic Company.

6. Behnke, K.C., 1981. Pellet mill performance as affected by mineral source. Feedstuffs. 53: 34-36.

7. Verner, W.A. 1988. Phosphates in pelleting: Best cost vs least cost. Feed Manage. 39: 56-58.

8. Lowe, R., and S. Zwart. 2007. Does the choice of feed phosphate affect pelleting behavior? Feed Compound. 27: 20-23.

9. Zublena, J.P., J. C. Barker, and T. A. Carter. 1997. Poultry Manure as a Fertilizer Source. North Carolina Cooperative Extension Service. 2010. $<$ http://www.soil.ncsu.edu/publications/Soilfacts/AG-439-05/>.

10. O’Dell, B.L. 1962. Mineral availability and metal binding constituents of the diet. Proc. Cornell Nutr. Conf. Feed Manfact. P. 72.

11. Evans, A.M., S.A. Loop, and J.S. Moritz. The effect of poultry litter biochar diet inclusion on feed manufacture and performance variables in 4-21D broilers. (In Press).

12. New Jersey Feed Lab Inc., Trenton, NJ.

13. Ronozyme HiPhos, DSM, Augusta, GA.

14. Hobart paddle mixer (model 4146) Hobart Corp., Troy, OH.

15. A 4.25 feet length, 1.02 feet diameter short term California Pellet Mill conditioner (3 steam inlet ports), 429 rpm shaft speed; 21 picks; 10-s feed retention time.

16. Master Model Pellet Mill, California Pellet Mills Company, Crawfordsville, IN.

17. A 10 feet length horizontal belt cooler.

18. Eurofins Scientific, Des Moines, IA.

19. AOAC. 2000. Method 2000.12. Phytase activity in feed: colorimetric enzymatic method. In official methods of analysis of AOAC international. $17^{\text {th }}$ ed. Assoc. Off. Anal. Chem., Arlington VA. 
20. Jiang, S., Z. Jiang, G. Zhou, and Z. Chen. 2011. Non-phytate phosphorus requirements and efficacy of a genetically engineered yeast phytase in yellow broilers from 1 to 21 days of age. J. Anim. Phys. Anim. Nutr. 95: 47 - 55.

21. Fluke 51 II, Everette, WA.

22. American Society for Agricultural Engineers, 1983. Methods for determining and expressing fineness of feed materials by sieving. Page 325 in American Society of Agricultural Engineers Standard S 319. Am. Soc. Agric. Eng. Yearbook Standards, Am. Soc. Am. Eng., St. Joseph, MI. Pellet durability index was determined by sifting $500 \mathrm{~g}$ of pellets from a treatment through a No. 6 American Society for Testing and Materials (ASTM) screen before being deposited into a Pfost tumbler. The sifted pellets were then tumbled in the container, dimensions 5 $\times 12 \times 12$ in., with a $2 \times 9$ in. plate fixed diagonally along the $12 \times 12$ in. side, for approximately $10 \mathrm{~min}$ at $50 \mathrm{rpm}$. The sample was then sifted again through the No. 6 (ASTM) mm screen, weighed, and the percentage of pellets was calculated by dividing the weight of pellets after tumbling by the weight of pellets before tumbling and then multiplying that value by 100 . Modified pellet durability index was similarly measured, with the exception of the addition of five, 13-mm hexagonal bolts to the $500 \mathrm{~g}$ of sample in the tumbler. Both analyses are meant to simulate the deleterious effects of transferring and handling the pellets.

23. Pellet quality was assessed one day following production using the New Holmen NHP Portable Pellet Durability Tester, Lignotech USA, INC., Rothschild, WI. $100 \mathrm{~g}$ of pellets were places in the chamber, blown about for 60 seconds by a jet of air, then weighed, giving a direct read of pellet durability. Fines are removed during the blowing process.=

24. Cutlip, S. E., Hott, J. M., Buchanan, N. P., Rack, A. L., Latshaw, J. D., and Moritz, J. S. 2008. The effect of steam-conditioning practices on pellet quality and growing broiler nutritional value. J. Appl. Poult. Res. 17:249-261.

25. W. A. Dozier, III, K. C. Behnke, C. K. Gehring and S. L. Branton. 2010. Effects of feed form on growth performance and processing yields of broiler chickens during a 42-day production period. J. Appl. Poult. Res. 19:219-226.

26. Cobb-Vantress, Siloam Springs, AR. 2008.

27. Pilgrim's Pride Hatchery, Moorefield, WV.

28. Fisher Scientific, Fairlawn, NJ

29. Sorvall Evolution RC Centrifuge, Asheville, NC

30. Bedford, M. R. and H. L. Classen. 1992. Reduction of intestinal viscosity through manipulation of dietary rye and pentosanase concentration is effected through changes in the carbohydrate composition of the intestinal aqueous phase and results in improved growth rate and food conversion efficiency in broiler chicks. The Journal of Nutrition 122, no. 3: 560

31. TC-602 Refrigerated Bath, Brookfield Engineering Laboratories Inc., Middleboro, MA

32. Brookfield LVDV-II+Pro Viscometer, Brookfield Engineering Laboratories Inc., Middleboro, MA. 
33. Lee, J. T., C. A. Bailey, and A. L. Cartwright. 2003. Guar meal germ and hull fractions differently affect growth performance and intestinal viscosity of broiler chickens. Poultry Science 82:1589-1595.

34. SAS Institute. 2014. The SAS System for Windows 2000. Release 8.1. SAS Inst. Inc., Cary, NC.

35. Apke, M.P., P.E. Waibel, and R.V. Morey. 1984. Bioavailability of phosphorus in poultry litter biomass ash residues for turkeys. Poult. Sci. 63: 2100-2102.

36. Muir, F., R.M. Leach Jr., and B.S. Heinrichs. 1990. Bioavailability of phosphorus from broiler litter ash for chicks. Poult. Sci. 69: 1845-1850.

37. Blake, J.P., and J.B. Hess. 2014. Poultry litter ash as a replacement for dicalcium phosphate in broiler diets. J. Appl. Poult. Res. 23: 101-107. 
Table 1. Proximate analysis values, mineral content, and heavy metal composition of PLB derived from built-up broiler litter.

\begin{tabular}{cc}
\hline Nutrient $^{1}$ & Value \\
\hline Moisture & $2.16 \%$ \\
\hline Crude Protein & $14.40 \%$ \\
\hline Crude Fat & $0.40 \%$ \\
\hline Calcium & $9.12 \%$ \\
\hline Phosphorus & $3.04 \%$ \\
\hline Sodium & $1.98 \%$ \\
\hline Non-phytate phosphorus ${ }^{2}$ & $2.90 \%$ \\
\hline Arsenic & $22 \mathrm{ppm}$ \\
\hline Nickel & $31 \mathrm{ppm}$ \\
\hline Chromium & $27 \mathrm{ppm}$ \\
\hline
\end{tabular}

${ }^{1}$ New Jersey Feed Labs, Inc. Trenton, NJ.

${ }^{2} \mathrm{nPP}=$ Total Phosphorus - (0.282 X Total Phytic Acid $)$ 
Table 2. Ingredient and calculated nutrient composition of diets provided to Cobb $x$ Cobb 500 broilers from 1-21 d of age.

\begin{tabular}{|c|c|c|c|c|}
\hline Ingredient & NC & PC & $2 \%$ PLB & 4\% PLB \\
\hline & $\%$ & $\%$ & $\%$ & $\%$ \\
\hline Corn & 54.57 & 54.57 & 54.57 & 54.57 \\
\hline Soybean Meal & 32.06 & 32.06 & 32.06 & 32.06 \\
\hline Animal and Vegetable Blend & 3.96 & 3.96 & 3.96 & 3.96 \\
\hline MBM & 2.50 & 2.50 & 2.50 & 2.50 \\
\hline Limestone & 1.28 & 1.04 & 0.97 & 0.89 \\
\hline Salt & 0.29 & 0.29 & 0.29 & 0.20 \\
\hline Methionine & 0.36 & 0.36 & 0.36 & 0.36 \\
\hline $\mathrm{NB}^{3000^{\mathrm{a}}}$ & 0.25 & 0.25 & 0.25 & 0.25 \\
\hline Lysine & 0.23 & 0.23 & 0.23 & 0.23 \\
\hline Threonine & 0.11 & 0.11 & 0.11 & 0.11 \\
\hline Dicalcium Phosphorus & 0.02 & 1.21 & 0.90 & 0.58 \\
\hline Coban ${ }^{b}$ & 0.05 & 0.05 & 0.05 & 0.05 \\
\hline $\mathbf{B M D}^{\mathrm{c}}$ & 0.08 & 0.08 & 0.08 & 0.08 \\
\hline Sand & 4.04 & 3.09 & 1.57 & --- \\
\hline PLB & --- & --- & 2.00 & 4.00 \\
\hline
\end{tabular}

\begin{tabular}{|ccccc|}
\hline & Calculated Nutrient Analysis & & \\
\hline ME (kcal/kg) & 1375 & 1375 & 1375 & 1375 \\
\hline CP (\%) & 21.46 & 21.46 & 21.75 & 22.04 \\
\hline Lysine (\%) & 1.18 & 1.18 & 1.18 & 1.18 \\
\hline Meth+Cys (\%) & 0.90 & 0.90 & 0.90 & 0.90 \\
\hline Calcium (\%) & 0.96 & 0.96 & 0.96 & 0.96 \\
\hline Available Phosphorus (\%) & 0.23 & 0.45 & 0.45 & 0.45 \\
\hline
\end{tabular}

${ }^{\text {A }}$ Supplied per kg of diet: manganese, 0.02\%; zinc 0.02\%; iron, 0.01\%; copper, 0.0025\%; iodine, 0.0003\%; selenium, 0.00003\%; folic acid, 0.69mg; choline, 386mg' riboflavin, 6.61mg; biotin, 0.03mg; vitamin $\mathrm{B}_{6}, 1.38 \mathrm{mg}$; niacin, 27.56mg; pantothenic acid, $6.61 \mathrm{mg}$; thiamine, 2.20mg; manadione, 0.83mg; vitamin $\mathrm{B}_{12}, 0.01 \mathrm{mg}$; vitamin E, $16.53 \mathrm{IU}$; vitamin $\mathrm{D}_{3}, 2133$ ICU; vitamin A, 7716 IU.

${ }^{\mathrm{B}}$ Active drug ingredient Monensin Sodium $60 \mathrm{gpb}$ (90 g/ton inclusion), Elanco Animal Health, Indianapolis, IN. As an aid in the prevention of coccidiosis caused by Eimeria necarix, Eimeria tenella, Eimeria acervulina, Eimeria brunette, Eimeriamivati, and Eimeria maxima.

${ }^{\mathrm{C}}$ Bacitracin Methylene Disalicylate $50 \mathrm{~g} / \mathrm{lb}$ (50 g/ton inclusion), Alpharma, Fort Lee, NJ. For increased rate of weight gain and improved feed efficiency. 
Table 3. Descriptive feed manufacture data for diets PC, NC, 2 and 4\% PLB

\begin{tabular}{cccccc} 
Treatment & $\begin{array}{c}\text { Production } \\
\text { Rate } \\
\text { (tonne/hr) }\end{array}$ & $\begin{array}{c}\text { Hot Pellet } \\
\text { Temperature } \\
\left({ }^{\circ} \mathbf{C}\right)\end{array}$ & $\begin{array}{c}\text { New } \\
\text { Holmen } \\
\text { Pellet Tester } \\
\mathbf{( \% )}\end{array}$ & $\begin{array}{c}\text { PDI }^{\mathbf{1}} \\
\mathbf{( \% )}\end{array}$ & $\begin{array}{c}\text { MPDI }^{\mathbf{2}} \\
\mathbf{( \% )}\end{array}$ \\
\hline PC & 1.09 & 82.0 & 30.0 & 58.0 & 44.8 \\
NC & 1.02 & 80.2 & 37.5 & 65.9 & 53.4 \\
\hline 2\% Biochar & 1.03 & 80.5 & 38.1 & 63.3 & 50.1 \\
\hline 4\% Biochar & 1.00 & 81.2 & 38.9 & 68.0 & 53.6 \\
\hline PC + Phytase & 1.08 & 81.2 & 32.2 & 55.4 & 41.6 \\
\hline NC + Phytase & 1.08 & 80.1 & 34.8 & 62.9 & 52.2 \\
\hline 2\% Biochar + Phytase & 1.08 & 82.4 & 35.6 & 60.7 & 47.7 \\
\hline 4\% Biochar + Phytase & 1.06 & 82.1 & 38.3 & 69.1 & 54.6 \\
\hline
\end{tabular}

${ }^{1}$ Pellet Durability Index

${ }^{2}$ Modified Pellet Durability Index 
Table 4. Effects on performance variables for 1-21 day broilers when fed PC, NC, 2 and 4\% PLB

\begin{tabular}{|c|c|c|c|c|c|c|c|}
\hline Diet Formulation & Phytase Addition & $\begin{array}{c}\text { Starting Pen } \\
\text { Weight } \\
\text { (kg/pen) }\end{array}$ & $\begin{array}{c}\text { EBW }^{1} \\
\text { (kg/bird) }\end{array}$ & $\begin{array}{c}\text { LWG }^{2} \\
\text { (kg/bird) }\end{array}$ & $\begin{array}{c}\mathrm{FI}^{3} \\
\text { (kg/pen) }\end{array}$ & $\begin{array}{c}\text { Mortality } \\
\text { Percentage } \\
(\%)\end{array}$ & $\begin{array}{c}\text { FCR }^{4} \\
\text { (kg:kg) }\end{array}$ \\
\hline \multirow[b]{2}{*}{ PC } & NO & 0.949 & $0.732^{\mathrm{abc}}$ & $0.690^{\mathrm{abc}}$ & $22.44^{\mathrm{a}}$ & $1.613^{\mathrm{b}}$ & $1.43^{\text {cde }}$ \\
\hline & YES & 0.948 & $0.739^{\mathrm{ab}}$ & $0.698^{\mathrm{ab}}$ & $21.96^{\mathrm{a}}$ & $0.538^{\mathrm{b}}$ & $1.38^{\mathrm{e}}$ \\
\hline \multirow{3}{*}{ NC } & NO & 0.950 & $0.430^{\mathrm{e}}$ & $0.389^{\mathrm{e}}$ & $12.43^{b}$ & $16.538^{\mathrm{a}}$ & $1.54^{\mathrm{a}}$ \\
\hline & YES & 0.954 & $0.723^{\mathrm{bc}}$ & $0.682^{\mathrm{bc}}$ & $22.58^{\mathrm{a}}$ & $1.613^{\mathrm{b}}$ & $1.46^{\mathrm{bcd}}$ \\
\hline & NO & 0.947 & $0.701^{\mathrm{cd}}$ & $0.658^{\mathrm{cd}}$ & $22.73^{\mathrm{a}}$ & $2.700^{b}$ & $1.53^{\mathrm{ab}}$ \\
\hline $2 \%$ PLB & YES & 0.955 & $0.762^{\mathrm{a}}$ & $0.721^{\mathrm{a}}$ & $23.19^{\mathrm{a}}$ & $1.613^{b}$ & $1.41^{\mathrm{de}}$ \\
\hline \multirow[b]{2}{*}{$4 \%$ PLB } & NO & 0.953 & $0.674^{\mathrm{d}}$ & $0.633^{\mathrm{d}}$ & $21.59^{\mathrm{a}}$ & $1.088^{b}$ & $1.49^{\mathrm{abc}}$ \\
\hline & YES & 0.955 & $0.734^{\mathrm{abc}}$ & $0.692^{\mathrm{abc}}$ & $22.32^{\mathrm{a}}$ & $1.625^{b}$ & $1.42^{\text {cde }}$ \\
\hline \multicolumn{2}{|c|}{ ANOVA P value } & 0.5584 & $<0.0001$ & $<0.0001$ & $<0.0001$ & $<0.0001$ & $<0.0001$ \\
\hline \multicolumn{2}{|c|}{ SEM $^{5}$} & 0.0036 & 0.0130 & 0.0130 & 0.6160 & 1.2698 & 0.0253 \\
\hline \multicolumn{2}{|c|}{ Fisher's LSD ${ }^{6}$} & 0.0104 & 0.0371 & 0.0371 & 1.7509 & 3.6089 & 0.0720 \\
\hline \multicolumn{8}{|c|}{ Marginal Means } \\
\hline PC & -- & 0.948 & $0.735^{\mathrm{a}}$ & $0.694^{\mathrm{a}}$ & $22.20^{\mathrm{a}}$ & $1.075^{b}$ & $1.40^{\mathrm{b}}$ \\
\hline NC & -- & 0.952 & $0.577^{\mathrm{C}}$ & $0.535^{\mathrm{c}}$ & $17.51^{b}$ & $9.225^{\mathrm{a}}$ & $1.50^{\mathrm{a}}$ \\
\hline $2 \%$ PLB & -- & 0.951 & $0.731^{\mathrm{a}}$ & $0.690^{\mathrm{a}}$ & $22.95^{\mathrm{a}}$ & $2.156^{\mathrm{b}}$ & $1.47^{\mathrm{a}}$ \\
\hline 4\% PLB & -- & 0.954 & $0.704^{\mathrm{b}}$ & $0.663^{\mathrm{b}}$ & $21.95^{\mathrm{a}}$ & $1.356^{\mathrm{b}}$ & $1.46^{\mathrm{a}}$ \\
\hline ---- & NO & 0.949 & $0.634^{\mathrm{b}}$ & $0.593^{b}$ & $19.79^{b}$ & $5.559^{\mathrm{a}}$ & 1.50 \\
\hline---- & YES & 0.953 & $0.740^{\mathrm{a}}$ & $0.698^{\mathrm{a}}$ & $22.51^{\mathrm{a}}$ & $1.347^{\mathrm{b}}$ & 1.41 \\
\hline \multicolumn{8}{|c|}{ Main Effects and Interaction Probabilities } \\
\hline \multicolumn{2}{|c|}{ Diet Formulation } & 0.4678 & $<0.0001$ & $<0.0001$ & $<0.0001$ & $<0.0001$ & 0.0062 \\
\hline \multicolumn{2}{|c|}{ Phytase Addition } & 0.1636 & $<0.0001$ & $<0.0001$ & $<0.0001$ & $<0.0001$ & $<0.0001$ \\
\hline \multicolumn{2}{|c|}{ Diet Formulation X Phytase Addition } & 0.6885 & $<0.0001$ & $<0.0001$ & $<0.0001$ & $<0.0001$ & 0.6815 \\
\hline
\end{tabular}

${ }^{1}$ Ending Bird Weight

${ }^{2}$ Live Weight Gain

${ }^{3}$ Feed Intake

${ }^{4}$ Feed Conversion Ratio

${ }^{5}$ Fisher's Least Significant Difference

${ }^{6}$ Standard Error of the Mean

${ }^{\mathrm{a}-\mathrm{e}}$ Means within a column without a common superscript differ significantly $(\mathrm{P} \leq 0.05)$. 
Table 5. Effects on digesta viscosity for 1-21 day broilers when fed PC, NC, 2 and 4\% PLB (with or without phytase).

Diet Formulation $\quad$ Phytase Addition 10 RPM 30 seconds 10 RPM 60 seconds 20 RPM 30 seconds 20 RPM 60 seconds

\begin{tabular}{|c|c|c|c|c|c|}
\hline & & $(\mathbf{c P})$ & (cP) & (cP) & (cP) \\
\hline \multirow[b]{2}{*}{ PC } & $\mathrm{NO}$ & 8.58 & 9.77 & 7.21 & 7.28 \\
\hline & YES & 12.56 & 12.57 & 8.49 & 8.25 \\
\hline \multirow{3}{*}{ NC } & NO & 9.23 & 9.39 & 7.05 & 7.60 \\
\hline & YES & 12.28 & 12.19 & 7.61 & 7.75 \\
\hline & NO & 10.76 & 11.52 & 7.17 & 6.98 \\
\hline $2 \%$ PLB & YES & 12.01 & 12.42 & 7.93 & 8.13 \\
\hline \multirow[b]{2}{*}{ 4\% PLB } & $\mathrm{NO}$ & 11.67 & 12.35 & 8.15 & 8.08 \\
\hline & YES & 10.55 & 11.17 & 7.14 & 7.41 \\
\hline \multicolumn{2}{|c|}{ ANOVA P value } & 0.6864 & 0.8235 & 0.8212 & 0.9537 \\
\hline \multicolumn{2}{|c|}{ SEM $^{1}$} & 1.7581 & 1.7333 & 0.7561 & 0.8308 \\
\hline \multicolumn{2}{|c|}{ Fisher's LSD ${ }^{2}$} & 4.9963 & 4.9262 & 2.149 & 2.3613 \\
\hline \multicolumn{6}{|c|}{ Marginal Means } \\
\hline PC & -- & 10.57 & 11.17 & 7.85 & 7.76 \\
\hline NC & -- & 10.76 & 10.79 & 7.33 & 7.67 \\
\hline $2 \%$ PLB & -- & 11.38 & 11.97 & 7.55 & 7.55 \\
\hline 4\% PLB & -- & 11.11 & 11.76 & 7.64 & 7.74 \\
\hline ---- & NO & 10.06 & 10.75 & 7.39 & 7.48 \\
\hline ---- & YES & 11.85 & 12.08 & 7.79 & 7.88 \\
\hline \multicolumn{6}{|c|}{ Main Effects and Interaction Probabilities } \\
\hline \multicolumn{2}{|c|}{ Diet Formulation } & 0.9663 & 0.9011 & 0.9224 & 0.9942 \\
\hline \multicolumn{2}{|c|}{ Phytase Addition } & 0.1473 & 0.2844 & 0.4601 & 0.4949 \\
\hline \multicolumn{2}{|c|}{ Diet Formulation X Phytase Addition } & 0.4699 & 0.6204 & 0.4701 & 0.6736 \\
\hline
\end{tabular}

${ }^{\mathrm{a}-\mathrm{e}}$ Means within a column without a common superscript differ significantly $(\mathrm{P} \leq 0.05)$

${ }^{1}$ Fisher's Least Significant Difference

Standard Error of the Mean 


\section{Curriculum Vitae \\ Ashley M. Evans, PhD Candidate}

• 1215 Valley View Woods Morgantown, WV 26505 • $\quad$ aevans6@mix.wvu.edu (304) 257-0246 •

Enthusiastic and works well within a team, but also proficient working as an individual. Not foreign to hard-work and thrives under pressure.

\section{EDUCATION}

Degree earned: Bachelors of Science, Animal and Nutritional Science, West Virginia University; May 2010

Undergraduate GPA: 3.18

Degree earned: Master of Science, Animal and Food Science, West Virginia University; May 2012

Thesis title: "Production and evaluation of novel exogenous phytase enzymes using several testing variables”

Graduate GPA: 3.48

Expected Degree: Doctor of Philosophy, Animal and Food Science, West Virginia University; May 2015

Dissertation title: "Effect of novel feed ingredients and additives on feed quality and broiler performance"

Current GPA: 3.68

\section{PUBLICATIONS}

\section{First Author Publications:}

\section{Peer-reviewed manuscripts}

A.M. Evans, D.L. Smith, and J.S. Moritz. Effects of algae incorporation into broiler starter diet formulations on nutrient digestibility and 3-21d bird performance. J. Appl. Poult. Res. (Under Review).

A.M. Evans, B.N. Swiger, K.P. Blemings, M.S. Lilburn, and J.S. Moritz. 2013. The effect of strain and finisher diet non-phytate phosphorus level on performance and litter composition in large tom production. Int. J. Poult. Sci. 13 (5): 246-252.

\section{Abstracts}

A.M. Evans, D.L. Smith, and J.S. Moritz. 2014. Algae biomass increases apparent amino acid digestibility using a Cobb 500 broiler model. Poultry Sci. Vol. 95 (Suppl. 1): 148.

A.M. Evans and J.S. Moritz. 2014. Effects of dietary supplementation on nutrient digestibility and growth performance of chicks fed diets with high amounts of meat and bone meal. Poultry Sci. Vol. 95 (Suppl. 1): 60.

A.M. Evans, D.L. Smith, and J.S. Moritz. 2013. Broiler diet formulation using algae biomass based on digestible nutrient content. Poultry Sci. Vol. 93 (Suppl. 1): 42. 
A.M. Evans, K.D. Baldock, D.L. Smith, and J.S. Moritz. 2012. Algae biomass as an energy source for animal feeds. Poultry Sci. Vol. 91 (Suppl. 1): P409.

\section{Co-author Publications:}

\section{Peer-reviewed manuscripts}

A.E. Lamp, A.M. Evans, and J.S. Moritz. The effects of pelleting and glucanase supplementation in hulled barley based diets on feed manufacture, broiler performance, and digesta viscosity. J. Appl. Poult. Res. (Under Review).

R.E. Loar, K.G.S. Wamsley, A.M. Evans, J.S. Moritz, and A. Corzo. Effects of varying conditioning temperature and mixer-added fat on feed manufacturing efficiency, 28- to 42-day broiler performance, early skeletal effect, and true amino acid digestibility. J. Appl. Poult. Res. 23: 444455.

\section{Abstracts}

B.G. Glover, A.M. Evans, and J.S. Moritz. 2014. The effects of modest improvement to pellet quality on tom turkey performance. Poultry Sci. Vol. 95 (Suppl. 1): 65.

R.E. Loar, K.G.S. Wamsley, A.M. Evans, J.S. Moritz, and A. Corzo. 2013. Effects of varying conditioning temperature and fat application on a broiler finisher diet. Poultry Sci. Vol. 93 (Suppl. 1): 190.

A. E. Lamp, A. M. Evans, and J. S. Moritz. 2013. Feed manufacture technique affects heat transfer to feed that may influence nutritional value. Poultry Sci. Vol. 92 (Suppl. 1): 216.

M.E. Lemons, K.G.S. Wamsley, A.E. Lamp, A.M. Evans, K.J. Shipe, and J.S. Moritz. 2012.

Lignosulfonate pellet

binder and fat increase broiler feed retention time. Poultry Sci. Vol. 91 (Suppl. 1): 130.

K.J. Shipe, A.M. Evans, K.G.S. Wamsley, and J.S. Moritz. 2012. Pelleting does not decrease lysine digestibility.

Poultry Sci. Vol. 91 (Suppl. 1): 132.

K.J. Shipe, A.M. Evans, K.G.S Lilly, L.K. Shires, B.N. Swiger, and J.S.Moritz. 2011. Effects of feed manufacture

techniques that vary feed exposure to pellet die heat and pressure on pellet quality and subsequent broiler lysine utilization. Poultry Sci. Vol. 90 (Suppl. 1): 389.

K.G.S. Lilly, L.K. Shires, B.N. Swiger, A.M. Evans, K.J. Shipe, and J.S. Moritz. 2011. Resolving pellet quality issues and improving turkey poult performance with the manufacture of commercial turkey diet formulations. Poultry Sci. Vol. 90 (Suppl. 1): 388.

L.K. Shires, B.N. West, K.G.S. Lilly, A.M. Evans and J.S. Moritz. 2011. The effects of early feed amino acid and late feed non-phytate phosphorus levels on large tom performance, yield, and litter composition. Poultry Sci. Vol. 90 (Suppl. 1): 321.

L.K. Shires, K.G.S. Lilly, B.N. Swiger, A.M. Evans and J.S. Moritz. 2011. The effect of marine and flaxseed oil inclusion in diets for pastured laying flocks on EPA, DHA, and consumer acceptability of eggs. Poultry Sci. Vol. 90 (Suppl. 1): 338.

K.G.S. Lilly, L.K. Shires, B.N. Swiger, A.M. Evans, K.J. Shipe, and J.S. Moritz. 2011. Manufacturing techniques to improve pellet quality of commercial turkey diet formulations and six week male poult performance. $18^{\text {th }}$ European Symposium on Poultry Nutrition.(Accepted Abstract \& Full Text Submission). Presentation was in Cesme- Izmir, Turkey. November 2011. 


\section{EXTENSION EXPERIENCE}

- Assisted with several poultry processing workshops around the state of West Virginia (Spring 2014)

- Led WVU poultry facilities tour for high school students from Turkey Knob, PA (5/21/2014)

- Provided an update about WVU poultry laboratory at West Virginia Poultry Association Spring Meeting (4/2/2014)

- Attended Mid-Atlantic Nutrition Conference in Baltimore, MD (3/25-27/2014)

- Assisted with cattle freeze-branding for the bull testing at Reymann Memorial Farm in Wardensville, WV (3/12-14/2014)

- Doddridge County FFA Farm Tour. Presented feed mill application, broiler production, and processing (10/23/2013)

- Assisted with Boy Scout Wood/Fire Skills Workshop (10/12/2013)

- Assisted with Tiger Cub Farm Visit (10/7/2013)

- Assisted with several poultry processing workshops around the state of West Virginia (Fall 2013)

- Assisted with poultry processing workshop at Doddridge Country Fair (8/26/2013)

- A-STEM Summer Camp. Presented on Food Production, Feeding an Increasing Population, and Feed Formulation (all focused on poultry) (8/5 - 7/2013)

- Monongalia County Poultry Judge (8/1/2013)

- Provided an update about WVU poultry laboratory at West Virginia Poultry Association Spring Meeting (4/2/2013)

- Attended Mid-Atlantic Nutrition Conference in Baltimore, MD (3/27-28/2013)

- Attended Feed Mill Managers Conference in Nashville, TN (3/20-21/2013)

- Boy Scout Merit Badge University. Presented on breeds and health concerns of sheep and differences in digestive anatomy of ruminants and non-ruminants with a hands-on laboratory $(2 / 9 / 2013)$

- Presented poultry litter biochar (PLB) research at Moorefield Fall Extension Educational Meeting $(11 / 14 / 2012)$

- Attended Gilmer County Poultry Workshop Educational Meeting (10/18/2012)

- Assisted with Tiger Cub Farm Visit (10/15/2012)

- Organizer for Career Development Events (9/23/2012, 6/18/2013)

- Hands-on Agriculture Day (9/20/2012)

- Berkeley County Fair Poultry Judge (8/7/2012)

- Assisted with Poultry Workshop at WVU Organic Field Day (8/4/2012, 8/15/2013)

- Presented update on research laboratory during West Virginia Poultry Association annual meeting (7/27/2012)

- Assisted with WV poultry week activities (7/24-25/2012)

- $\quad$ Ag in the Classroom (6/15/2012)

- Preston County Kid's Safety Day (6/9/2012)

- Assist with planning for WV Poultry Week, state fair activities (Summer 2012, 2013)

- Assisted with activities and displays (birds and poster) for Monongalia County and WV State Fair (Summer 2012)

- Assist with Veterinary Technician classes to help the students learn about poultry and teach them to efficiently draw blood from poultry

- Led the chick brooder section of a broiler processing workshop for small farm producers (3/1/2012)

- Assisted with Tiger Cub Farm Visit (11/28/2011)

- Organizer and Poultry Judge for Career Development Events (9/22/2010, 9/23/2011)

- Assisted with Poultry Workshop at WVU Organic Field Day (8/4/2011)

- Assisted with WV poultry week activities (7/26-7/27/2011) 
- Preston County Kid’s Safety Day (6/4/2011)

- $\quad$ Attended Grazing Conference (3/4/2011)

- Assisted with activities and displays (birds and poster) for Monongalia County and WV State Fair (Summer 2011)

- Preston County Kids Day Fair Poultry Presentation

- Assist with planning for WV Poultry Week, state fair activities

- Guest Lecturer for Intro to Animal Science Course

\section{RESEARCH EXPERIENCE}

\section{National Meeting Paper Presentations}

- 2014 Poultry Science Association (Corpus Christi, TX; Graduate Student)

"Effects of enzyme supplementation on nutrient digestibility and growth performance of chicks fed diets containing meat and bone meal"

"Algae biomass as a viable feed ingredient for broilers based on performance and ileal amino acid digestibility"

- 2013 Poultry Science Association (San Diego, CA; Graduate Student)

"Broiler diet formulation using algae biomass based on digestible nutrient content"

- 2011 Poultry Science Association (St. Louis, MI; Graduate Student)

"The effects of early feed amino acid and late feed non-phytate phosphorus levels on large tom performance, yield, and litter composition"

\section{National Meeting Poster Presentations}

- 2012 Poultry Science Association (Athens, GA; Graduate Student)

"Algae biomass as an energy source for animal feeds"

\section{Other Research Experience}

- Recipient of 2014 Northeast SARE graduate student grant; proposal entitled "The effects of poultry litter biochar on pellet quality, 21-day broiler performance, bone mineralization, digesta viscosity, and amino acid digestibility”; award totaled \$14,989. http://wvutoday.wvu.edu/n/2014/09/26/wvu-grad-student-receives-sustainable-agriculture-grant

- Led study utilizing algae biomass in Cobb 500 broiler diets and its effect on live bird performance, ileal digestibility, and amino acid digestibility (Summer 2013)

- Led twelve contract studies with Verenium Corp. utilizing four phytase enzyme variants and different testing variables (2011 - 2013)

- Led study utilizing poultry litter biochar (PLB) in Cobb 500 broiler diets and its effects on mineral sparing (Fall 2012)

- Presented research to Verenium Corp. in San Diego, Ca. (7/21-7/24/2011)

- Led eight contract studies with Verenium Corp. utilizing xylanase and glucanase enzyme variants and different concentrations and their effects on energy utilization in single comb white leghorn roosters (Spring and Summer 2011)

- Contract Studies with JBS United, Enzivia, Phytex, Poet Nutrition, Virginia Poultry Grower’s Coop

- Contract Pelleting Studies with JBS United and Phytex 


\section{TEACHING EXPERIENCE}

- Teaching Assistant for Advanced Animal Nutrition (Role includes lecturing occasionally in class) (ANNU 362)

- Teaching Assistant for Companion Animals Class (Role includes lecturing occasionally in class) (A\&VS 275)

- Guest lecturer at Eastern New Mexico University (12/2/2011)

\section{EDUCATION HONORS/AWARDS}

\section{Graduated from Moorefield High School in 2006:}

- President's Academic Award

- Top of the Mountain Award

- National Honor Society Member, Moorefield High School Chapter (2004-2006)

- Girl's Tennis Team Member (2006)

\section{Scholarships/Grants Received:}

- Promise Scholarship (2006-2007)

- AACU Scholarship (2006-2007)

- Mountaineer Scholarship (2006-2007)

- PELL Grant (2007-2010)

- SMART Grant (2007-2010)

- West Virginia Higher Education Grant (2007-2010)

Awards and Honors:

- Davis College of Agriculture, Forestry, and Consumer Science Dean’s List (2009)

\section{OTHER EXPERIENCE}

\section{Moorefield Church of the Brethren}

1995 - present

- Help teach Sunday School class

- Prepare and direct Sunday School class Christmas Play

- Door greeter

- Help collect offerings

- Occasional participate in choral activities

\section{West Virginia Department of Highways}

- Temporary/summer employment

- Main flagger for both primary and secondary road crews

- Animal removal from highway

- Assisted with various office tasks, including payroll, entrance permits, and employee records

- Assisted with fiscal year-end inventory 


\section{Veterinary Hospital Volunteer}

- Assisted with various surgeries

- Filled prescriptions

- Performed fecal analysis

- Handled pets and cleaned their cage

\section{SKILLS}

- Proficient in Window's Microsoft Programs

- Internet Literate

- Poultry Handling, Judging, and Husbandry

- Feed Manufacture and Diet Formulation

- Precision-feeding

- Cecectomy Surgery

- Tibia and Ileum Extraction

- Experience with Brookfield Viscometer

- Experience with statistical programs R, SAS, JMP, and SPSS

Animal specific courses taken:

-Animal Nutrition 260 \& 360

-Poultry Production 367\& Lab 369

-Animal Nutrition 362

-Poultry Judging 338

-Environmental Microbiology 341

-Veterinary Anatomy 401

- Companion Animal Science 275

-Alpaca Production 273

-Growth/Lactation Physiology 400

-Animal Physiology 301

-Behavior Patterns of Animals 480

-Reproductive Physiology 424

-Introduction to Genetics 371

-Biochemistry 410

Graduate Courses:

-Applied Water Microbiology 508

-Statistics 511,512,513

-Animal Biotechnology 514

-Food Microbiology 545

-General Biochemistry 610

-Nutritional Biochemistry 512

-Nutritional Graduate Seminar 696

-Vitamins and Minerals in Animal Nutrition 693

Agriculture Extension and Horticulture Courses Taken:

-Directing FFA and SAE 426

-Greenhouse Management 445

-Principles of Cooperative Extension 440

-Program Evaluation 651
-Program Development 650

-Research Methods and Design 642

-Data Analysis/Interpretation 644

-Professional Extension Field Experience 